\title{
Firms and the Intergenerational Transmission of Labor Market Advantage
}

\author{
Per Engzell \\ University College London
}

\author{
Nathan Wilmers \\ MIT Sloan
}

November 2022

\begin{abstract}
Pay inequality stems both from firm pay-setting and from workers' individual characteristics. Yet, intergenerational mobility research focuses on transmission of individual traits, and has failed to test how firms shape the inheritance of inequality. We study this question using three decades of Swedish population register data, and decompose the intergenerational earnings correlation into firm pay premiums and worker effects. One quarter of the intergenerational earnings correlation at midlife is explained by sorting between firms with unequal pay. Employer or industry inheritance account for a small share of this firm-based earnings transmission. Instead, high-education and highoccupation workers disproportionately land at high-paying firms. Parental referral networks and the inheritance of industry and labor market context play a supplementary role. As workers with high-education or high-status jobs are increasingly also employed at high paying firms, firm sorting could become increasingly important to intergenerational earnings transmission.
\end{abstract}

Equality of opportunity often comes down to the banalities of a job application, an interview, an offer. Opportunity is celebrated when a troubled kid gets his foot in the door at a unionized hospital (Anderson, 2000), or when a young worker's score on a civil service exam lands a coveted public sector job (Newman, 2009). Opportunity is undermined by a manager who recommends his own son for a plum starting position (Staiger, 2021), or by a white-shoe investment bank that screens candidates on experience with lacrosse and squash (Rivera, 2012). Equal opportunity, and its betrayal, seems to depend on how workers sort across employers. ${ }^{1}$

Yet, a half century of research on intergenerational mobility has largely ignored the role of employers. Instead, researchers argue that social origin influences opportunity via lasting effects on individual worker characteristics (Black and Devereux, 2011; Bowles et al., 2009; Jencks et al., 1979; Morgan et al., 2006; Sewell et al. 1969). Parents with greater resources are able to invest in their children in numerous ways, and cultivate traits in them such as skill, agreeableness, or work orientation, that are valued in the labor market (Farkas, 2003, Lareau, 2011). This standard approach rests on the assumption that individual characteristics pay off in a competitive labor market. ${ }^{2}$ 
A growing body of research challenges this assumption. Working at a highor low-paying firm affects earnings beyond what would be expected from individual worker characteristics (Abowd et al., 1999, Card et al., 2013, Groshen, 1991). Recent changes in the labor market suggest that these firm effects may play a prominent role in intergenerational earnings transmission. Between-firm inequality has grown across many developed countries (Tomaskovic-Devey et al., 2020). Moreover, occupation and worker characteristics are increasingly correlated with working at a high-paying firm (Card et al., 2013; Criscuolo et al., 2020; Wilmers and Aeppli 2021). This consolidation of potentially independent dimensions of inequality - firm and occupation or education - means that even understanding how individual traits affect intergenerational earnings transmission requires studying firms.

We shed light on the role of firms in several ways. The first question is simple: exactly how much do firm pay premiums matter for intergenerational earnings persistence? Second, is firm-based transmission mostly relevant in the early career or does it carry lasting advantages? Third, how does stratification by firms map on to other, more commonly studied dimensions such as education and occupation? And lastly, how is this firm-based labor market advantage perpetuated? Here, we clarify several mechanisms through which firm pay premiums contribute to intergenerational transmission: by amplifying the pay-off to education or occupation; by parental networks and referrals biasing firm sorting; and through the inheritance of a position in a particular labor market, industry or firm.

Empirically, we draw on population-wide linked employer-employee data from Sweden, which offer a sufficiently long time span to observe both parents and children at prime working age. We distinguish the components of earnings attributable to two sources: (a) the firm one works at and (b) durable individual worker traits. To do this, we bring methods from research on labor market inequality to the study of intergenerational mobility (Abowd et al., 1999). The firm component is the premium associated with working at a given firm, conditional on the composition of its workers. The individual earnings component reflects worker traits that are consistently rewarded across firms. In additional analyses, we test mechanisms by studying how education, parental co-working networks and structural labor market positions mediate firm sorting.

Our approach uncovers several new facts about the role of employers in intergenerational earnings persistence. Firm sorting on social background is evident at labor market entry and persists throughout the career. The firm premium among children from privileged backgrounds is relatively constant in absolute terms, but accounts for a shrinking relative part of earnings transmission as individual earnings fan out over the career. Yet, even in mature earnings, firm-based mechanisms account for a full quarter of intergenerational persistence. Education and occupational attainment accounts for roughly two-thirds of firm sorting by social background. Most of the remaining third is accounted for in equal parts by referral networks from a parent and inheritance of opportunity structure. Firms are an especially potent explanation for the part of income inheritance not accounted for by education or occupation: half of the direct effect of parent on child earnings, and most of the class origin gap in earnings, is explained by sorting across high- and 
low-paying firms. We conclude that firm sorting is an important and understudied channel in the intergenerational transmission of advantage.

\section{Firm premiums and worker earnings}

Contemporary employment has bifurcated by firm. Superstar firms in technology and professional services offer staggering compensation, while outsourced contractors, shrinking manufacturers and monopsonistic retailers pay far less. If in an earlier era, Ford Motor Company offered relatively high pay to production workers, now it is a largely managerial and professional segment of the workforce, at companies like Google and Goldman Sachs, that benefit from employment at a high-paying firm. These patterns have appeared across multiple developed countries and, alongside increased returns to skill, are a primary cause of rising earnings inequality (Criscuolo et al., 2020; Tomaskovic-Devey et al., 2020).

This bifurcation highlights the role played by firm pay premiums, or durable, firm-wide differences in pay that affect workers' earnings. Some firms are highpaying, and consistently pay their workers more across job titles (Groshen, 1991). Firm pay premiums persist even when comparing firms with similar occupational composition (Groshen, 1991; Wilmers and Aeppli, 2021) and employing workers of similar skill or ability level (Song et al., 2018). Premiums persist over time and are not adjustments to temporary shocks (Engbom et al., 2022). Firm premiums are also quantitatively important for worker earnings, accounting for $15 \%$ to $30 \%$ of earnings inequality in developed countries (Criscuolo et al. 2020). The sources of firm premiums range from observable differences in production technology (Barth et al. 2018), industry (Haltiwanger and Spletzer, 2020) and firm size (Cobb and Lin, 2017), to subtler differences in human capital complementarities (Kremer, 1993), unionization (Tomaskovic-Devey et al., 2020) and rent sharing (Kline et al., 2019). Regardless of their source, firm premiums offer durable rewards in the labor market, above what would be expected from an individual worker's human capital.

Addressing these pay differences between firms requires updating theories of stratification, just as prior mobility research has repeatedly incorporated newly ascendant sources of inequality. Marx argued that ownership of the means of production, rather than inherited title, increasingly determined the distribution of economic resources. Blau and Duncan (1967) countered that the separation of ownership from control required attention to gradational differences between employees of different authority. Goldthorpe (1982) argued that the autonomy of much office work fostered a more durable "service relation" distinct from the labor contract, while Weeden and Grusky (2005) underlined how core class mechanisms such as closure and solidarity can operate at the levels of occupations. These shifts in stratification research have thus tracked the rise of capitalists; the managerial revolution; the post-industrial transition; and the subsequent fracturing of class identities. If in contemporary labor markets, defined by superstar firms and skill segregation, economic attainment increasingly involves matching to a high-paying firm, how does this affect intergenerational mobility? 
If firm premiums are randomly distributed with respect to social background, or if they are more likely to accrue to children of low-earning parents, then they could increase intergenerational earnings mobility, relative to a perfectly competitive labor market. In contrast, if high-income background workers disproportionately sort to high-premium firms, then these premiums increase earnings transmission. Thus the nature of worker sorting determines the effect of firm premiums on intergenerational mobility: are high-income background workers more likely to sort to high-premium firms than low-income background workers?

Prior research on shifting worker-firm sorting is suggestive that firm premiums in the contemporary labor market exacerbate intergenerational earnings transmission. From the mid-twentieth century, firm premiums were associated with bluecollar employers, often large and unionized (Cobb and Lin, 2017, Wilmers, 2019). These relatively high-paying jobs for non-college workers provided generational security for low-earning families: union cards and jobs in specific plants were passed from fathers and uncles to sons and nephews (Bryson and Davies, 2019). Similarly, ethnic labor market niches in large cities protected relatively high-paying public sector or construction jobs for particular immigrant groups (Waldinger, 1999). The monopolization of these firm premiums can provide higher earnings for relatively low-education and -status background workers, in a way that offsets the disadvantages they accrue in educational attainment.

Since the 1970s however, high-paying blue collar employers have faced increasing cost pressure that has undermined their firm premiums (Sørensen, 2000. Wilmers, 2018). However, firm premiums have not thereby disappeared. On the contrary, in recent decades firm premiums have either grown in importance (Criscuolo et al., 2020) or remained stable (Song et al. 2018) across most developed countries. But, there has been a reallocation of firm premiums from blue-collar workers toward white-collar and professional employees (Criscuolo et al., 2020; Song et al., 2018, Wilmers and Aeppli, 2021). In the place of high-paying blue collar employers, the rise of finance (Krippner, 2011), superstar technology firms (Autor et al., 2020), and high-paying sole-proprietorships (Smith et al., 2019) have meant a quite different industry and occupational composition of high-paying firms. These new sources of firm premiums are often marked by credentialism and social exclusion, as in finance (Neely, 2022), or provide opportunity for direct transmission of high-paying positions, as in family inheritance of sole-proprietorships (Corak and Piraino, 2011). Recent changes in the allocation of firm premiums across industries and occupations therefore make them particularly likely to benefit high-income background workers.

\section{Limits of human capital explanations for inter- generational earnings mobility}

Despite this potentially growing role of firm premiums in intergenerational mobility, stratification research remains fixated on the influence of socialization on individual traits (Becker and Tomes, 1986, Black and Devereux, 2011; Cunha et al., 2010. Farkas, 2003; Jæger and Breen, 2016; Morgan et al., 2006). While early models of 
status attainment posited the direct involvement of parents in finding a job (Blau and Duncan, 1967), this focus was soon replaced by psychological influences on ability, aspirations and, ultimately, schooling (Sewell et al., 1969: Sewell and Hauser, 1975). The resulting model faced repeated criticism for its one-sided focus on the individual and failure to consider wider labor market dynamics (Baron, 1984; Baron and Bielby, 1980; Featherman, 1981; Spilerman, 1977; Stolzenberg, 1978). Yet, a compelling alternative failed to emerge and the status attainment model remains, implicitly or explicitly, the primary backdrop for stratification research.

By and large, then, the field today remains preoccupied with education and other forms of human capital (Bloome et al., 2018; Breen and Müller, 2020, Horowitz, 2018, Karlson, 2019). This is not without reason, as education is both the main conduit of social reproduction and a vehicle for intergenerational mobility (Hout, 2012; Torche, 2015).

However, recent research emphasizes that human capital is not the only source of advantage for privileged children (Bernardi and Ballarino, 2016, Witteveen and Attewell, 2017, 2020). Among UK managers and professionals with similar educational background, high-class children end up higher-paid, in part by sorting to larger and more centrally located firms (Laurison and Friedman, 2016). In the US, while education accounts for the bulk of occupational status transmission, it only accounts for about half of the intergenerational persistence in family income (Torche, 2016). Even the classical finding that high-skilled labor markets operate more meritocratically is weaker when income is studied, and when accounting for selection processes into education (Fiel, 2020; Zhou, 2019).

We argue that both the role of education, and the effects of social background over and above education, can be clarified by attention to how workers sort across high- and low-paying firms. Before turning to our quantification of the role of firm premiums in intergenerational earnings transmission, we distinguish specific mechanisms through which high-income background workers could sort to highpaying firms.

\section{Firm premium mechanisms of intergenerational transmission}

Through what specific mechanisms does a high-earning family background sort workers to higher-paying firms? Consider an example of a job applicant, with highearning parents, who obtains a job at a high-paying investment bank. Why was she chosen over a competitor from a lower-earning background? One possibility is that the applicant obtained, perhaps with parental encouragement, an advanced degree in a job-relevant major like finance or economics. Another possibility is that the high-earning background applicant had a father working as a managing director at the bank, who put in a good word for his daughter. Or perhaps the applicant simply lives in a high-income city that features a concentration of high-paying firms.

This example shows that firm premiums can matter for intergenerational mobility in several ways. High-paying firms can select for high human capital workers, amplifying the usual status transmission traits. Second, high-paying firms and in- 
dustries can be obtained through parental referral and co-worker network ties, as a type of social capital. Lastly, children may work for similar employers to their parents, even in the absence of activated network ties, simply due to facing a similar opportunity structure. In the following, we elaborate these mechanisms, before testing them empirically.

\subsection{Amplifying pay-offs to human capital}

Traditional explanations of intergenerational stratification focus on the role of schooling. But schools not only impart skills, they are also sorting devices (Domina et al., 2017; Hirsch, 1977; Thurow, 1975). Especially at the higher end of the institutional hierarchy, a small number of schools serve as pipelines for elite employers (Binder et al., 2016, Bühlmann et al., 2022, Rivera, 2016, Weinstein, 2018). In the Scandinavian context we study, field of study can be a more powerful source of stratification than institution (Borgen and Mastekaasa, 2018; Hällsten, 2010; Hällsten and Thaning, 2018). Through sorting, firms may amplify the human capital advantages focused on in prior intergenerational mobility research.

Note that our empirical approach defines human capital broadly, beyond levels or even fields of education. Children of high-earning parents may cultivate cultural dispositions that gain the confidence of gatekeepers at high-premium firms Armstrong and Hamilton, 2013). As long as class-based dispositions are domain general, like ease and entitlement, they can both benefit children as individual traits and in the firm sorting process (Bourdieu, 1984; Khan, 2010; Lareau, 2011). Indeed, recent qualitative studies of elite employers all emphasize the importance of tacit cultural performance to getting in and staying employed. A study of accounting, broadcasting and architecture firms found that behavioral codes, often learned in elite educational environments, gave high-class background workers an advantage (Friedman and Laurison, 2020). In hedge funds, upper-class men succeed by embodying stereotypes about high risk-tolerance and trustworthiness (Neely, 2022).

If higher-skill workers become more likely to sort to high-premium firms, then firm premiums will increasingly amplify, rather than offset, returns associated with human capital. Prior research finds that this correlation between human capital and firm premiums is positive and rising across multiple countries (Card et al. 2013 , Criscuolo et al. 2020, Song et al., 2018). One US analysis finds that a quarter of the higher education pay premium is attributable to sorting across high-paying firms (Engbom and Moser, 2017). Consistent with this amplification mechanism, a contemporaneous study of Israel finds that high-earning background children disproportionately sort to high-paying firms and that this sorting is largely due to those children's individual traits (Dobbin and Zohar, 2021). In the Israeli context, firm sorting amplifies the pay-offs to workers' human capital.

\subsection{Job referral networks and biased sorting}

Social networks are a ubiquitous source of inequality (Bourdieu, 2000, DiMaggio and Garip, 2012, Lin, 2002; Small, 2009) and the job search process is no exception Castilla et al., 2013; Granovetter, 1974; Marsden and Gorman, 2001; Trimble and 
Kmec, 2011). While much research has focused on "weak ties," acquaintances with distant and infrequent interaction (Granovetter, 1973), such ties may themselves be passed down via strong ties such as family, especially early in the career. Due to the lasting power of networks, an early advantage can pay dividends throughout the career (McDonald, 2011; McDonald and Elder Jr, 2006).

The most direct way that a parent can transmit a high-paying firm to their child is by securing them a job at the parent's own firm. This can happen when a parent owns a business, more common among high than low class parents, and hires a child into it (Corak and Piraino, 2011). More frequent however, is when a parent employed at a high-premium firm refers their child to work there. Staiger (2021) finds that in the US, $7 \%$ of children find their first stable job at the employer of one of their parents. Similar results on parental referral of children at labor market entry are also found in Sweden (the context we study in the empirical analysis below) (Kramarz and Skans, 2014).

However, direct referral is only one way that well-placed parents can help their child get a leg up in the labor market. The mobilization of weak ties may turn out to be a more powerful lever. For example, parents can activate their former co-worker social networks on behalf of their children. These co-workers are more likely to be linked to high-premium firms if the parent was a high-earner. San (2022) finds that in Israel, these parental networks are used in hiring and that they increase earnings for more advantaged workers with higher quality networks. These former co-worker networks can link children to a broader array of firms and industries than those at which a parent worked directly.

\subsection{Inheritance of opportunity structure}

Beyond this direct referral process, parents at high-paying employers can pass along to their children employment in their high-paying industry, even if the children do not obtain a position in the same firm as the parent. Older research stressed the role of industry in processes of stratification (Bibb and Form, 1977, Spilerman, 1977; Tolbert, 1983). Industry inheritance can occur via informal, industry-specific training provided by parent to child, analogous to the occupation-specific informal training and lifestyles that transmit occupational microclasses (Gerstl and Cohen, 1964; Jonsson et al. 2009).

Even more simply, collocation in the same labor market can induce a positive correlation between parental income and children's firm sorting. This is particularly clear in a labor market dominated by a small number of employers Goldstein, 2017; Jahoda et al., [1933]1971). But it can also occur in a context of high between-region inequality (Manduca, 2019), such that starting in a low-income region cuts off access to high-paying firms (Beggs and Villemez, 2001). Indeed, recent intergenerational mobility research has emphasized how the inheritance of local labor markets can explain part of transmission not mediated by education (Carniero et al. 2020; Morris, 2022; Rothstein, 2019, Zwysen, 2016) 


\subsection{Auxiliary channels}

We focus on human capital amplification, job referral networks and opportunity structure as the mechanisms with the strongest support in prior research. This list is not exhaustive, however, and there are other ways that parents could facilitate sorting to high-paying firms. For example, parents can provide financial resources that allow children to search longer or more effectively for a job (Pfeffer and Hällsten, 2012; Toft and Friedman, 2021) and children obtain valuable social networks through schooling (Fletcher and Han, 2021; Mijs and Roe, 2021). Likewise, some residual could be attributable to cultural matching. In cultural matching, cultural capital is not domain-general, as in the examples above, but rather helps in interactions with specific high-class alters: interest in lacrosse and squash only helps for employment in a particular subset of firms (Rivera, 2012). Some of these channelsparticularly, cultural matching - are challenging to observe in the kind of large-scale representative data that we use, and we leave them for future research.

\section{Data and approach}

To test these ideas, we incorporate firm premiums into a path analysis. We focus on earnings and study the correlation between parents and children. To assess the role of firm sorting in intergenerational transmission, we decompose earnings for each generation into components attributable to differences in individual worker characteristics and differences in pay at the firms those workers sort into. We then use the components of this decomposition to identify the specific paths through which firms shape intergenerational mobility.

For data, we construct an earnings panel linking parents and their children in Statistics Sweden's Longitudinal Integration Database for Health Insurance and Labor Market Studies (LISA). The data contain annual labor earnings for the full Swedish population spanning the period 1990-2019, with consistent individual and firm identifiers. As results look similar for fathers and mothers, we display mothers' earnings separately in Appendix A1. We include children born 1975-1978 and biological parents born 1940-1960. While we are able to link families beyond this span, these cohort restrictions allow annual earnings to be measured at prime working age for both generations within the 1990-2019 observation window of LISA.

Our analysis follows several steps. First, we estimate a two-way fixed effects model on the working population of Sweden born 1940-1985 and aged 25-65 for the years 1990-2019 (Section 4.1). We use this model to extract firm pay premiums, controlling for time-invariant worker characteristics, and consistent worker premiums, controlling for firm sorting. Next, we link these firm and worker earnings components across generations by estimating a path model of fathers' influence on children's mid-career earnings at age 38-42 (Section 4.2). We then consider how the contributions of firm-related earnings transmission pathways vary across the career by studying children between ages 25 and 40 (Section 4.3). Then, we establish how firm-based sorting intersects with education and occupation-dimensions that have been the focus of past mobility research (Section 4.4). Finally, we use various co- 
variates to clarify which mechanisms account for firm sorting by social background (Section 4.5).

\subsection{Two-way decomposition of earnings}

We analyze intergenerational transmission of annual labor earnings. In our main analysis we follow the practice, common in recent work, of studying the intergenerational rank correlation of incomes for parents $Y_{i}^{*}$ and children $Y_{i}$ (Bloome et al., 2018; Dahl and DeLeire, 2008; Engzell and Mood, 2021). To reduce the influence of gender and life-cycle earnings profiles, as well as economy-wide shocks and inflation, we create percentile ranks within each cell defined by gender, age, and earnings year. Log earnings produce similar results and are presented in Appendix A2 below.

To assess the role of firms in intergenerational mobility, we separate labor earnings into parts attributable to firm-based earnings premiums and to individual worker traits. This decomposition allows us to estimate firm premiums while controlling for the broad array of individual worker characteristics, including education, prominent in prior intergenerational mobility research. Specifically, we follow recent work which has fit two-way fixed effects models on linked employer-employee data (Abowd et al., 1999; Card et al., 2013; Song et al., 2018). ${ }^{3}$ Our model can be written:

$$
Y_{i t}=\alpha_{i}+X_{i t}^{\prime} \beta+\psi_{j(i, t)}+u_{i t}
$$

where $Y_{i t}$ is labor earnings in year $t$ for worker $i$ in firm $j, X_{i t}^{\prime}$ is a vector of gender, education, age, and full interactions between the three, $\beta$ is the set of associated coefficients, $\psi_{j(i, t)}$ is a firm- specific intercept associated with the firm employing individual $i$ at time $t, \alpha_{i}$ is an individual-level intercept, and $u_{i t}$ is an idiosyncratic error term.

The key terms for our analysis are the firm premium $\psi_{j}$ and the individual worker components $\alpha_{i}$ and $X_{i t}$. The firm-level term $\psi_{j}$ captures the degree to which a firm pays relatively high or low wages, after adjusting for the composition of their workers. This variation is typically driven by sector, industry, product, and location, alongside more idiosyncratic firm characteristics, like profitability, collective bargaining coverage or company-wide compensation policies. The individual worker-level component $\alpha_{i}$ captures variation in unobserved, time-invariant worker heterogeneity, independent of any additional benefit from working in a specific firm. Combined with the controls for observable worker characteristics in the vector $X_{i t}$, $\alpha_{i}$ reflects individual productivity and human capital, but it also captures less meritocratic determinants of individual workers' pay that have consistent effects across employers, like persistent discrimination.

There are two issues with this canonical model that have received growing attention. First, limited mobility bias may increase the variance of estimated firm fixed effects at firms that have little exposure to workers moving between firms (Andrews et al., 2008; Kline et al., 2020). This occurs because the firm fixed effects $\psi_{j}$ are estimated using workers who transition between firms in the data. Reassuringly, models with similar Swedish data to what we use in the current paper show that firm effects account for almost exactly the same share of earnings variance when this bias is corrected (Engbom et al., 2022). We also pool a very long time span 
of 30 years of data, which recent work finds mitigates potential mobility bias that arises in estimating two-way fixed effects models over short time spans (Lachowska et al., 2020).

Second, the time-invariant nature of $\alpha_{i}$ assumes that an individual's latent wage is constant conditional on observed characteristics, but this may be an unrealistic assumption (Bihagen, 2008, Cheng and Song, 2019). We deal with this fact by including highly flexible age-earnings trajectories in $X_{i t}^{\prime} \beta$ that are allowed to vary with individual characteristics. Specifically, we include a set of age dummies interacted with gender and education in five levels. Following Engbom et al. (2022), we assume that earnings rank is roughly constant between ages 45 to 54 by grouping these ages together as our reference category. The predicted worker component of earnings is then the sum of the individual-specific intercept $\alpha_{i}$ and the estimated age-earnings profile $X_{i t}^{\prime} \beta$ :

$$
\hat{Y}_{i t}=\underbrace{\hat{\alpha}_{i}+X_{i t}^{\prime} \hat{\beta}}_{\text {worker }\left(W_{i t}\right)}+\underbrace{\hat{\psi}_{j(i, t)}}_{\text {firm }\left(F_{i t}\right)} .
$$

To ensure that this estimation strategy is robust, we implement a number of alternative solutions below. First, we extend the earnings trajectories by letting them depend on up to 47 levels of education, as well as 118 detailed fields of study. Second, we break our estimation sample up into distinct 5-year periods which allows each worker and firm to be associated with a number of fixed effects throughout the observation window. Third, we extend the canonical specification with one that allows for individual slopes by age as part of the worker component (Rüttenauer and Ludwig, 2020). None of these alternative strategies make any major changes to our results and we therefore display them separately in Appendix A3.

\subsection{Path model}

Having estimated the separate firm and individual worker contributions to earnings, we explore transmission in a path model. Does intergenerational earnings transmission work through the inheritance of individual traits as in traditional intergenerational mobility research? Or is a significant part of intergenerational advantage instead due to sorting to high-paying firms? Figure 1 displays the model, where the superscript ${ }^{*}$ denotes the parental generation. We model earnings as a function of firm and worker components in each generation:

$$
\begin{aligned}
Y_{i}^{*} & =a_{1} F_{i}^{*}+b_{1} W_{i}^{*}+\epsilon_{1 i}, \\
Y_{i t} & =a_{2 t} F_{i t}+b_{2 t} W_{i t}+\epsilon_{2 i t},
\end{aligned}
$$

where $Y_{i}^{*}$ is the father's average earnings from 1990-1999, $Y_{i t}$ is the child's earnings at age $t$, and the right-hand side variables are the corresponding firm $\left(F_{i}^{*}, F_{i t}\right)$ and worker $\left(W_{i}^{*}, W_{i t}\right)$ components. The pathways we are interested in are the following:

Firm-to-firm: $\quad Y_{i}^{*} \leftarrow F_{i}^{*} \rightarrow F_{i t} \rightarrow Y_{i t}$

Worker-to-firm: $\quad Y_{i}^{*} \leftarrow W_{i}^{*} \rightarrow F_{i t} \rightarrow Y_{i t}$

Firm-to-worker: $\quad Y_{i}^{*} \leftarrow F_{i}^{*} \rightarrow W_{i t} \rightarrow Y_{i t}$

Worker-to-worker: $Y_{i}^{*} \leftarrow W_{i}^{*} \rightarrow W_{i t} \rightarrow Y_{i t}$ 


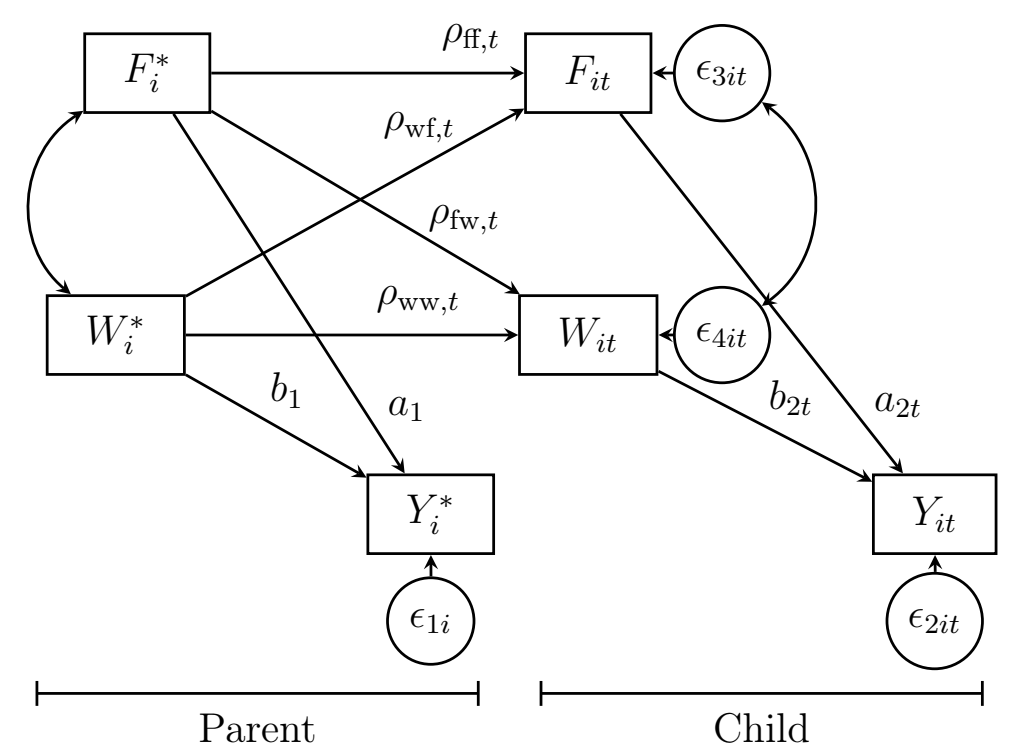

Figure 1: Path model.

Note: The figure shows the path model underlying the decomposition in Table 1. $Y$ denotes earnings, $F$ and $W$ denote firm and worker components of earnings, and asterisk $\left({ }^{*}\right)$ denotes the parental generation. Four paths exhaust the transmission of earnings from parent to child: firm-to-firm, worker-to-firm, firm-to-worker, and worker-to-worker. We estimate this model with all components transformed to percentile ranks, such that parameters represent rank correlations.

We estimate the importance of each of these paths of transmission by taking the product of each intergenerational correlation of earnings components (denoted by $\rho$ with $f$ firm and $w$ worker subscripts) and the importance of each component for overall earnings within each generation ( $a$ and $b$ from Equations 3 and 4 ) (Duncan, 1966). Given a set of assumptions that we describe further in Appendix A4, the intergenerational earnings correlation at child's age $t$ can then be decomposed as:

$$
\begin{aligned}
\rho_{t} & =\operatorname{corr}\left(Y_{i}^{*}, Y_{i t}\right) \\
& =\underbrace{\rho_{\mathrm{ff}, t} \cdot a_{1} \cdot a_{2 t}}_{\text {firm-to-firm }}+\underbrace{\rho_{\mathrm{wf}, t} \cdot b_{1} \cdot a_{2 t}}_{\text {worker-to-firm }}+\underbrace{\rho_{\mathrm{fw}, t} \cdot a_{1} \cdot b_{2 t}}_{\text {firm-to-worker }}+\underbrace{\rho_{\mathrm{ww}, t} \cdot b_{1} \cdot b_{2 t}}_{\text {worker-to-worker }} .
\end{aligned}
$$

Equation 5 shows that the relative contribution of each mechanism to the overall intergenerational correlation depends not only on the correlation between father's component and child's component (the $\rho$ terms), but also on the importance of those components for each generation's earnings (the $a$ and $b$ terms). For example, a high correlation between father's firm premium and son's firm premium may account for a small share of the overall intergenerational correlation if the firm premium is a small component of overall earnings.

\subsection{Firm contributions to mobility by career stage}

So far, we have abstracted from the dimension of children's age. The 30-year span of our data lets us observe fathers and children over several years near mid-career earnings. Here we describe how we implement this focus on mid-career earnings, 
and how we extend this analysis to study earnings mobility throughout the early career.

In all our analyses, we treat parental social background as a constant. We do so by collapsing father's earnings $Y_{i}^{*}$ across the first 10 years in our data, 19901999. Fathers are in the age range $30-59$, which is a time when male earnings are relatively representative of lifetime income (Engzell and Mood, 2021). Because the average of a uniform variable is generally not uniform, we reimpose the rank transform within (child) gender-age cells to retain the interpretation of coefficients as rank-order correlations. We create measures of fathers' firm-level component $F_{i}^{*}$ and individual worker-level component $W_{i}^{*}$ in the same way, by collapsing predicted values over the years 1990-1999 and repeating the rank transform.

For children, we first focus on earnings centered on age 40 in our main analyses. To achieve reliability, we collapse observed ranks throughout ages $38-42$, excluding the 1978 cohort who is only followed until age 41. Earnings at age 40 is a good proxy for lifetime income, unlike earnings earlier in the career (Engzell and Mood, 2021; Nybom and Stuhler, 2017). We average the firm and individual worker fixed effects $\left(F_{i t}, W_{i t}\right)$ over the same ages, 38-42. Like for the fathers, we reimpose the rank transform after taking multi-year averages.

In a second step of analysis, we separate out annual earnings $Y_{i t}$ for each year between the ages 25-40. This means following children from 2000-2015 for our oldest cohort (born 1975) and 2003-2018 for our youngest (born 1978). These agespecific estimates allow us to track the importance of different earnings components to mobility across career stages.

\subsection{Overlap with education and occupation}

Next, we ask two questions about how firm-based advantages overlap with education and occupation. First, how much of the economic returns to education and occupation are mediated by firm sorting? Second, how much of residual influence of social background on earnings - that is, not mediated by education or occupationis explained by firm sorting? We look both at the direct association between parent and child earnings, and differences in pay by social class background.

Our data on education consist of 44 discrete levels and 358 detailed fields, which together make up 1,993 unique categories. Occupational data consist of Swedish census codes at the 3 digit (150 categories) and 4 digit (431 categories) level. Education data are for the most part reported directly by the degree-granting institution and we use the individual's highest completed level of education as of 2019. Occupational data come from various sources, including payroll data from large or public-sector employers, as well as surveys of small enterprises. Like with education, we use data on occupations from 2019.

To capture economic returns in a single coefficient, we first regress the individual's earnings rank around age 40 on a set of indicator variables reflecting the categories, and store predicted values from this regression. We then calculate the correlation between predicted and actual earnings rank, as well as partial correlations that account for the son's firm component of earnings. 
To study direct effects of social origin, we first focus on the residual association between father and child earnings that remains when the influence of the child's education or occupation is partitioned out. Moreover, we look at the class gap in earnings within occupations. Here we code the class origin from father's occupation in the 1990 census. We rely on the Swedish socioeconomic classification (SEI), similar to the Erikson-Goldthorpe class schema (Carlsson et al., 1974). We group fathers of the middle and higher salariat $(46,56)$ together with professionals $(60)$, and contrast them against remaining categories: workers (11-22), lower salariat (36), farmers (79), and entrepreneurs (89). The class pay gap is defined as the difference in percentile rank of children from high and low class, once detailed education or occupation are accounted for.

\subsection{Distinguishing mechanisms of children's firm sorting}

In further analyses, we go on to test a set of theoretically relevant explanations for the firm sorting advantage by social origin: sorting by human capital, job referral networks, and structural locations in the labor market.

First, we ask how much of the firm sorting advantage is explained by sorting on educational and occupational attainment. We regress the child's firm component of earnings on father's total earnings, and see how their rank correlation changes with the same detailed educational and occupational controls as above. We also test whether firm sorting is due to unobserved individual worker characteristics. High-paying firms may be particularly good at identifying and attracting high productivity workers. If this is the case, then firm sorting advantages for high-class workers may be due to their individual characteristics. To test this, we control for the child's individual component of earnings $W_{i t}$ in our firm sorting regression.

We operationalize job referral in two ways. First, we look at direct referral as the incidence of working at the same workplace as the father. Second, we identify indirect referral as finding work with a senior colleague who at some point earlier has worked with the father. We allow coworking to happen at any time throughout the career, but cap the workplace size for establishing a link at 1000 people. To ensure that these overlaps do not simply capture other mechanisms such as geographical propinquity we also identify a group of "placebo" hires. In these, there is a third worker connecting the father's and child's workplace but no shared overlap in time, the overlap with the father occurred after the son, or the worker entered the son's workplace after the son was hired. Again, we regress the child's firm component of earnings on father's earnings and inspect how the coefficient differs for groups who experience job referral versus those who do not.

To address structural location in the labor market, we study geographic immobility, industry overlap, and firm inheritance. In these analyses, we focus on the father's and child's main employer, defined as as where the father held the longest tenure throughout the period 1990-1999, or the son throughout 2000-2019. Hence, we do not directly observe whether a father referred a child to their firm. Especially with large employers, overlap could occur by chance, so this is a broader mechanism than the referral networks identified above. Geographic immobility occurs when the father's and son's main employer are both located in the same municipality, and sec- 


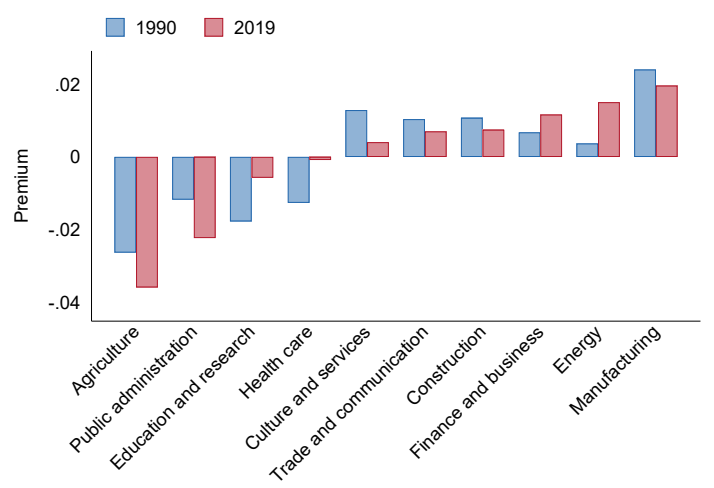

(a) Firm premiums

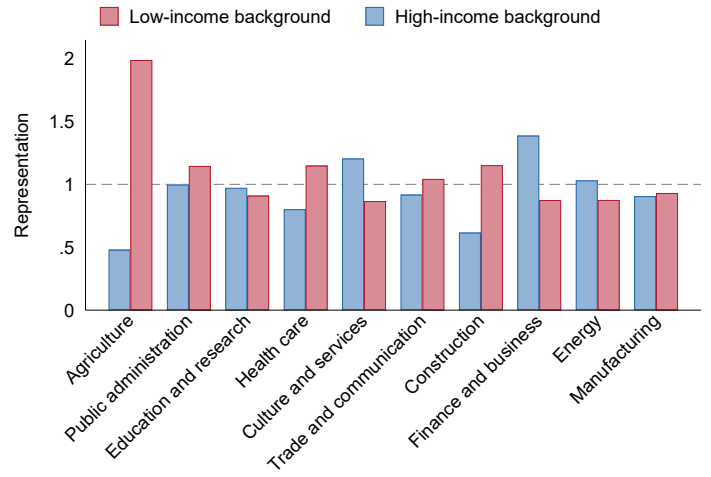

(b) Relative representation

Figure 2: Changing firm premiums and sorting on social background by industry.

Note: The left panel shows the average firm premium (log earnings, hundreds of SEK) by industry in 1990 and 2019. Rising premiums are evident in Finance and business and Energy, while declining premiums are evident in most other industries. The right panel shows the relative representation of children (sons and daughters) born to fathers earning in the top and bottom quintile, by age 40. Positive values indicate overrepresentation relative to children from the middle three quintiles, negative values indicate underrepresentation. Children from low-income backgrounds are overrepresented in industries with declining firm premiums.

tor inheritance when they are located in the same 1-digit industry. Sweden consists of 290 municipalities, the population of which averaged about 30,000 in 2000. The 1-digit level of the Swedish industry classification (SNI) encompasses 10 categories: agriculture, construction, culture and services, education and research, energy, finance and business, health care, manufacturing, public administration, trade and communication, as well as an "unspecified" category. Here, too, we regress the child's firm component of earnings on father's earnings and inspect how the coefficient differs for groups who share municipality, industry, or employment with their father with those who do not. her public at the level of state, county, or municipality — and distinguishing between public institutions and publicly owned firms - or private.

\section{Results}

To motivate our analysis, in Figure 2, left panel, we plot the changing firm premium across industries over our observation period. Negative firm premiums are found in agriculture, public administration, education and research, and health care, and positive premiums in all other industries. However, the trend across these industries differs. Looking at industries with positive premiums, the premium has been shrinking in culture and services, trade and communication, construction, and manufacturing, while the energy and finance and business sectors have seen growing premiums over time. At the low end, premiums for agriculture and public administration have grown increasingly negative. 


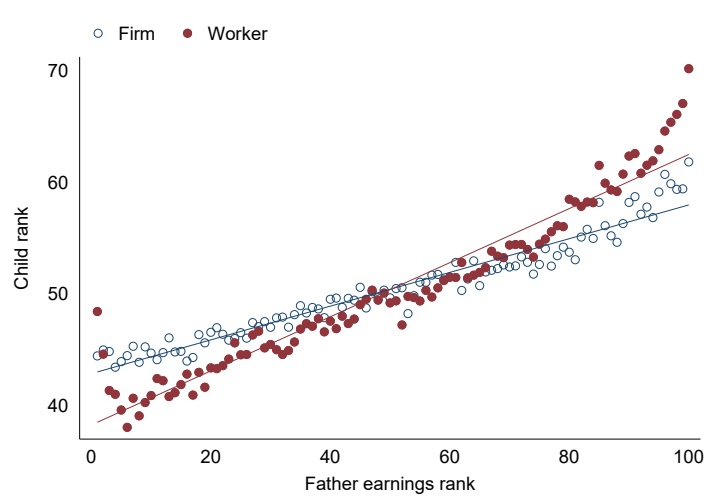

(a) Sons

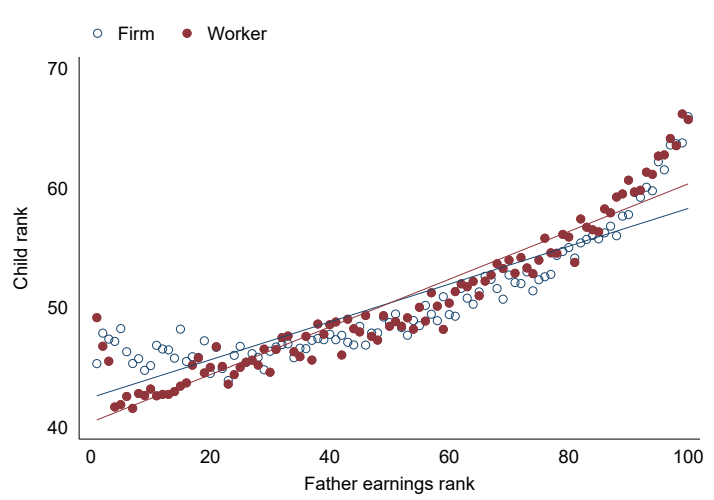

(b) Daughters

Figure 3: Average child firm and worker rank by father's earnings rank.

Note: The figure shows the child's expected firm and worker rank at every percentile of father's earnings rank. Father earnings rank measured 1990-1999, children's firm and worker rank measured as a 5-year average centered on age 40. Father's earnings are independently associated both with children's individual earnings and the relative pay of the employer they sort to.

In Figure 2, right panel, we show the distribution of children born into the top and bottom earnings quintile across industries by age 40. Low-income background children disproportionately sort to fields with a negative premium like agriculture and public administration. Or, when they are found in high-premium industries, such as construction or trade and communication, that premium has been shrinking over time. By contrast, high-income background children are found in industries with positive and growing premiums, such as energy or, particularly, finance and business.

\subsection{The contribution of firms to overall intergenerational earnings persistence}

We first assess the extent to which parental earnings predict children's firm sorting, and not just the individual, time-invariant component of children's earnings. Figure 3 displays children's firm and individual worker components of earnings at each percentile of father earnings. We focus on children's mid-career earnings centered on age 40 and we separate results by child gender.

Figure 3 shows that fathers' earnings have a substantial association with both the individual worker and and firm components of child earnings. For sons, the individual worker effect association is 0.24 with fathers' earnings, comparable to the earnings correlation itself, at $\rho=0.24$ (see Appendix Table A7). The firm-level association is smaller but nevertheless substantial, at 0.15. For daughters, the worker and firm associations are more similar: the individual worker effect association is 0.20 and the firm-level association 0.16 , compared to an overall earnings correlation of $\rho=0.20$ (see Appendix Table A7). So, father's earnings predicts not only the individual worker component of earnings children's earnings, emphasized in prior intergenerational mobility research, but also the firm sorting component. 
Table 1: Decomposition parameters at child age 38-42.

\begin{tabular}{rlll} 
& & \multicolumn{2}{c}{ Estimate (percent) } \\
\cline { 2 - 3 } Parameter & \multicolumn{1}{c}{ Sons } & Daughters \\
\hline firm-to-firm & $=\rho_{\mathrm{ff}} \cdot a_{1} \cdot a_{2}$ & $0.016(6.80 \%)$ & $0.007(3.91 \%)$ \\
worker-to-firm $=\rho_{\mathrm{wf}} \cdot b_{1} \cdot a_{2}$ & $0.037(16.4 \%)$ & $0.036(19.2 \%)$ \\
firm-to-worker $=\rho_{\mathrm{fw}} \cdot a_{1} \cdot b_{2}$ & $0.013(5.66 \%)$ & $0.008(4.45 \%)$ \\
worker-to-worker & $=\rho_{\mathrm{ww}} \cdot b_{1} \cdot b_{2}$ & $0.162(71.1 \%)$ & $0.137(72.4 \%)$ \\
$\mathrm{ff}+\mathrm{wf}+\mathrm{fw}+\mathrm{ww}$ & $=\operatorname{corr}\left(Y_{i}^{*}, Y_{i}\right)$ & $0.228(100 \%)$ & $0.189(100 \%)$ \\
\hline$\rho_{\mathrm{ff}}=\operatorname{corr}\left(F_{i}^{*}, F_{i}\right)$ & 0.120 & 0.070 \\
$\rho_{\mathrm{wf}}$ & $=\operatorname{corr}\left(W_{i}^{*}, F_{i}\right)$ & 0.126 & 0.150 \\
$\rho_{\mathrm{fw}}$ & $=\operatorname{corr}\left(F_{i}^{*}, W_{i}\right)$ & 0.048 & 0.031 \\
$\rho_{\mathrm{ww}}$ & $=\operatorname{corr}\left(W_{i}^{*}, W_{i}\right)$ & 0.263 & 0.218 \\
$a_{1}$ & $=\operatorname{corr}\left(F_{i}^{*}, Y_{i}^{*} \mid W_{i}^{*}\right)$ & 0.363 & 0.366 \\
$b_{1}$ & $=\operatorname{corr}\left(W_{i}^{*}, Y_{i}^{*} \mid F_{i}^{*}\right)$ & 0.837 & 0.835 \\
$a_{2}$ & $=\operatorname{corr}\left(F_{i}, Y_{i} \mid W_{i}\right)$ & 0.355 & 0.289 \\
$b_{2}$ & $=\operatorname{corr}\left(W_{i}, Y_{i} \mid F_{i}\right)$ & 0.738 & 0.751 \\
\hline
\end{tabular}

Note: Path components of the intergenerational earnings correlation as described in Figure 1 Father earnings rank measured 1990-1999, children's earnings rank measured as a 5-year average centered on age 40. The most important path is worker-to-worker, followed by worker-to-firm, firm-to-firm, and firm-to-worker. Even in mature earnings, firm-based mechanisms account for a full quarter of intergenerational persistence.

Given these strong correlations, we next ask how much firm sorting contributes to the overall persistence of earnings across generations. To do this, we need to estimate all of the separate terms in Equation 5 of our decomposition framework above. We bring these components together in Table 1, which details the proportional contribution to the earnings correlation of each of the four paths: firm-to-firm, worker-to-firm, firm-to-worker, worker-to-worker. Filling in the path model is critical, as, consistent with earlier work on the two-way worker-firm fixed effect model, the worker component is substantially more important to explaining overall earnings variation (as captured for sons in the firm correlation $a_{2}=0.36$ compared to the worker effect correlation $b_{2}=0.74$ ). Although father's earnings strongly predict son's firm premium, the firm premium, for both generations, accounts for less variation in earnings than does the stable worker component.

Taking these different correlations with overall earnings into account, we find that the worker-to-worker path accounts for between $71 \%$ (sons) and $72 \%$ (daughters) of the total intergenerational earnings correlation. Firm-related pathways account for the remaining quarter of intergenerational mobility. This decomposition shows that while worker characteristics are the dominant source of intergenerational earnings transmission, firm sorting plays an important role in the mobility process.

Table 1 also provides our first evidence distinguishing mechanisms through which firm premiums affect intergenerational mobility. Although the underlying firm-to-firm $\left(\rho_{\mathrm{ff}}\right)$ and worker-to-firm $\left(\rho_{\mathrm{wf}}\right)$ correlations are similar, the worker-to-firm path is more important for the overall intergenerational correlation because father's 
individual worker component of earnings is a more influential predictor of earnings than is his firm premium rank. Specifically, the firm-to-firm and firm-to-worker paths each account for about $6-7 \%$ of the intergenerational earnings correlation for sons, and about $4 \%$ for daughters. Markedly more important is the worker-to-firm path which alone accounts for more than half of the share explained by firms: $16 \%$ of the overall correlation for sons and $19 \%$ for daughters.

This first set of results shows that children of high-earning parents disproportionately sort to high premium firms. While this process is not the main channel of intergenerational earnings persistence, it accounts for around a quarter - a quantitatively meaningful share. We further show that the main source of this firm-related intergenerational transmission is the worker-to-firm path. In the remaining analysis, we clarify the specific ways through which this path, and the other mechanisms of firm-related transmission, affects intergenerational persistence.

\subsection{Firm effects across career stages}

We have shown how firm and individual worker earnings components contribute to intergenerational earnings transmission at mid-career, but not how these components change over the early career period. Some sources of persistence-like firm inheritance and direct parental aid in job search - should be strongest at the early career stage, before tapering out by mid-career.

Figure 4 tests this by decomposing the intergenerational earnings correlation into its path components at each year of a child's career. Firm sorting is indeed most important early in the career and mediates the bulk of earnings transmission in the first few years of labor market entry. This fades gradually to about a quarter of the total correlation by age 40 (for relative numbers, see Figure A23).

This decline across the career in the firm-related share of earnings transmission is due to the increase in importance of the worker-to-worker path, as the child's worker component becomes a more important portion of their earnings. At the same time, firm-to-firm transmission faces a small decline in absolute terms and a large relative decline. Having a parent employed at a high-earning firm mainly benefits workers when they are young.

In contrast, the worker-to-firm transmission path grows in absolute terms and retains an important share of intergenerational earnings persistence up through age 40. Note that this pathway, in which children of high-earning parents end up working at high-premium firms, could be important both at early and later career stages. Direct parental aid should matter mainly early on, when parents are still active and engaged with their children's labor market attainment. Indirect human and social capital sorting advantages, in contrast, could pay off throughout a child's career. The continued importance of the worker-to-firm pathway up through peak earnings years suggests that it mainly operates through social capital and human capital amplification channels, rather than through direct parental aid in job search. 


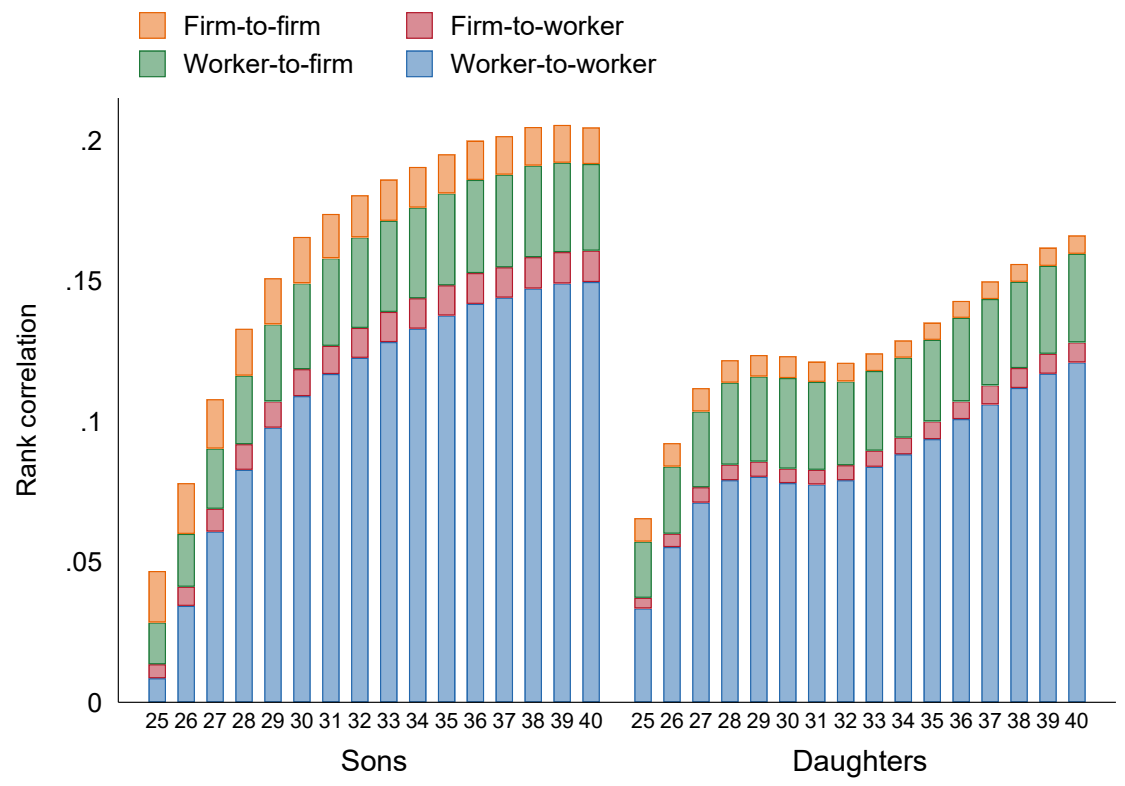

Figure 4: Decomposition of the intergenerational earnings correlation over the early career.

Note: Path components of the intergenerational earnings correlation as described in Figure 1 and Table 1, by sex and age of child. Father earnings rank measured 1990-1999, children's earnings measured annually for each age between 25 and 40. Firm sorting is present at labor market entry and persists throughout the career.

\subsection{Overlap with education and occupation}

Our analysis so far shows that a quarter of intergenerational earnings transmission is mediated by sorting across high- and low-premium firms. How does this map onto prior mobility research, which focuses on education and occupation? To answer this question, in Figure 5 we perform a set of analyses where we juxtapose our firmbased model with other paths of persistence commonly studied in the literature. In this and following sections, we focus on sons and display results for daughters in Appendix A5.

Existing intergenerational mobility research stresses education as the main conduit of both economic persistence and mobility. So we first ask how much of the economic returns to education is mediated by sorting to high- or low-paying firms. We also perform the same analysis for returns to occupational attainment. Education is measured by 44 levels and 358 fields (1,993 unique combinations), while occupations comprise 150 or 431 categories depending on level (see Section 4.4). Figure 5, top left, shows that firm sorting accounts for a substantial share of the economic returns to educational and occupational attainment. Firm sorting accounts for a quarter of the returns to education level, and a third of the returns to field of education. It also accounts for a quarter of economic returns to occupation.

Recent research highlights the direct effect of social origin, that is, persistence in economic status not accounted for by educational attainment. In Figure 5, top right, we estimate the residual association between father and son earnings rank 


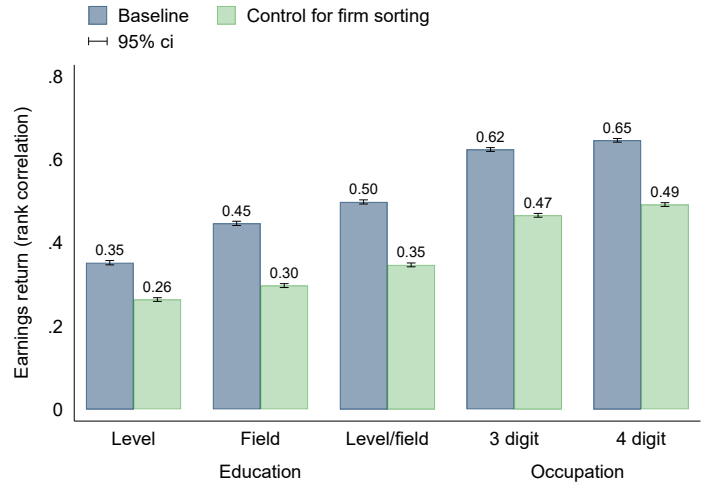

(a) Returns to education/occupation

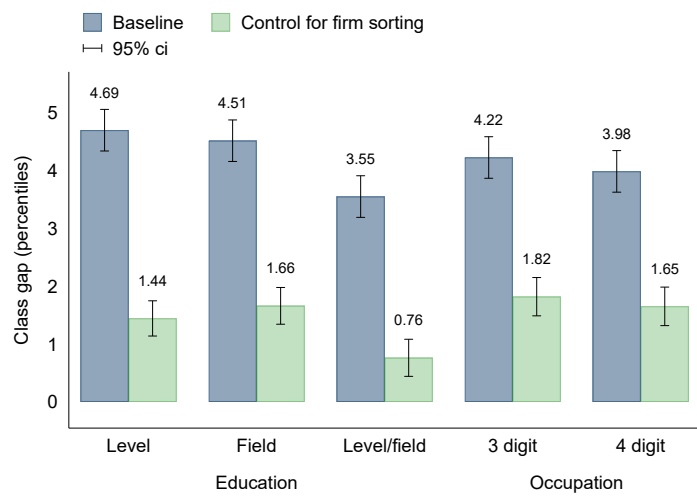

(c) Class origin gap in earnings

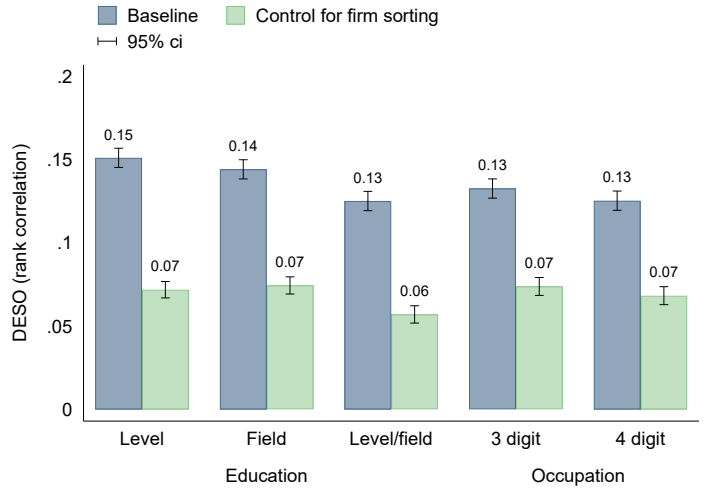

(b) Direct effect of social origin

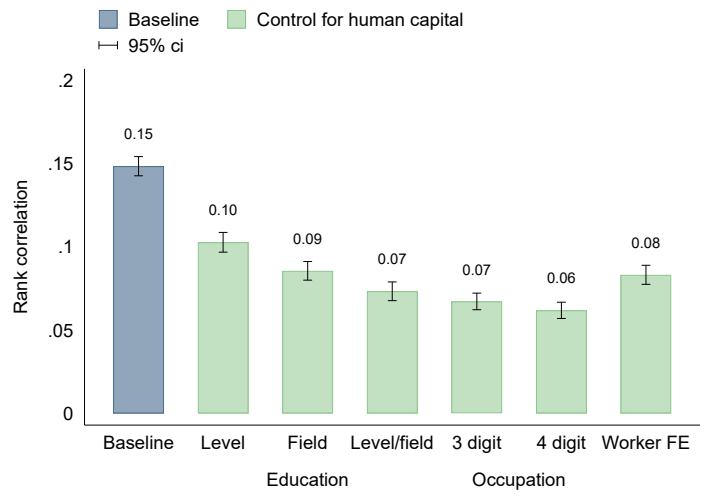

(d) Firm sorting with human capital controls

Figure 5: Overlap of firm sorting with education and occupation.

Note: The first three panels show the proportion explained by son's firm sorting: (a) earnings rank returns to education/occupation, (b) direct effect of father on son earnings rank, net of son's education/occupation, (c) son's gap in earnings rank by father's social class, net of own education/occupation. Panel (d) shows the rank correlation between father earnings and son firm premium before and after adjusting for son's education/occupation and worker component of earnings. Corresponding results for daughters shown in Appendix Figure A9.

when adjusting for education, as well as occupation, using the same detailed categories above. The figure shows that this direct association is sizeable but shrinks by half once we further adjust for the firm component of sons' earnings. In other words, firm sorting accounts for half of the direct effect of social origin in common models of intergenerational earnings persistence.

An alternative way to study the lingering effect of social origin in the labor market is through the "class gap" in earnings within occupations (Hällsten, 2013, Laurison and Friedman, 2016). Figure 5, bottom left, shows that there is a gap in earnings rank of about 4 percentile points within detailed categories of education or occupation, comparing sons from higher and lower class backgrounds. Strikingly, a majority of this gap is accounted for by firm sorting. Adjusting for the son's firm component of earnings reduces the class gap within educational categories by $79 \%$ (level and field) and within occupations by $59 \%$ (4 digit). 


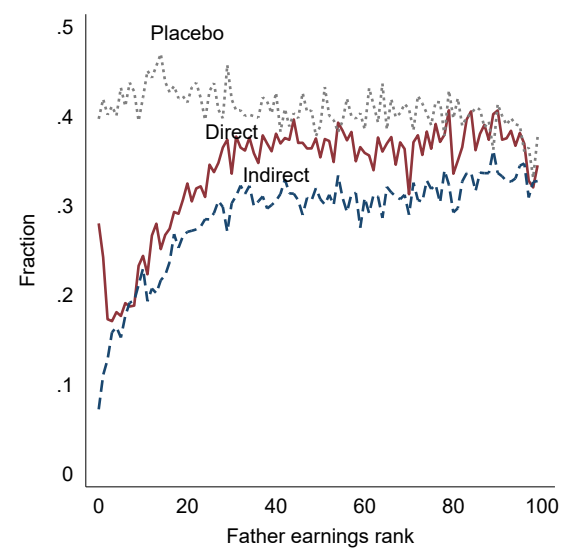

(a) Incidence by father earnings

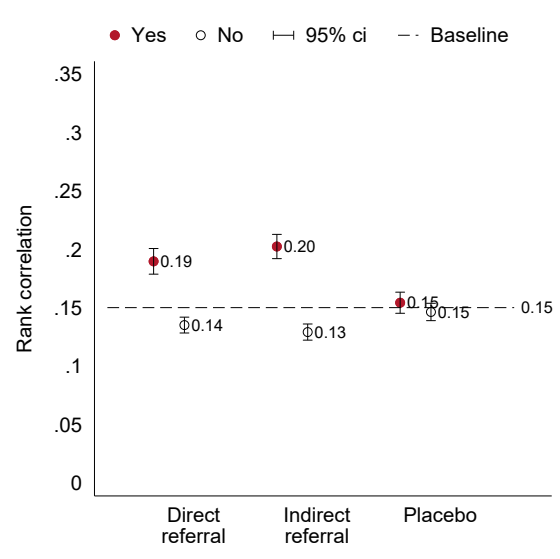

(b) Firm sorting coefficient

Figure 6: Job referral networks.

Note: The left panel shows the incidence of direct and indirect job referral, as well as placebo referrals, among sons by father earnings rank. Referrals defined as being hired at the workplace of father or father's former colleague, at any point in the son's early career. The right panel shows the rank correlation between father earnings and son firm premium, splitting the sample by direct, indirect, and placebo referrals. Corresponding results for daughters shown in Appendix Figure A10.

Conversely, we ask how much of the firm sorting advantage by social origin is explained by controls for education, occupation, and the individual worker fixed effect in Figure 5, bottom right. The association reflects the rank correlation between father earnings and son's firm component of earnings. Accounting for education explains half of the social origin differential in sorting to high- and low-paying firms, while the proportion accounted for by occupation is slightly higher, up to $60 \%$. We also adjust for the son's worker component of earnings, as a comprehensive control for human capital, capturing all traits that are consistently rewarded across employers. The proportion accounted for in this way is similar to that due to education, consistent with education being a main determinant of individual earnings.

To sum, firm sorting is a powerful dimension of stratification that overlaps partly, but only partly, with better studied dimensions such as educational or occupational attainment. Strikingly, firm sorting is a more potent explanation for mechanisms of stratification not well captured by observed human capital, whether operationalized as direct effects of social origin in the origin-education-destination triangle, or as the class pay gap between individuals in the same occupation. This suggests that firms constitute a fruitful way forward for understanding these persistent forms of inherited advantage in contemporary labor markets.

\subsection{Job referral networks}

If educational and occupational attainment do not fully account for inherited advantages due to firm sorting, what does? A natural candidate is referral networks in the labor market. We distinguish between direct referral, where a son is hired into 
the father's firm, and indirect referral, where there is a third worker who provides a link between the father and the firm that the son is hired into. In addition, we distinguish a "placebo" group where a coworker link with the father exists, but the temporal order makes it impossible for this contact to have served as a referral for the son (see Section 4.5).

Both direct and indirect referral are a common experience, as shown in Figure 6. left. About a third of sons have worked with their father or found work with a father's colleague at some point throughout their career. Direct referral is more common than indirect for sons, while the reverse holds true for daughters, but the differences are small (Appendix Figure A10). Experience of both direct and indirect referral is less common in the bottom part of the father's earnings distribution. The group of placebo hires reveals that the incidence of shared contacts does not differ across the father's earnings distribution. Hence, these differences reflect disparities in the mobilization of social capital, arguably because such contacts are more valuable at higher levels of father's earnings.

We demonstrate the consequences of job referral in Figure 6, right. Here we regress the son's firm component of earnings around age 40 on the father's earnings rank, and partition the sample by whether the son has experienced any job referral in the past. The size of the association in the full sample is shown by the dashed line as a reference. The results reveal that the firm sorting coefficient is $26 \%$ larger among those who experienced direct referral, and 35\% larger with indirect referral. When these groups are excluded, the coefficient is reduced by $10 \%$ and $14 \%$, respectively, from the baseline of 0.15. By contrast, there is no difference between treatment and control groups when our placebo definition of job referral is used. In sum, social capital translates into firm sorting that in turn cements earnings persistence. Our placebo analysis supports a causal interpretation of this mechanism.

\subsection{Structural location and firm inheritance}

Even in the absence of valuable network ties, children may work for similar employers as their parents due to local opportunity structures, or other forms of propinquity. Here we test for three further explanations: geographic immobility, industry inheritance, and employer inheritance. Our geographical unit is the municipality, and we study industry overlap at the 1-digit level (see Section 4.5). Unlike in the above analysis, we focus on employers rather than workplaces, and on the main employer of both the father and son throughout the observation period.

Figure 7, left, shows that $37 \%$ of sons find their main job in the same municipality as their father, $22 \%$ in the same industry, and $6 \%$ in the same firm. Geographic immobility and industry inheritance are both less common in the bottom of the father's earnings distribution. Industry inheritance increases continuously with father's earnings, whereas geographic immobility peaks among those born in the middle of the distribution. Sharing a main employer with one's father is relatively uncommon throughout the father's earnings distribution. This suggests that most use of parental contacts shown in Figure 6 reflects access to "stepping-stone" jobs, rather than to permanent employment. 


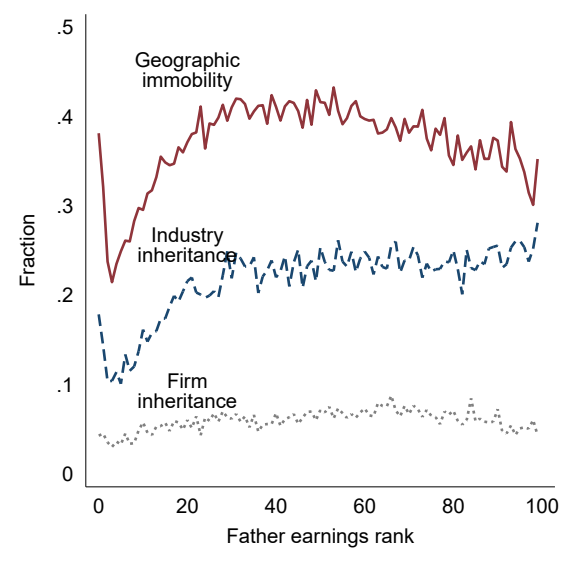

(a) Incidence by father earnings

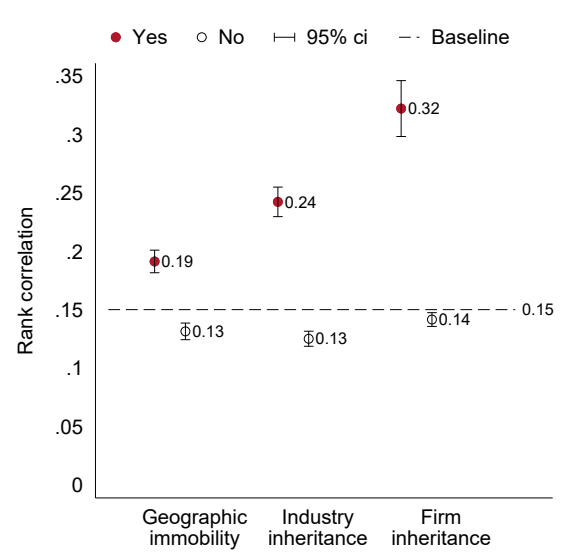

(b) Firm sorting coefficient

Figure 7: Geographic immobility, industry and firm inheritance.

Note: The left panel shows the incidence of geographic immobility, industry inheritance, and firm inheritance, among sons by father earnings rank. Immobility/inheritance relative to father municipality, 1-digit industry, and main employer measured by son's age 40 . The right panel shows the rank correlation between father earnings and son firm premium, splitting the sample by immobility/inheritance. Corresponding results for daughters shown in Appendix Figure A11.

To test how these forms of structural overlap shape firm sorting, we regress the son's firm component of earnings around age 40 on the father's earnings rank, and partition the sample by geographic immobility, industry inheritance, and employer inheritance. For sons who find their main job in the same municipality, industry or firm as their father, the rank correlation between father earnings and the son's firm component of earnings is $27 \%, 61 \%$, and $115 \%$ stronger, respectively. When these groups are excluded, the coefficient is reduced by $12 \%, 17 \%$, and $6 \%$ respectively, from the baseline of 0.15. Thus, geographic immobility and industry inheritance explain a substantial share of form the sorting advantage. By contrast, firm inheritance is relatively inconsequential as this group is small enough that the association in the comparison group is not appreciably weaker than in the whole sample.

\subsection{Multivariate results}

In Table 2, we bring all the above explanations together in one model. As before, we regress the son's firm component of earnings around age 40 on the father's earnings rank. We then add stepwise controls starting with education, occupation, and the worker component of earnings. We use the most detailed variables: 1,993 education codes and 431 occupation codes. For the subsequent variables reflecting referral networks, structural location, and firm inheritance we include both the main term and an interaction with father earnings rank. In this way, the remaining coefficient captures persistence in the comparison group who do not experience job referral or structural persistence.

Controlling for the son's observed and unobserved human capital, as well as his occupation, together explains two thirds of the firm sorting advantage by social 
Table 2: Association between father earnings and firm sorting, with controls. Sons only, daughters in Appendix Table A3.

\begin{tabular}{lcccc}
\hline & $\mathrm{b} / \mathrm{se}$ & $\mathrm{b} / \mathrm{se}$ & $\mathrm{b} / \mathrm{se}$ & $\mathrm{b} / \mathrm{se}$ \\
\hline Coefficient & 0.149 & 0.046 & 0.030 & 0.014 \\
& $(0.003)$ & $(0.003)$ & $(0.004)$ & $(0.004)$ \\
Education & - & $\checkmark$ & $\checkmark$ & $\checkmark$ \\
Occupation & - & $\checkmark$ & $\checkmark$ & $\checkmark$ \\
Worker FE & - & $\checkmark$ & $\checkmark$ & $\checkmark$ \\
Direct referral & - & - & $\checkmark$ & $\checkmark$ \\
Indirect referral & - & - & $\checkmark$ & $\checkmark$ \\
Geographic immobility & - & - & - & $\checkmark$ \\
Industry inheritance & - & - & - & $\checkmark$ \\
Firm inheritance & - & - & - & $\checkmark$ \\
$\mathrm{N}$ & 112931 & 112931 & 112931 & 112931 \\
\hline
\end{tabular}

Note: The table shows the rank correlation between father earnings and son firm premium, introducing mediating variables using ordinary least squares. Father earnings rank measured 19901999, son firm rank measured as a 5-year average centered on age 40. Codes for education and occupation comprise 1,993 and 431 categories, respectively. Terms for referral, immobility, and inheritance include an interaction with father earnings rank. Corresponding results for daughters shown in Appendix Table A3.

origin (69\%). Adding controls for direct and indirect referral explains another tenth of the remaining association (11\%), as does adjusting for structural location and firm inheritance (11\%). Only a small proportion of the firm sorting advantage remains unexplained $(9 \%)$. The proportions explained for daughters are similar, with $63 \%, 9 \%$, and $12 \%$ in each step, leaving a somewhat larger proportion of the firm sorting advantage unexplained (17\%) (Appendix Table A3).

\section{Conclusion}

Much research in social stratification has focused on education, occupation, and upward mobility inside firms. But rising between-firm inequality has divided the economy between high-paying superstar firms and low-wage laggards. These labor market changes have been accompanied by empirical methods that identify unequal firm premiums by controlling for firms' worker composition. Moreover, recent qualitative research suggests that firm sorting can be influenced by social background, whereby advantaged job applicants obtain entry to elite firms.

In this paper, we clarify how inequality in firm pay premiums affects intergenerational mobility. Empirically, we find that the endowment of individual traits accounts for the majority of earnings transmission, consistent with the main thrust of stratification research. Yet, more than a quarter of earnings transmission occurs through firm sorting. Even by age 40, children from privileged origins continue to work in higher-paying firms than their less fortunate peers. This firm-related transmission occurs mainly because parents with high individual earnings have children 
who are more likely to be hired to work in high-paying firms. Network referral and inheritance of structural position in a local labor market or industry play supplementary, but smaller roles.

Notably, children from privileged origins enjoy a firm sorting advantage regardless of the sources of parents' earnings advantage. Parents with high individual pay support and cultivate their children to obtain jobs at high-paying firms, even when the parent did not work at such a firm. These results show how "achieved" or skill-based rewards in one generation can harden into "ascribed" or class-based advantages in the next. Parents who achieve a high individual standing by dint of luck or hard work face a problem in how to pass on their advantage. The skills that gained the parent their position may be costly to transfer, or turn out to be obsolete. Strategic knowledge about the education system or labor market, along with the mobilization of network ties, are less costly ways to pass on this status.

Educational attainment explains an important part, up to half, of firm sorting by social background. Meanwhile, firm sorting explains only about a quarter of the returns to education. However, firm sorting explains a much larger portion of the intergenerational earnings advantage not mediated by education or occupation. This residual is of growing concern: as access to education and white-collar jobs reaches an increasing share of the population, privileged parents will be pressed for new means to reproduce their success. We have showed that firm sorting explains half of the direct effect of parent on child earnings after education and occupation is partitioned out. Firm sorting also explains most of the class origin gap in earnings that much recent scholarship has focused on (Laurison and Friedman, 2016).

The firm-based approach that we take holds promise for understanding the role of networks in the reproduction of economic success. About a third of sons from homes above median income have shared a workplace with their father, and a similar proportion with a former colleague of the father. These referrals yield a payoff, not through permanent employment but rather as stepping-stone jobs on the path to a lucrative career. Inheritance of a main employer is rare and surprisingly inconsequential. While parental referral is transient, children's benefits in terms of firm sorting are lasting. These results are consistent with existing work on the returns to social capital over the life course (McDonald and Elder Jr, 2006).

Our results on the role of firms as an amplifier of human capital should change how we think about education in the labor market. Educational advantage may be less attributable to skills than some would like to believe, and more about firm sorting through networks and strategic knowledge. A wealth of qualitative work already testifies to the importance of these mechanisms Ashley, 2022, Ho, 2009, Rivera, 2016), yet mainstream stratification research lags behind with its focus on individuals over institutions and networks. A firm-based approach is a promising way forward. The use of new big-data sources and computational tools could identify pipelines between elite educational institutions and elite employers. We expect that the importance of this process could vary across time and place, as the extent of social background sorting into institutions and firms varies.

Another implication of our work concerns how the distribution of firm premia across sectors and industries shape intergenerational advantage. Future research may identify labor markets in which firm-mediated advantage is weaker or inter- 
rupted altogether. Such research could also help distinguish the kinds of firms and the sources of firm pay premiums that tend to provide mobility opportunities from the kinds that lock-in advantages for already privileged workers. As initial descriptive work down these lines, we have showed that workers sort to firms across very different industries based on social origin. While trends such as skill segregation and superstar firms will amplify the social background returns to this process, policies of centralized bargaining and minimum wages can mollify them. This points to an agenda on how comparative labor organization might shape the inheritance of advantage.

Future research should also assess how the influence of firms on intergenerational mobility varies with the overall importance of firms in determining workers' pay. Sweden is a conservative case here, as firm premiums account for a relatively small share of earnings inequality compared to other developed countries (Criscuolo et al. 2020). But, more broadly, across most rich countries, earnings inequality is increasingly between-firms (Tomaskovic-Devey et al., 2020), due to a combination of increased positive worker sorting across firms and persistently important firm pay premiums (Card et al., 2013; Song et al., 2018). In economies in which firms substantially determine worker earnings, such as the US, we expect firms' role in intergenerational mobility to be amplified.

Since its origins in the 1960s, status attainment research has consistently focused on ways that high-status parents endow children with education and other individual resources valued in the labor market. Although this research program has proven extraordinarily productive, it has also obscured ways that social reproduction is influenced by structural features of the labor market. A strong undercurrent of stratification research has questioned this focus on the individual, hypothesizing labor market segmentation as a driving force behind intergenerational stratification (Baron, 1984, Baron and Bielby, 1980, Featherman, 1981, Spilerman, 1977; Stolzenberg, 1978). For the first time, availability of large-scale administrative data and new empirical methods make it possible to test this hypothesis. Our findings demonstrate the promise of incorporating firms into an analysis of intergenerational mobility and should inspire further work toward this aim.

\section{Notes}

${ }^{1}$ We use the terms "employer" and "firm" synonymously, although employers in our data span a wider set of entities than firms, including non-profits or public sector organizations. In Appendix A8 we provide more discussion and test the robustness of our results to exclusion of the public sector.

2 We focus on earnings as opposed to occupation or class. Earnings are appealing as a relatively final indicator of labor market success, being a consequence rather than a cause of labor market position (Mood, 2017). Sociological debate on occupational stratification has, at least in part, judged alternative indices by how well they predict earnings (Goldthorpe and McKnight, 2006; Kim et al., 2018; Shahbazian and Bihagen, 2022). We study earnings rather than income as earnings have a clear link to employers, and focus on fathers as the main breadwinner in the parental generation. We use earnings rank consistent with the traditional sociological focus on understanding relative mobility, as opposed to margin-dependent measures such as the intergenerational elasticity (Bloome et al., 2018). 
${ }^{3}$ We follow the convention in this literature of using fixed rather than random effects. That convention is not arbitrary: a fixed-effects specification is needed to cleanly purge individual effects from firm-level effects and vice versa. Moreover, given that we have population data, there is no need to assume a particular distribution (e.g., normal) on group effects as in the random-effects model, and fixed effects are therefore more appropriate.

\section{References}

Abowd, John M., Francis Kramarz, and David N. Margolis. 1999. "High Wage Workers and High Wage Firms." Econometrica 67:251-333.

Anderson, Elijah. 2000. Code of the street: Decency, violence, and the moral life of the inner city. WW Norton \& Company.

Andrews, Martyn J, Len Gill, Thorsten Schank, and Richard Upward. 2008. "High wage workers and low wage firms: negative assortative matching or limited mobility bias?" Journal of the Royal Statistical Society: Series A (Statistics in Society) 171:673-697.

Armstrong, Elizabeth A and Laura T Hamilton. 2013. Paying for the Party. Harvard University Press.

Ashley, Louise. 2022. Highly Discriminating: Why the City Isn't Fair and Diversity Doesn't Work. Policy Press.

Autor, David, David Dorn, Lawrence F Katz, Christina Patterson, and John Van Reenen. 2020. "The fall of the labor share and the rise of superstar firms." Quarterly Journal of Economics 135:645-709.

Baron, James N. 1984. "Organizational perspectives on stratification." Annual Review of Sociology 10:37-69.

Baron, James N. and William T. Bielby. 1980. "Bringing the Firms Back in: Stratification, Segmentation, and the Organization of Work." American Sociological Review 45:737-765.

Barth, Erling, James Davis, and Richard B. Freeman. 2018. "Augmenting the Human Capital Earnings Equation with Measures of Where People Work." Journal of Labor Economics 36:S71-S97.

Becker, Gary S and Nigel Tomes. 1986. "Human capital and the rise and fall of families." Journal of Labor Economics 4:S1-S39.

Beggs, John J and Wayne J Villemez. 2001. "Regional labor markets." In Sourcebook of Labor Markets, edited by Ivar Berg and Arne L Kalleberg, pp. 503-529. Springer.

Bernardi, Fabrizio and Gabriele Ballarino. 2016. Education, Occupation and Social Origin: A comparative analysis of the transmission of socio-economic inequalities. Edward Elgar Publishing. 
Bibb, Robert and William H Form. 1977. "The effects of industrial, occupational, and sex stratification on wages in blue-collar markets." Social Forces 55:974-996.

Bihagen, Erik. 2008. "Does Class Matter Equally for Men and Women? A Study of the Impact of Class on Wage Growth in Sweden 1999-2003." Sociology 42:522540 .

Binder, Amy J, Daniel B Davis, and Nick Bloom. 2016. "Career funneling: How elite students learn to define and desire "prestigious' jobs." Sociology of Education 89:20-39.

Black, Sandra and Paul Devereux. 2011. "Recent Developments in Intergenerational Mobility." In Handbook of Labor Economics, edited by Orley Ashenfelter and David Card, volume 4, pp. 1487-1541. North Holland Press, Elsevier.

Blau, Peter M and Otis Dudley Duncan. 1967. The American occupational structure. New York: John Wiley \& Sons.

Bloome, Deirdre, Shauna Dyer, and Xiang Zhou. 2018. "Educational inequality, educational expansion, and intergenerational income persistence in the United States." American Sociological Review 83:1215-1253.

Borgen, Nicolai T and Arne Mastekaasa. 2018. "Horizontal stratification of higher education: the relative importance of field of study, institution, and department for candidates' wages." Social Forces 97:531-558.

Bourdieu, Pierre. 1984. Distinction: A social critique of the judgement of taste. Harvard University Press.

Bourdieu, Pierre. 2000. The Social Structures of the Economy. London: Polity.

Bowles, Samuel, Herbert Gintis, and Melissa Osborne Groves. 2009. Unequal chances: Family background and economic success. Princeton University Press.

Breen, Richard and Walter Müller. 2020. Education and Intergenerational Social Mobility in Europe and the United States. Stanford University Press.

Bryson, Alex and Rhys Davies. 2019. "Family, place and the intergenerational transmission of union membership." British Journal of Industrial Relations 57:624650 .

Bühlmann, Felix, François Schoenberger, Lena Ajdacic, and Fabien Foureault. 2022. "Elite recruitment in US finance: How university prestige is used to secure top executive positions." The British Journal of Sociology 73:667-684.

Card, David, Jörg Heining, and Patrick Kline. 2013. "Workplace Heterogeneity and the Rise of West German Wage Inequality." Quarterly Journal of Economics 128:967-1015.

Carlsson, Gosta, Robert Erikson, Carl Löfwall, and Bo Wärneryd. 1974. "Socioekonomiska grupperingar." Statistisk tidskrift 5:381. 
Carniero, P, Sarah Cattan, Lorraine Dearden, Laura van der Erve, Sonya Krutikova, and Lindsey Macmillan. 2020. "The long shadow of deprivation: Differences in opportunities across England." Social Mobility Commission Research Report.

Castilla, Emilio J, George J Lan, and Ben A Rissing. 2013. "Social networks and employment." Sociology Compass 7:999-1026.

Cheng, Siwei and Xi Song. 2019. "Linked Lives, Linked Trajectories: Intergenerational Association of Intragenerational Income Mobility." American Sociological Review 84:1037-1068.

Cobb, J Adam and Ken-Hou Lin. 2017. "Growing apart: The changing firm-size wage premium and its inequality consequences." Organization Science 28:429446.

Corak, Miles and Patrizio Piraino. 2011. "The Intergenerational Transmission of Employers." Journal of Labor Economics 29:37-68.

Correia, Sergio. 2019. "REGHDFE: Stata module to perform linear or instrumentalvariable regression absorbing any number of high-dimensional fixed effects."

Criscuolo, Chiara, Alexander Hijzen, Cyrille Schwellnus, Erling Barth, Wen-Hao Chen, Richard Fabling, Priscilla Fialho, Balazs Stadler, Richard Upward, Wouter Zwysen, Katarzyna Grabska-Romagosa, Ryo Kambayashi, Timo Leidecker, Oskar Nordström Skans, Capucine Riom, and Duncan Roth. 2020. "Workforce composition, productivity and pay: the role of firms in wage inequality." OECD Economics Department Working Papers.

Cunha, Flavio, James J Heckman, and Susanne M Schennach. 2010. "Estimating the technology of cognitive and noncognitive skill formation." Econometrica 78:883931.

Dahl, Molly W and Thomas DeLeire. 2008. "The association between children's earnings and fathers' lifetime earnings: estimates using administrative data." University of Wisconsin-Madison, Institute for Research on Poverty.

DiMaggio, Paul and Filiz Garip. 2012. "Network effects and social inequality." Annual Review of Sociology .

Dobbin, Caue and Tom Zohar. 2021. "Quantifying the Role of Firms in Intergenerational Mobility." Mimeo.

Domina, Thurston, Andrew Penner, and Emily Penner. 2017. "Categorical inequality: Schools as sorting machines." Annual Review of Sociology 43:311-330.

Duncan, Otis Dudley. 1966. "Path analysis: Sociological examples." American Journal of Sociology 72:1-16.

Engbom, Niklas and Christian Moser. 2017. "Returns to education through access to higher-paying firms: Evidence from US matched employer-employee data." American Economic Review 107:374-78. 
Engbom, Niklas, Christian Moser, and Jan Sauermann. 2022. "Firm pay dynamics."

Engzell, Per and Carina Mood. 2021. "How Robust are Estimates of Intergenerational Income Mobility?" SocArXiv, http://osf.io/preprints/socarxiv/ gd2t6.

Farkas, George. 2003. "Cognitive skills and noncognitive traits and behaviors in stratification processes." Annual Review of Sociology 29:541-562.

Featherman, David L. 1981. "Social stratification and mobility: two decades of cumulative social science." American Behavioral Scientist 24:364-385.

Fiel, Jeremy E. 2020. "Great equalizer or great selector? Reconsidering education as a moderator of intergenerational transmissions." Sociology of Education 93:353371.

Fletcher, Jason and Joel Kaiyuan Han. 2021. "High schools and intergenerational mobility." Research in Social Stratification and Mobility 76:100621.

Fox, Liana, Florencia Torche, and Jane Waldfogel. 2016. "Intergenerational mobility." In The Oxford Handbook of the Social Science of Poverty, edited by David Brady and Linda M Burton. Oxford University Press.

Friedman, Sam and Daniel Laurison. 2020. The Class Ceiling: Why it Pays to be Privileged. Bristol: Policy Press.

Gerstl, Joel E and Lois K Cohen. 1964. "Dissensus, situs and egocentrism in occupational ranking." The British Journal of Sociology 15:254-261.

Goldstein, Amy. 2017. Janesville: An American Story. Simon and Schuster.

Goldthorpe, John H. 1982. "On the service class, its formation and future." In Social class and the division of labour, edited by Anthony Giddens and Gavin Mackenzie, pp. 162-185. Cambridge University Press.

Goldthorpe, John H and Abigail McKnight. 2006. "The economic basis of social class." In Mobility and Inequality: Frontiers of Research in Sociology and Economics, edited by Stephen L Morgan, David B Grusky, and Gary S Fields, pp. 109-136. Stanford University Press.

Granovetter, Mark. 1974. Getting a Job: A Study of Contacts and Careers. University of Chicago press.

Granovetter, Mark S. 1973. "The strength of weak ties." American journal of sociology 78:1360-1380.

Groshen, Erica L. 1991. "Sources of Intra-Industry Wage Dispersion: How Much Do Employers Matter?" Quarterly Journal of Economics 106:869-884.

Hällsten, Martin. 2010. "The structure of educational decision making and consequences for inequality: A Swedish test case." American Journal of Sociology 116:806-54. 
Hällsten, Martin. 2013. "The class-origin wage gap: heterogeneity in education and variations across market segments." The British Journal of Sociology 64:662-690.

Hällsten, Martin and Max Thaning. 2018. "Multiple dimensions of social background and horizontal educational attainment in Sweden." Research in Social Stratification and Mobility 56:40-52.

Haltiwanger, John C and James R Spletzer. 2020. "Between Firm Changes in Earnings Inequality: The Dominant Role of Industry Effects." National Bureau of Economic Research.

Hirsch, F. 1977. The Social Limits to Growth, London (1976). Routledge.

Ho, Karen. 2009. Liquidated: an ethnography of Wall Street. Duke University Press.

Horowitz, Jonathan. 2018. "Relative education and the advantage of a college degree." American Sociological Review 83:771-801.

Hout, Michael. 2012. "Social and economic returns to college education in the United States." Annual Review of Sociology 38:379-400.

Jæger, Mads Meier and Richard Breen. 2016. "A dynamic model of cultural reproduction." American Journal of Sociology 121:1079-1115.

Jahoda, Marie, Paul F Lazarsfeld, and Hans Zeisel. [1933]1971. Marienthal: The sociography of an unemployed community. Chicago: Aldine Atherton.

Jencks, Christopher et al. 1979. Who gets ahead? The determinants of economic success in America. New York: Basic Books.

Jonsson, Jan O, David B Grusky, Matthew Di Carlo, Reinhard Pollak, and Mary C Brinton. 2009. "Microclass mobility: Social reproduction in four countries." American Journal of Sociology 114:977-1036.

Karlson, Kristian Bernt. 2019. "College as equalizer? Testing the selectivity hypothesis." Social Science Research 80:216-229.

Khan, Shamus R. 2010. Privilege: The Making of an Adolescent Elite at St. Paul's School. The William G. Bowen Series. Princeton University Press.

Kim, ChangHwan, Christopher R Tamborini, and Arthur Sakamoto. 2018. "The sources of life chances: does education, class category, occupation, or short-term earnings predict 20-year long-term earnings?" Sociological Science 5:206-233.

Kline, Patrick, Neviana Petkova, Heidi Williams, and Owen Zidar. 2019. "Who profits from patents? Rent-sharing at innovative firms." Quarterly Journal of Economics 134:1343-1404.

Kline, Patrick, Raffaele Saggio, and Mikkel Sølvsten. 2020. "Leave-out estimation of variance components." Econometrica 88:1859-1898. 
Kramarz, Francis and Oskar Nordström Skans. 2014. "When Strong Ties are Strong: Networks and Youth Labour Market Entry." The Review of Economic Studies $81: 1164-1200$.

Kremer, Michael. 1993. "The O-ring theory of economic development." Quarterly Journal of Economics 108:551-575.

Krippner, Greta R. 2011. Capitalizing on crisis: The political origins of the rise of finance. Harvard University Press.

Lachowska, Marta, Alexandre Mas, Raffaele D Saggio, and Stephen A Woodbury. 2020. "Do firm effects drift? Evidence from Washington administrative data." National Bureau of Economic Research.

Lareau, Annette. 2011. Unequal Childhoods: Class, Race, and Family Life. University of California Press.

Laurison, Daniel and Sam Friedman. 2016. "The Class Pay Gap in Higher Professional and Managerial Occupations." American Sociological Review 81:668-695.

Lin, Nan. 2002. Social capital: A Theory of Social Structure and Action. Cambridge University Press.

Manduca, Robert A. 2019. "The contribution of national income inequality to regional economic divergence." Social Forces 98:622-648.

Marsden, Peter V and Elizabeth H Gorman. 2001. "Social networks, job changes, and recruitment." In Sourcebook of Labor Markets, edited by Ivar Berg and Arne L Kalleberg, pp. 467-502. Springer.

McDonald, Steve. 2011. "What you know or who you know? Occupation-specific work experience and job matching through social networks." Social Science Research 40:1664-1675.

McDonald, Steve and Glen H Elder Jr. 2006. "When does social capital matter? Non-searching for jobs across the life course." Social Forces 85:521-549.

Mijs, Jonathan J. B. and Elizabeth L. Roe. 2021. "Is America coming apart? Socioeconomic segregation in neighborhoods, schools, workplaces, and social networks, 1970-2020." Sociology Compass 15:e12884.

Mood, Carina. 2017. "More than money: social class, income, and the intergenerational persistence of advantage." Sociological Science 4:263-287.

Morgan, Stephen L, David B Grusky, and Gary S Fields. 2006. Mobility and Inequality: Frontiers of Research in Sociology and Economics. Stanford University Press.

Morris, Katy. 2022. "Where DESO Disappears: Spatial inequality and social stratification at labour market entry." European Sociological Review . 
Neely, Megan Tobias. 2022. Hedged Out: Inequality and Insecurity on Wall Street. Univ of California Press.

Newman, Katherine S. 2009. No Shame in My Game: The Working Poor in the Inner City. Vintage.

Nybom, Martin and Jan Stuhler. 2017. "Biases in standard measures of intergenerational income dependence." Journal of Human Resources 52:800-825.

Pfeffer, Fabian T and Martin Hällsten. 2012. "Mobility regimes and parental wealth: The United States, Germany, and Sweden in comparison." SOEPpapers on Multidisciplinary Panel Data Research, DIW Berlin.

Rivera, Lauren A. 2012. "Hiring as Cultural Matching: The Case of Elite Professional Service Firms." American Sociological Review 77:999-1022.

Rivera, Lauren A. 2016. Pedigree. Princeton University Press.

Rothstein, Jesse. 2019. "Inequality of educational opportunity? Schools as mediators of the intergenerational transmission of income." Journal of Labor Economics 37:S85-S123.

Rüttenauer, Tobias and Volker Ludwig. 2020. "Fixed effects individual slopes: Accounting and testing for heterogeneous effects in panel data or other multilevel models." Sociological Methods 83 Research .

San, Shmuel. 2022. "Who Works Where and Why? Parental Networks and the Labor Market." Available at SSRN.

Sewell, William H, Archibald O Haller, and Alejandro Portes. 1969. "The educational and early occupational attainment process." American Sociological Review pp. 82-92.

Sewell, William H and Robert M Hauser. 1975. Education, Occupation, and Earnings. Achievement in the Early Career. Academic Press.

Shahbazian, Roujman and Erik Bihagen. 2022. "Does Your Class Give More than a Hint of Your Lifetime Earnings?: Assessing Indicators for Lifetime Earnings Over the Life Course for Sweden." European Sociological Review .

Small, Mario Luis. 2009. Unanticipated Gains: Origins of Network Inequality in Everyday Life. Oxford University Press.

Smith, Matthew, Danny Yagan, Owen Zidar, and Eric Zwick. 2019. "Capitalists in the Twenty-first Century." Quarterly Journal of Economics 134:1675-1745.

Song, Jae, David J Price, Fatih Guvenen, Nicholas Bloom, and Till von Wachter. 2018. "Firming Up Inequality." Quarterly Journal of Economics 134:1-50.

Sørensen, Aage B. 2000. "Toward a sounder basis for class analysis." American Journal of Sociology 105:1523-1558. 
Spilerman, Seymour. 1977. "Careers, labor market structure, and socioeconomic achievement." American Journal of Sociology 83:551-593.

Staiger, Matthew. 2021. "The Intergenerational Transmission of Employers and the Earnings of Young Workers." Equitable Growth Working Paper.

Stolzenberg, Ross M. 1978. "Bringing the boss back in: Employer size, employee schooling, and socioeconomic achievement." American Sociological Review pp. 813-828.

Thurow, Lester C. 1975. Generating Inequality. Basic books.

Toft, Maren and Sam Friedman. 2021. "Family wealth and the class ceiling: the propulsive power of the bank of Mum and Dad." Sociology 55:90-109.

Tolbert, Charles M., II. 1983. "Industrial Segmentation and Men's Intergenerational Mobility." Social Forces 61:1119-1137.

Tomaskovic-Devey, Donald, Anthony Rainey, Dustin Avent-Holt, Nina Bandelj, István Boza, David Cort, Olivier Godechot, Gergely Hajdu, Martin Hällsten, Lasse Folke Henriksen, et al. 2020. "Rising between-workplace inequalities in highincome countries." Proceedings of the National Academy of Sciences 117:92779283.

Torche, Florencia. 2015. "Analyses of intergenerational mobility: An interdisciplinary review." The ANNALS of the American Academy of Political and Social Science 657:37-62.

Torche, Florencia. 2016. "Education and the intergenerational transmission of advantage in the US." In Education, Occupation and Social Origin, edited by Fabrizio Bernardi and Gabriele Ballarino. Edward Elgar Publishing.

Trimble, Lindsey B and Julie A Kmec. 2011. "The role of social networks in getting a job." Sociology Compass 5:165-178.

Waldinger, Roger David. 1999. Still the Promised City? African-Americans and New Immigrants in Postindustrial New York. Harvard University Press.

Weeden, Kim A and David B Grusky. 2005. "The case for a new class map." American Journal of Sociology 111:141-212.

Weinstein, Russell. 2018. "Employer screening costs, recruiting strategies, and labor market outcomes: An equilibrium analysis of on-campus recruiting." Labour Economics 55:282-299.

Wilmers, Nathan. 2018. "Wage Stagnation and Buyer Power: How Buyer-Supplier Relations Affect U.S. Workers' Wages, 1978 to 2014." American Sociological Review 83:213-242. 
Wilmers, Nathan. 2019. "Solidarity within and across workplaces: How crossworkplace coordination affects earnings inequality." RSF: The Russell Sage Foundation Journal of the Social Sciences 5:190-215.

Wilmers, Nathan and Clem Aeppli. 2021. "Consolidated Advantage: The New Organizational Dynamics of Wage Inequality, 1999-2018." American Sociological Review forthcoming.

Witteveen, Dirk and Paul Attewell. 2017. "Family background and earnings inequality among college graduates." Social Forces 95:1539-1576.

Witteveen, Dirk and Paul Attewell. 2020. "Reconsidering the "meritocratic power of a college degree'." Research in Social Stratification and Mobility 66:100479.

Zhou, Xiang. 2019. "Equalization or selection? Reassessing the "meritocratic power" of a college degree in intergenerational income mobility." American Sociological Review 84:459-485.

Zwysen, Wouter. 2016. "Crowding out of disadvantaged young adults in Germany: background matters depending on local labour market." European Sociological Review 32:662-674. 


\section{Appendix for: Firms and the Intergenerational Transmission of Labor Market Advantage (for online publication only)}

\section{A1 Mothers' earnings}

In our main analysis we measure parental earnings by focusing on fathers. In this section, we replicate our main results using mother's earnings. The results for our specific argument about the role of firms are quite consistent across the choice of reference parent. There are other differences though, that likely reflect gender-specific transmission mechanisms. Specifically, sons have a stronger earnings transmission from fathers than from mothers, while daughters have a similar level of transmission from both parents (compare Table A1 and main text Table 1). However, this absolute difference does not much affect the share of transmission accounted for by firms, or its development across career stages (see Figure A2). If anything, focusing on mothers and sons, rather than fathers and sons, further weakens the firm-to-firm transmission path for sons. But, our general conclusion about the share of transmission accounted for by firm-related paths, and the dominant role of the worker-to-firm path specifically, holds across choice of parent.

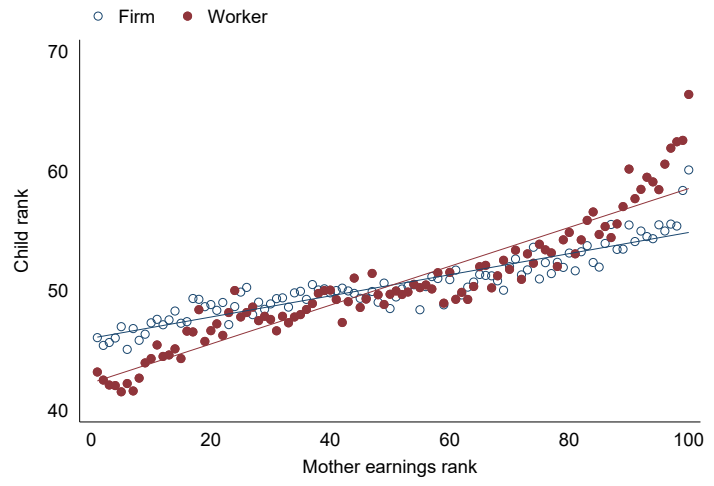

(a) Sons

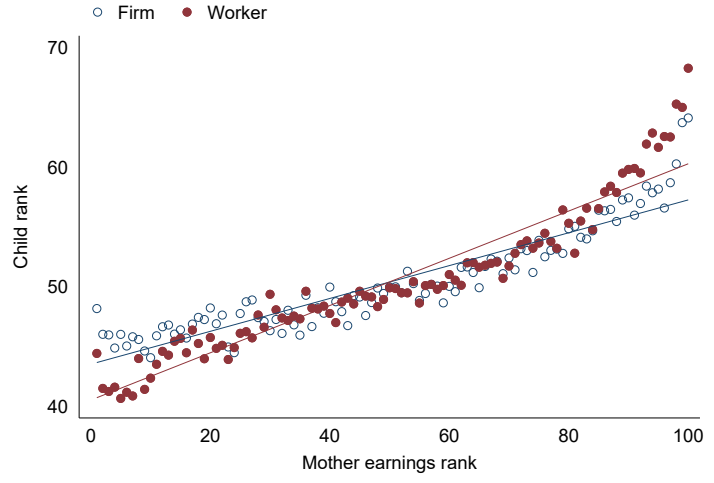

(b) Daughters

Figure A1: Average child firm and worker rank by mother's earnings rank. 
Table A1: Decomposition parameters at child age 38-42. Mother's earnings.

\begin{tabular}{rlll} 
& & \multicolumn{2}{c}{ Estimate (percent) } \\
\cline { 2 - 4 } Parameter & \multicolumn{1}{c}{ Sons } & Daughters \\
\hline firm-to-firm & $=\rho_{\mathrm{ff}} \cdot a_{1} \cdot a_{2}$ & $0.007(4.58 \%)$ & $0.009(4.73 \%)$ \\
worker-to-firm $=\rho_{\mathrm{wf}} \cdot b_{1} \cdot a_{2}$ & $0.024(15.8 \%)$ & $0.031(16.3 \%)$ \\
firm-to-worker & $=\rho_{\mathrm{fw}} \cdot a_{1} \cdot b_{2}$ & $0.008(5.53 \%)$ & $0.007(3.96 \%)$ \\
worker-to-worker & $=\rho_{\mathrm{ww}} \cdot b_{1} \cdot b_{2}$ & $0.112(74.0 \%)$ & $0.140(75.0 \%)$ \\
$\mathrm{ff}+\mathrm{wf}+\mathrm{fw}+\mathrm{ww}$ & $=\operatorname{corr}\left(Y_{i}^{*}, Y_{i}\right)$ & $0.151(100 \%)$ & $0.187(100 \%)$ \\
\hline$\rho_{\mathrm{ff}}$ & $=\operatorname{corr}\left(F_{i}^{*}, F_{i}\right)$ & 0.077 & 0.122 \\
$\rho_{\mathrm{wf}}$ & $=\operatorname{corr}\left(W_{i}^{*}, F_{i}\right)$ & 0.078 & 0.124 \\
$\rho_{\mathrm{fw}}$ & $=\operatorname{corr}\left(F_{i}^{*}, W_{i}\right)$ & 0.045 & 0.039 \\
$\rho_{\mathrm{ww}}$ & $=\operatorname{corr}\left(W_{i}^{*}, W_{i}\right)$ & 0.178 & 0.219 \\
$a_{1}$ & $=\operatorname{corr}\left(F_{i}^{*}, Y_{i}^{*} \mid W_{i}^{*}\right)$ & 0.251 & 0.250 \\
$b_{1}$ & $=\operatorname{corr}\left(W_{i}^{*}, Y_{i}^{*} \mid F_{i}^{*}\right)$ & 0.855 & 0.854 \\
$a_{2}$ & $=\operatorname{corr}\left(F_{i}, Y_{i} \mid W_{i}\right)$ & 0.357 & 0.289 \\
$b_{2}$ & $=\operatorname{corr}\left(W_{i}, Y_{i} \mid F_{i}\right)$ & 0.737 & 0.751
\end{tabular}

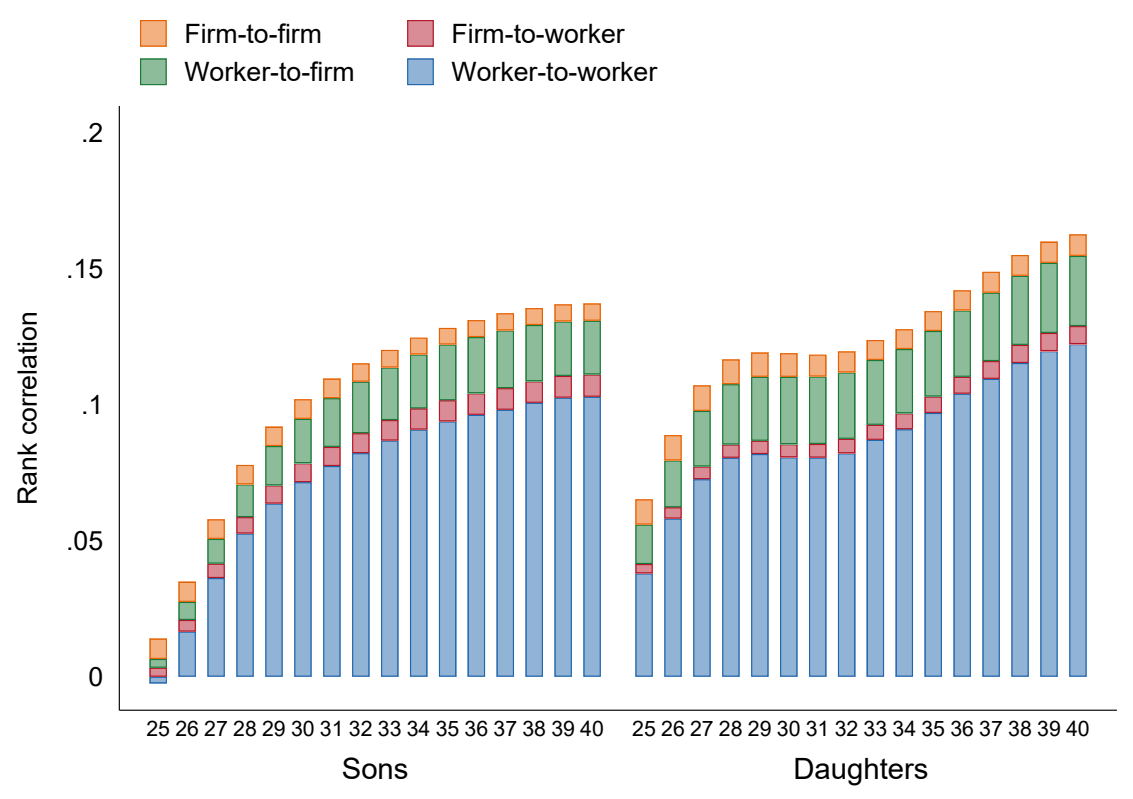

Figure A2: Decomposition of the intergenerational earnings correlation over the early career, by sex and age of child. Mother's earnings. 


\section{A2 Log earnings}

Much prior work using two-way fixed effects earnings models has predicted logged earnings as the dependent variable: the variance of logged earnings is a usefully decomposable measure of labor market earnings inequality. Because in this paper we address the literature on intergenerational mobility, rather than earnings inequality, we focus in the main text on studying rank transformed earnings. But here we show results using log income to estimate the log-linear correlation in earnings. This measure is closely associated with the standard intergenerational earnings elasticity, but adjusts for potential differences in dispersion between the parent's and child's generation (Fox et al., 2016).

Results are similar with this alternative transformation of the dependent variable. The overall intergenerational earnings correlation is somewhat stronger for sons with the log-linear approach, and somewhat stronger for daughters with rank. Firm-related components matter proportionately slightly more in the logs, due to weaker worker-to-worker transmission for both sons and daughters (compare Table A2 and main text Table 11). But the absolute correlations for the firm components are nearly identical across these specifications. Likewise, Figure A3 shows that trajectories over the career in the log-linear approach are very similar to those in the rank approach in the main text.

Table A2: Decomposition parameters at child age 38-42. Log earnings.

\begin{tabular}{|c|c|c|c|c|}
\hline \multirow{2}{*}{\multicolumn{3}{|c|}{ Parameter }} & \multicolumn{2}{|c|}{ Estimate (percent) } \\
\hline & & & \multirow{2}{*}{$\frac{\text { Sons }}{0.016(8.89 \%)}$} & \multirow{2}{*}{$\frac{\text { Daughters }}{0.007(4.95 \%)}$} \\
\hline firm-to-firm & $=$ & $\rho_{\mathrm{ff}} \cdot a_{1} \cdot a_{2}$ & & \\
\hline worker-to-firm & $=$ & $\rho_{\mathrm{wf}} \cdot b_{1} \cdot a_{2}$ & $0.035(18.7 \%)$ & $0.036(24.1 \%)$ \\
\hline firm-to-worker & $=$ & $\rho_{\mathrm{fw}} \cdot a_{1} \cdot b_{2}$ & $0.006(3.10 \%)$ & $0.005(3.29 \%)$ \\
\hline worker-to-worker & $=$ & $\rho_{\mathrm{ww}} \cdot b_{1} \cdot b_{2}$ & $0.129(69.3 \%)$ & $0.102(67.7 \%)$ \\
\hline $\mathrm{ff}+\mathrm{wf}+\mathrm{fw}+\mathrm{ww}$ & $=$ & $\operatorname{corr}\left(Y_{i}^{*}, Y_{i}\right)$ & $0.185(100 \%)$ & $0.151(100 \%)$ \\
\hline$\rho_{\mathrm{ff}}$ & $=$ & $\operatorname{corr}\left(F_{i}^{*}, F_{i}\right)$ & 0.087 & 0.048 \\
\hline$\rho_{\mathrm{wf}}$ & $=$ & $\operatorname{corr}\left(W_{i}^{*}, F_{i}\right)$ & 0.093 & 0.118 \\
\hline$\rho_{\mathrm{fw}}$ & $=$ & $\operatorname{corr}\left(F_{i}^{*}, W_{i}\right)$ & 0.019 & 0.016 \\
\hline$\rho_{\mathrm{ww}}$ & $=$ & $\operatorname{corr}\left(W_{i}^{*}, W_{i}\right)$ & 0.210 & 0.171 \\
\hline$a_{1}$ & $=$ & $\operatorname{corr}\left(F_{i}^{*}, Y_{i}^{*} \mid W_{i}^{*}\right)$ & 0.425 & 0.430 \\
\hline$b_{1}$ & $=$ & $\operatorname{corr}\left(W_{i}^{*}, Y_{i}^{*} \mid F_{i}^{*}\right)$ & 0.844 & 0.843 \\
\hline$a_{2}$ & $=$ & $\operatorname{corr}\left(F_{i}, Y_{i} \mid W_{i}\right)$ & 0.443 & 0.365 \\
\hline$b_{2}$ & $=$ & $\operatorname{corr}\left(W_{i}, Y_{i} \mid F_{i}\right)$ & 0.725 & 0.706 \\
\hline
\end{tabular}




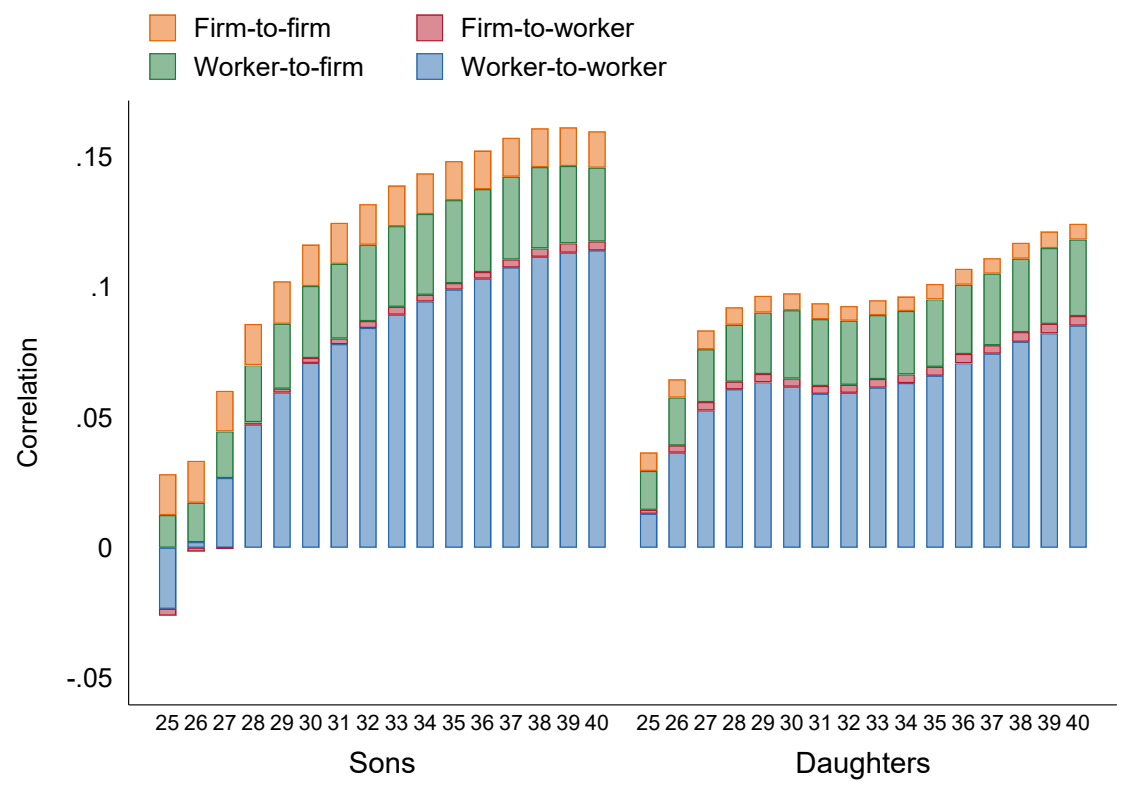

Figure A3: Decomposition of the intergenerational earnings correlation over the early career, by sex and age of child. Log earnings. 


\section{A3 Alternative age-earnings profiles}

In our main analysis, we account for population heterogeneity in age-earnings profiles by estimating flexibly specified trajectories that depend on an interaction between gender and four levels of education. Here, we extend this analysis by allowing even greater flexibility in the modeling of earnings over the life course. First, we let trajectories depend on up to 47 levels of education (Figure A4, as well as 116 detailed fields of study (Figure A5). This makes little difference to our results.

Second, we break our estimation sample up into distinct 5-year periods. This allows each worker and firm to be associated with a number of fixed effects throughout the observation window and thus allows for more flexible trajectories workers as well as varying firm premiums (Figure A6). Again, the picture is similar although firms account for a slightly higher proportion of intergenerational earnings transmission.

Third, we extend the canonical specification with one that allows for individual slopes by age as part of the worker component (Correia, 2019, Rüttenauer and Ludwig, 2020). This model can be written:

$$
Y_{i t}=\alpha_{i}+\gamma_{i} a g e_{i t}+X_{i t}^{\prime} \beta+\psi_{j(i, t)}+u_{i t} .
$$

Note the individual subscript $i$ on both the intercept $\alpha_{i}$ and the age-earnings slope $\gamma_{i}$. This specification arguably risks overfitting individual trajectories and is liable to soak up some of the effects due to varying firm premiums over the career. Nevertheless, even in this stringent specification, firm-based mechanisms account for a fifth of earnings transmission at the height of the career (Figure A7).

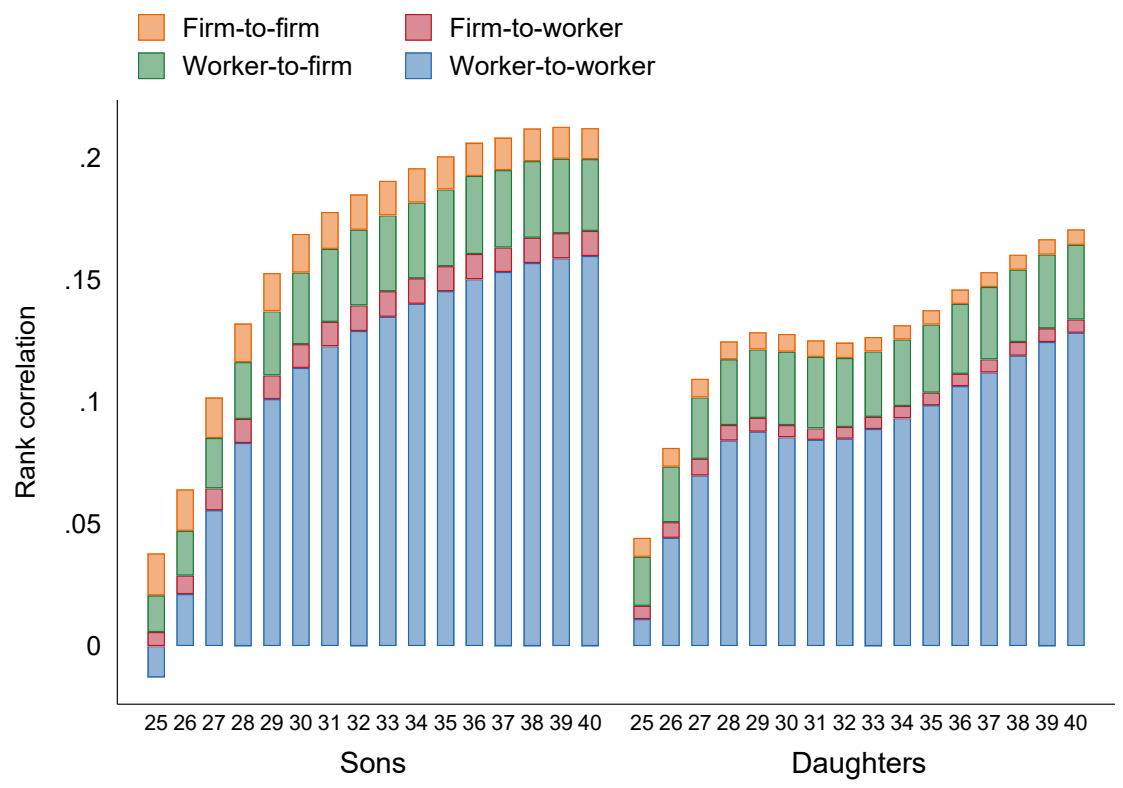

Figure A4: Decomposition of the intergenerational earnings correlation by sex and age of child, detailed levels of education. 


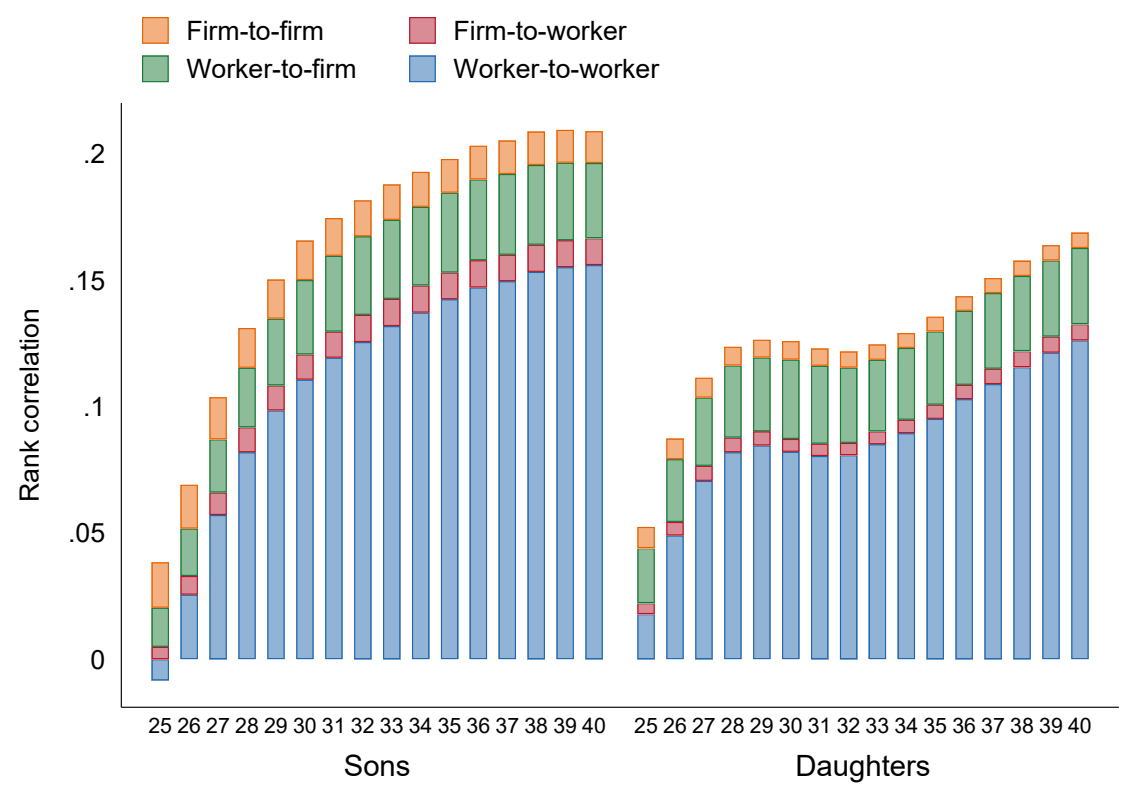

Figure A5: Decomposition of the intergenerational earnings correlation by sex and age of child, detailed fields of study.

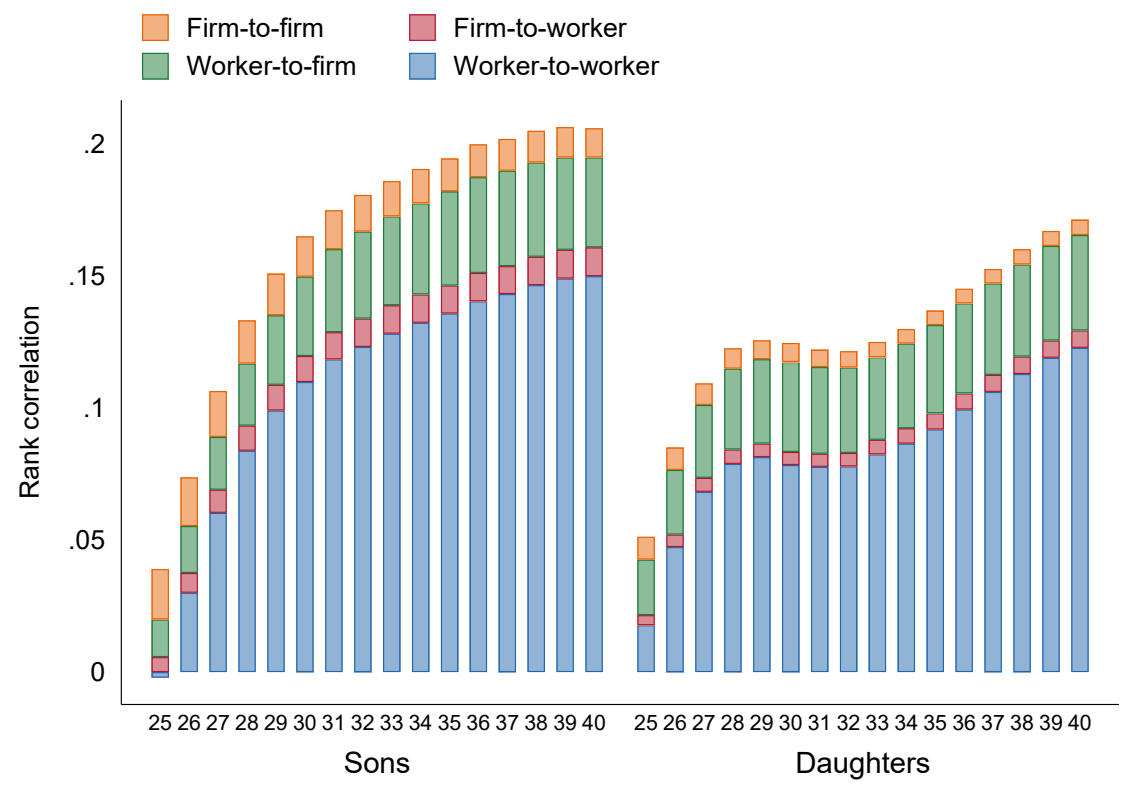

Figure A6: Decomposition of the intergenerational earnings correlation by sex and age of child, distinct 5-year periods. 


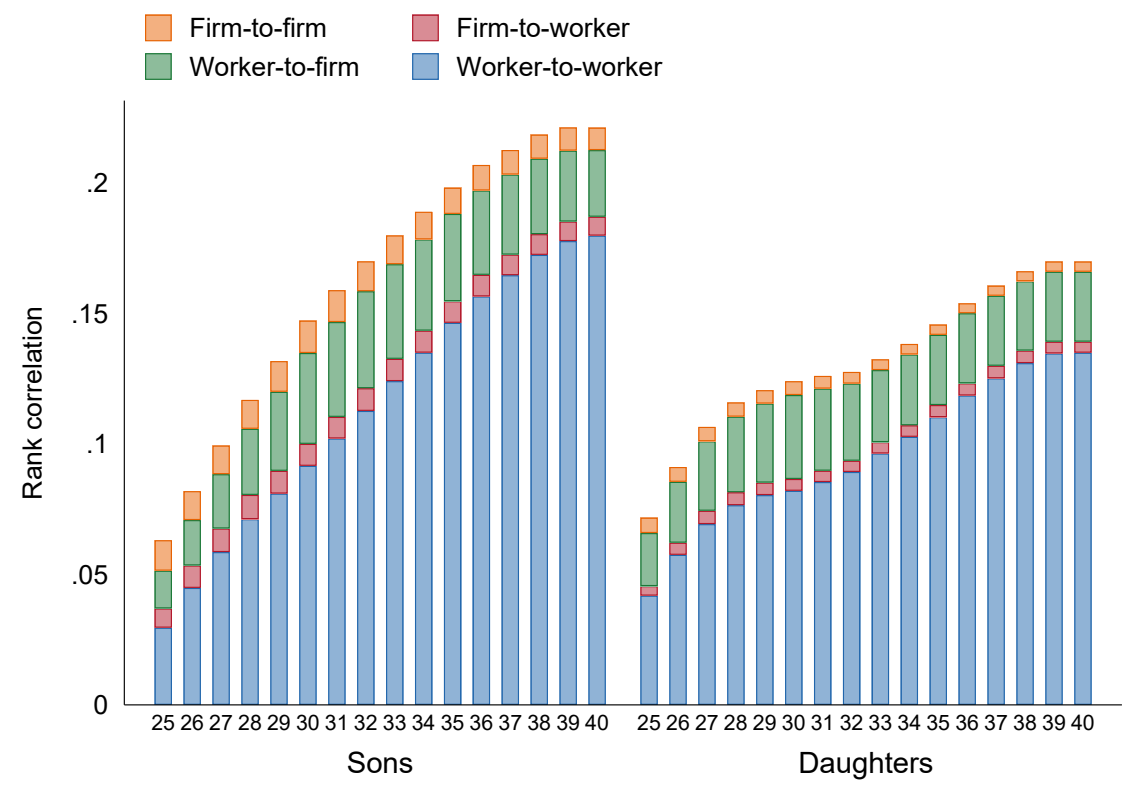

Figure A7: Decomposition of the intergenerational earnings correlation by sex and age of child, fixed effects individual slopes. 


\section{A4 Path model assumptions}

In this section, we provide more detail on the assumptions of the path decomposition, and how our estimates will be affected by potential violations thereof. The first set of assumptions that we stipulate to arrive at Equation 5 in the main text is a set of orthogonality conditions:

$$
\begin{aligned}
Y_{i}^{*} & =a_{1} F_{i}^{*}+b_{1} W_{i}^{*}+\epsilon_{1 i}, & & \epsilon_{1 i} \perp F_{i}^{*}, W_{i}^{*} \\
Y_{i t} & =a_{2 t} F_{i t}+b_{2 t} W_{i t}+\epsilon_{2 i t}, & & \epsilon_{2 i t} \perp F_{i t}, W_{i t} \\
F_{i t} & =a_{3 t} F_{i}^{*}+b_{3 t} W_{i}^{*}+\epsilon_{3 i t}, & & \epsilon_{3 i t} \perp F_{i}^{*}, W_{i}^{*} \\
W_{i t} & =a_{4 t} F_{i}^{*}+b_{4 t} W_{i}^{*}+\epsilon_{4 i t}, & & \epsilon_{4 i t} \perp F_{i}^{*}, W_{i}^{*}
\end{aligned}
$$

Equations A2 A5 describe the standard least squares regression assumptions: that the regressors of each equation are orthogonal to the residual term of their respective equation. The graph in main text Figure 11 implies a further set of constraints:

$$
\begin{aligned}
E\left(F_{i t} \epsilon_{1 i}\right)=E\left(W_{i t} \epsilon_{1 i}\right) & =0, \\
E\left(F_{i}^{*} \epsilon_{2 i t}\right)=E\left(W_{i}^{*} \epsilon_{2 i t}\right) & =0, \\
E\left(\epsilon_{1 i} \epsilon_{2 i t}\right) & =0 .
\end{aligned}
$$

Equations A6 A7 state that the residual in the father's (child's) earnings equation is orthogonal to the child's (father's) firm and worker components, while Equation A8 states that the two residuals are orthogonal to each other. Given these conditions, it follows from Duncan (1966) that the intergenerational earnings correlation can be decomposed into the four discrete paths that capture our mechanisms of interest.

What happens if these conditions break down? Equations A2 A5 cannot be tested and have to be accepted by fiat, as in any least squares regression. Equations A6 A7 are testable and violations are easy to incorporate by adding the following five terms to our decomposition (we thank Richard Breen for helping us elaborate this point).

$$
\begin{aligned}
\rho_{t} & =\underbrace{\rho_{\mathrm{ff}, t} \cdot a_{1} \cdot a_{2 t}}_{\text {firm-to-firm }}+\underbrace{\rho_{\mathrm{wf}, t} \cdot b_{1} \cdot a_{2 t}}_{\text {worker-to-firm }}+\underbrace{\rho_{\mathrm{fw}, t} \cdot a_{1} \cdot b_{2 t}}_{\text {firm-to-worker }}+\underbrace{\rho_{\mathrm{ww}, t} \cdot b_{1} \cdot b_{2 t}}_{\text {worker-to-worker }} \\
& +\underbrace{\operatorname{corr}\left(\epsilon_{1 i}, F_{i t}\right) a_{2 t}}_{\text {residual-to-firm }}+\underbrace{\operatorname{corr}\left(\epsilon_{1 i}, W_{i t}\right) b_{2 t}}_{\text {residual-to-worker }}+\underbrace{\operatorname{corr}\left(F_{i}^{*}, \epsilon_{2 i t}\right) a_{1}}_{\text {firm-to-residual }} \\
& +\underbrace{\operatorname{corr}\left(W_{i}^{*}, \epsilon_{2 i t}\right) b_{1}}_{\text {worker-to-residual }}+\underbrace{\operatorname{corr}\left(\epsilon_{1 i}, \epsilon_{2 i t}\right)}_{\text {residual-to-residual }} .
\end{aligned}
$$

In Figure A8 below, we relax the constraints in Equation A6 A7 to provide a more complete picture of the contours of transmission. Most important of the additional terms from Equation A9 are the worker-to-residual one, followed by residual-to-worker, and residual-to-residual. The terms for firm-to-residual and residual-to-firm turn out to be negligible. In other words, our main model does a good job at capturing firm-based transmission, but there are age-specific patterns of individual correlations that are lost. Specifically, this analysis reveals that, had 
it not been for the firm component of child earnings, the intergenerational earnings correlation would be negative for both sons and daughters at age 25. Nevertheless, our qualitative results remain similar: throughout most of the early career, firm-mediated components account for between a fourth and a fifth of the total intergenerational earnings correlation.

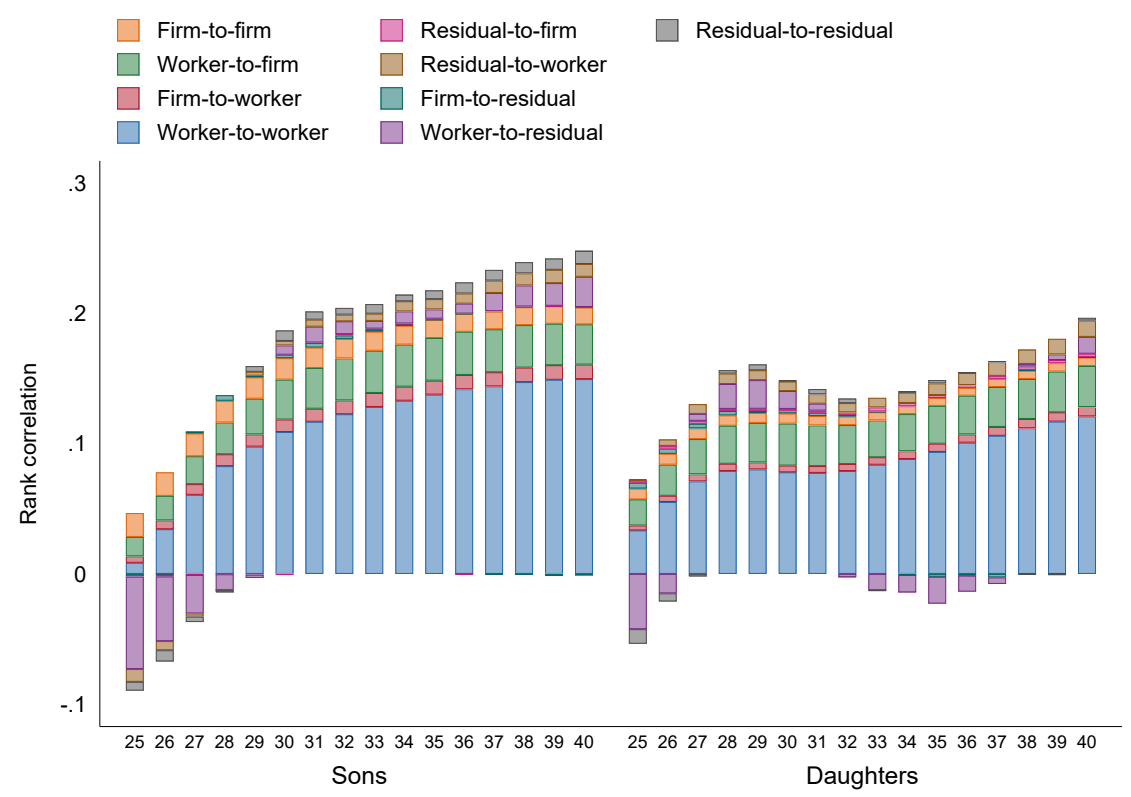

(a)

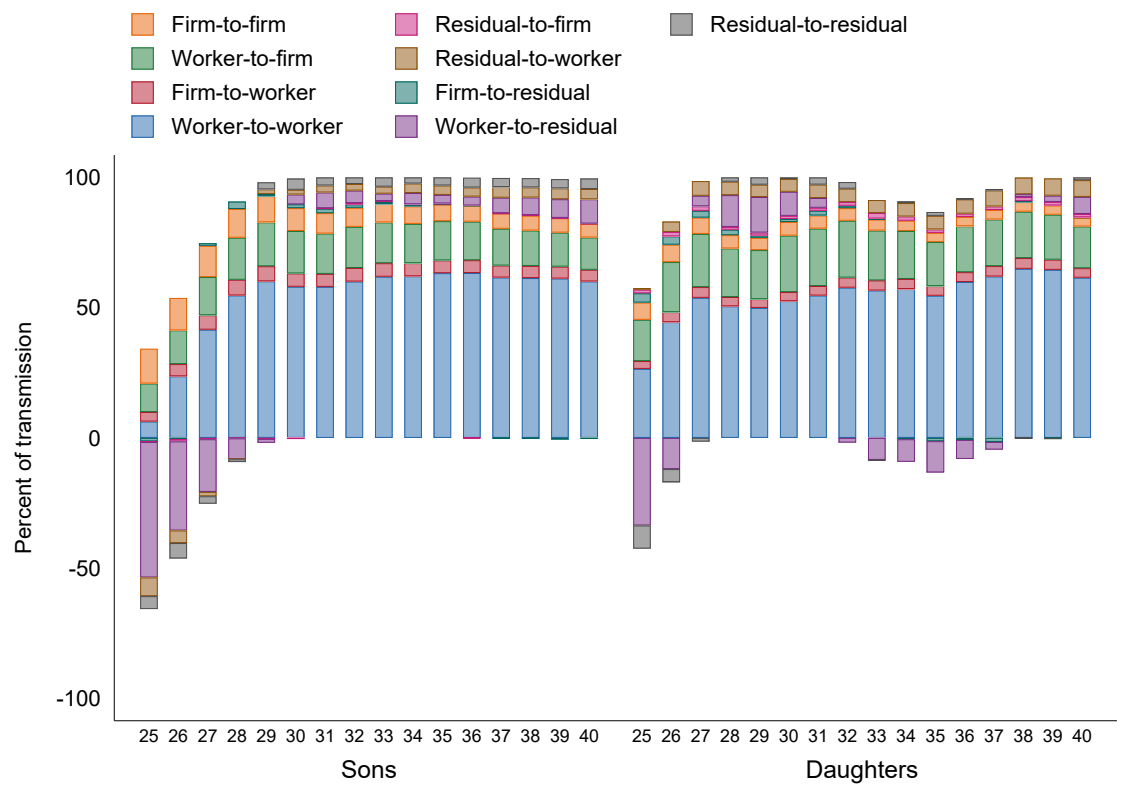

(b)

Figure A8: Residual decomposition of the intergenerational earnings correlation by sex and age of child. Absolute numbers top, relative numbers bottom. 


\section{A5 Mechanism results for daughters}

In this section, we show results on mechanism for daughters, corresponding to the results shown for sons in the main text. Figure A9 shows the overlap of firm sorting with educational and occupational attainment for daughters, corresponding to main text Figure 5 for sons. Figure A10 and Figure A11 shows results for daughters on job referral networks, structural location in the labor market and firm inheritance, corresponding to main text Figure 6 and Figure 7 for sons. Table A3 shows multivariate regression results for daughters, corresponding to main text Table 2 for sons.

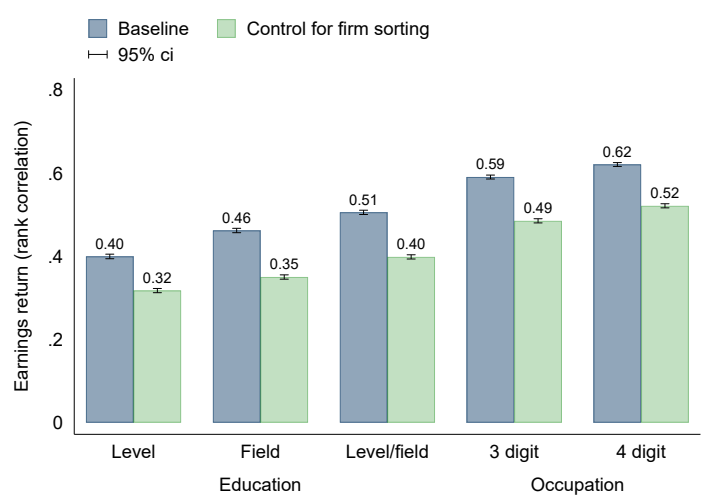

(a) Returns to education/occupation

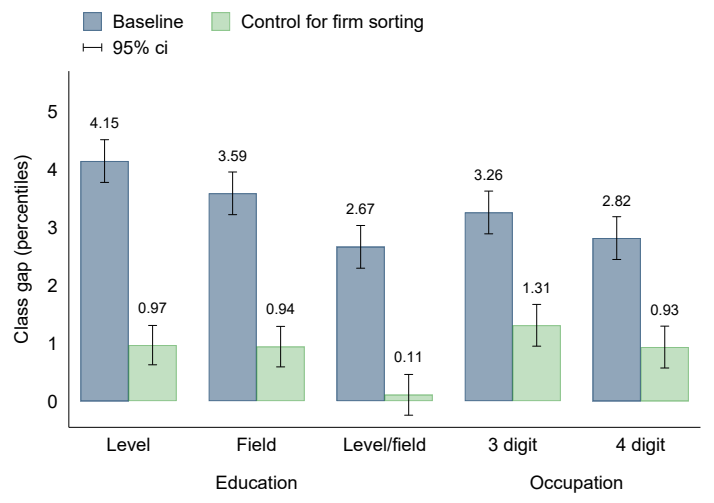

(c) Class origin gap in earnings

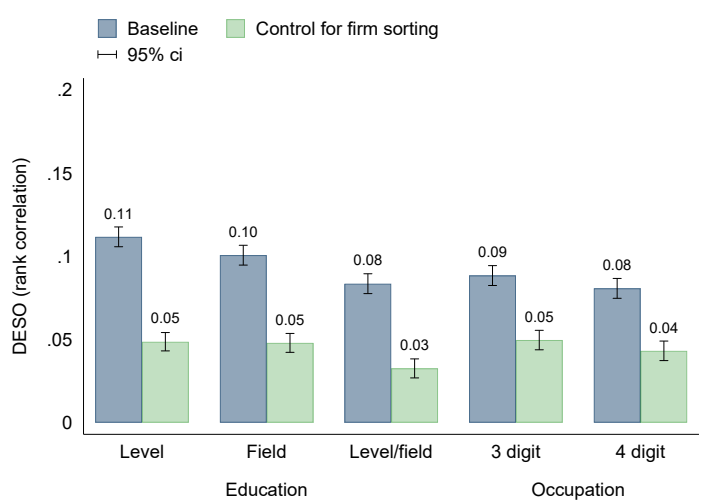

(b) Direct effect of social origin

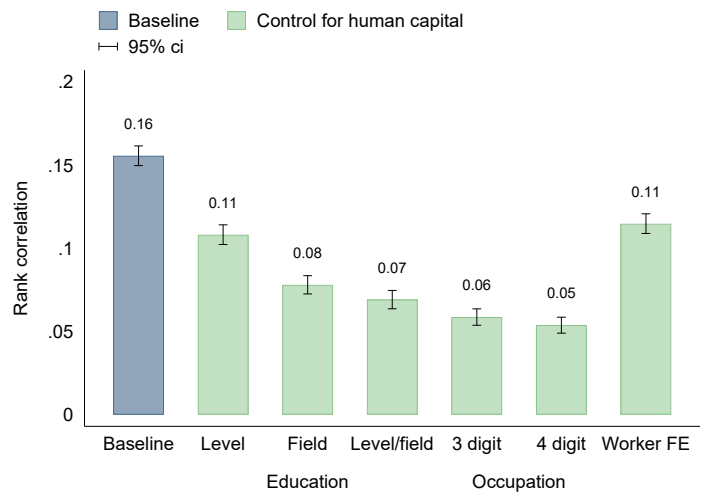

(d) Firm sorting with human capital controls

Figure A9: Overlap of firm sorting with education and occupation. Daughters. 


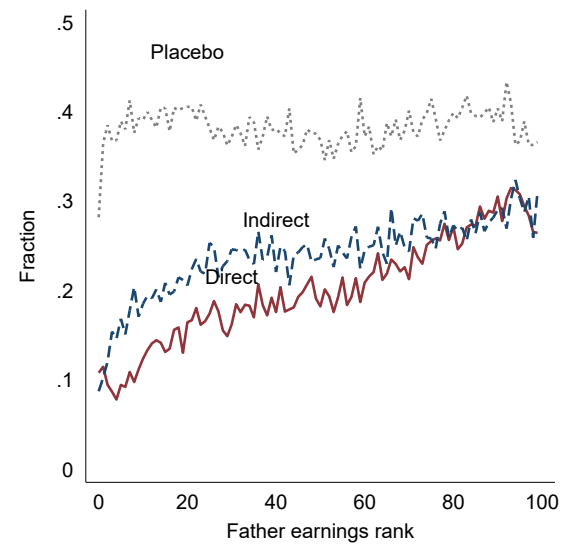

(a) Incidence by father earnings

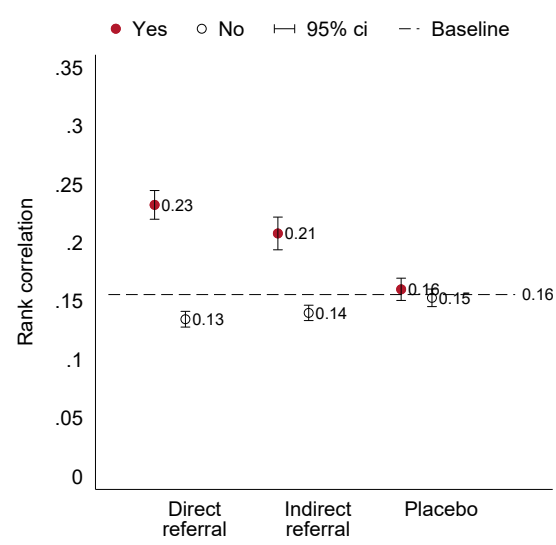

(b) Firm sorting coefficient

Figure A10: Job referral networks. Daughters.

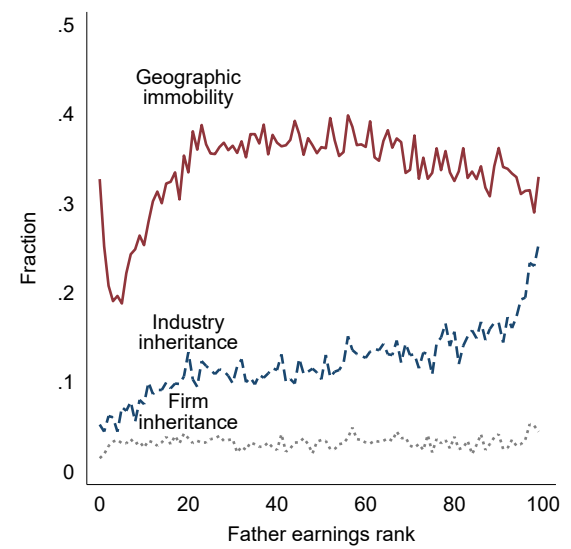

(a) Incidence by father earnings

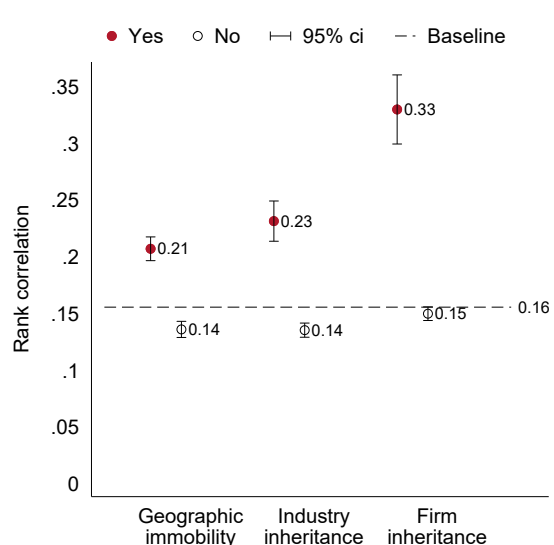

(b) Firm sorting coefficient

Figure A11: Geographic immobility, industry and firm inheritance. Daughters. 
Table A3: Association between father earnings and firm sorting, with controls. Daughters.

\begin{tabular}{lcccc}
\hline & $\mathrm{b} / \mathrm{se}$ & $\mathrm{b} / \mathrm{se}$ & $\mathrm{b} / \mathrm{se}$ & $\mathrm{b} / \mathrm{se}$ \\
\hline Coefficient & 0.156 & 0.058 & 0.044 & 0.026 \\
& $(0.003)$ & $(0.003)$ & $(0.003)$ & $(0.004)$ \\
Education & - & $\checkmark$ & $\checkmark$ & $\checkmark$ \\
Occupation & - & $\checkmark$ & $\checkmark$ & $\checkmark$ \\
Worker FE & - & $\checkmark$ & $\checkmark$ & $\checkmark$ \\
Direct referral & - & - & $\checkmark$ & $\checkmark$ \\
Indirect referral & - & - & $\checkmark$ & $\checkmark$ \\
Geographic immobility & - & - & - & $\checkmark$ \\
Industry inheritance & - & - & - & $\checkmark$ \\
Firm inheritance & - & - & - & $\checkmark$ \\
$\mathrm{N}$ & 107180 & 107180 & 107180 & 107180 \\
\hline
\end{tabular}




\section{A6 Industrial composition and firm survival}

In times of rapid structural transformation, the firm pathway of intergenerational persistence that we study might become less important. Large changes have taken place in firms over the two generations we study, including a shift away from manufacturing to services, a decline in unionized jobs and growth of precarious employment, and replacement of big conglomerates by smaller networked firms. Note, however, that the data needs of our method mean that we only study 1990-1999 for parents and 2000 onwards for children. Figure A12 shows that industrial composition has remained relatively constant over this period, except for a large decline in manufacturing. A smaller decline in health care is also evident, as is a growth in finance and business. Despite a slow shift in industrial composition, the amount of firm turnover over this period is high (Figure A13). Of firms that employed fathers in 1990, only between a fifth and a quarter survive until the end of our observation period, a figure which excludes solo entrepreneurs (Figure A14. This could explain the relatively modest role for firm inheritance that we find. In Tables A4 and A5. we split the analysis by whether the father's main employer is a firm that survives until 2019, when our observation period ends. This shows that firm-to-firm transmission is strikingly similar regardless of whether a father worked for a surviving firm or not.

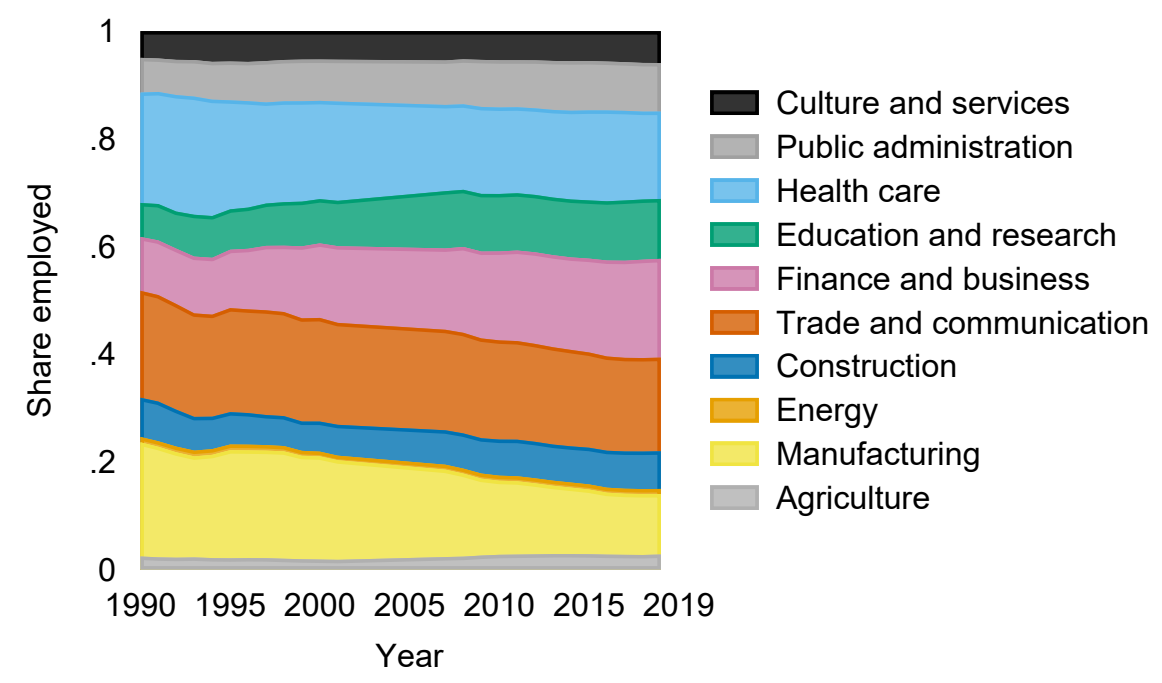

Figure A12: Industry employment shares over time. 


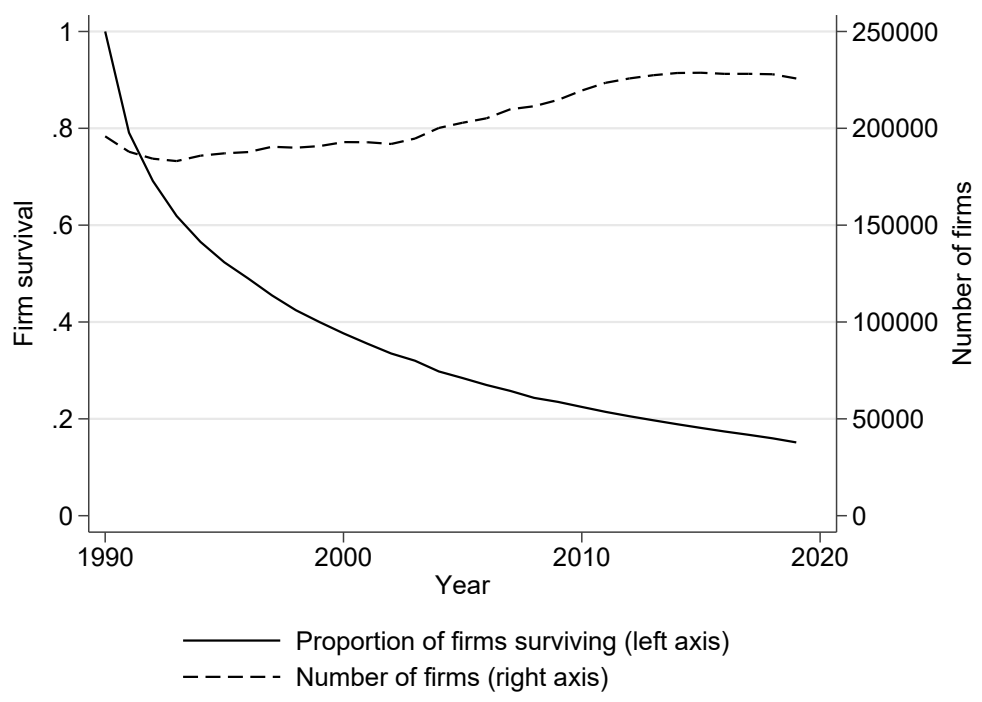

Figure A13: Firm survival and number of firms by year, population.

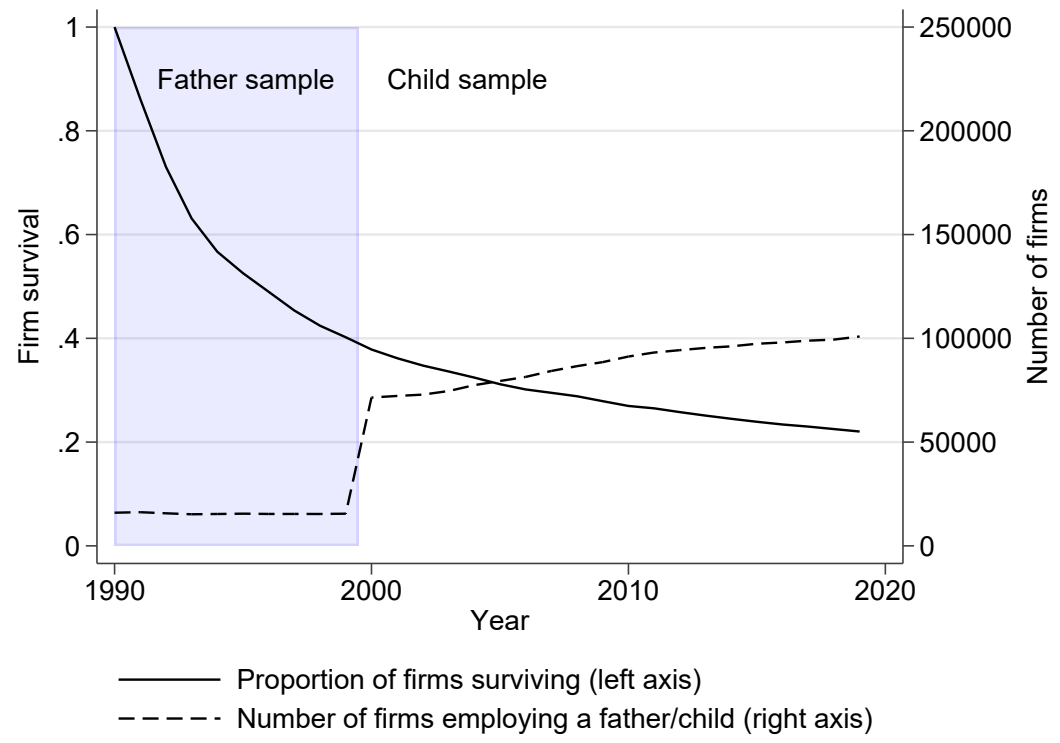

Figure A14: Firm survival and number of firms by year, analytical sample. 
Table A4: Decomposition parameters at child age 38-42. Fathers in surviving firms.

\begin{tabular}{rlll} 
& & \multicolumn{2}{c}{ Estimate (percent) } \\
\cline { 2 - 3 } Parameter & \multicolumn{1}{c}{ Sons } & Daughters \\
\hline firm-to-firm & $=\rho_{\mathrm{ff}} \cdot a_{1} \cdot a_{2}$ & $0.016(6.66 \%)$ & $0.007(3.34 \%)$ \\
worker-to-firm & $=\rho_{\mathrm{wf}} \cdot b_{1} \cdot a_{2}$ & $0.035(150 \%)$ & $0.039(19.6 \%)$ \\
firm-to-worker & $=\rho_{\mathrm{fw}} \cdot a_{1} \cdot b_{2}$ & $0.009(3.79 \%)$ & $0.003(1.43 \%)$ \\
worker-to-worker & $=\rho_{\mathrm{ww}} \cdot b_{1} \cdot b_{2}$ & $0.176(74.6 \%)$ & $0.152(75.6 \%)$ \\
$\mathrm{ff}+\mathrm{wf}+\mathrm{fw}+\mathrm{ww}$ & $=\operatorname{corr}\left(Y_{i}^{*}, Y_{i}\right)$ & $0.236(100 \%)$ & $0.201(100 \%)$ \\
\hline$\rho_{\mathrm{ff}}=\operatorname{corr}\left(F_{i}^{*}, F_{i}\right)$ & 0.139 & 0.072 \\
$\rho_{\mathrm{wf}}$ & $=\operatorname{corr}\left(W_{i}^{*}, F_{i}\right)$ & 0.120 & 0.161 \\
$\rho_{\mathrm{fw}}$ & $=\operatorname{corr}\left(F_{i}^{*}, W_{i}\right)$ & 0.037 & 0.012 \\
$\rho_{\mathrm{ww}}$ & $=\operatorname{corr}\left(W_{i}^{*}, W_{i}\right)$ & 0.279 & 0.239 \\
$a_{1}$ & $=\operatorname{corr}\left(F_{i}^{*}, Y_{i}^{*} \mid W_{i}^{*}\right)$ & 0.326 & 0.325 \\
$b_{1}$ & $=\operatorname{corr}\left(W_{i}^{*}, Y_{i}^{*} \mid F_{i}^{*}\right)$ & 0.847 & 0.846 \\
$a_{2}$ & $=\operatorname{corr}\left(F_{i}, Y_{i} \mid W_{i}\right)$ & 0.347 & 0.289 \\
$b_{2}$ & $=\operatorname{corr}\left(W_{i}, Y_{i} \mid F_{i}\right)$ & 0.745 & 0.752 \\
& & &
\end{tabular}

Table A5: Decomposition parameters at child age 38-42. Fathers in non-surviving firms.

\begin{tabular}{rlll} 
& & \multicolumn{2}{c}{ Estimate (percent) } \\
\cline { 2 - 3 } Parameter & \multicolumn{1}{c}{ Sons } & Daughters \\
\hline firm-to-firm & $=\rho_{\mathrm{ff}} \cdot a_{1} \cdot a_{2}$ & $0.014(6.67 \%)$ & $0.008(4.51 \%)$ \\
worker-to-firm & $=\rho_{\mathrm{wf}} \cdot b_{1} \cdot a_{2}$ & $0.039(180 \%)$ & $0.032(18.7 \%)$ \\
firm-to-worker & $=\rho_{\mathrm{fw}} \cdot a_{1} \cdot b_{2}$ & $0.017(7.91 \%)$ & $0.014(8.25 \%)$ \\
worker-to-worker & $=\rho_{\mathrm{ww}} \cdot b_{1} \cdot b_{2}$ & $0.145(67.4 \%)$ & $0.117(68.5 \%)$ \\
$\mathrm{ff}+\mathrm{wf}+\mathrm{fw}+\mathrm{ww}$ & $=\operatorname{corr}\left(Y_{i}^{*}, Y_{i}\right)$ & $0.215(100 \%)$ & $0.171(100 \%)$ \\
\hline$\rho_{\mathrm{ff}}$ & $=\operatorname{corr}\left(F_{i}^{*}, F_{i}\right)$ & 0.098 & 0.066 \\
$\rho_{\mathrm{wf}}$ & $=\operatorname{corr}\left(W_{i}^{*}, F_{i}\right)$ & 0.130 & 0.136 \\
$\rho_{\mathrm{fw}}$ & $=\operatorname{corr}\left(F_{i}^{*}, W_{i}\right)$ & 0.058 & 0.046 \\
$\rho_{\mathrm{ww}}$ & $=\operatorname{corr}\left(W_{i}^{*}, W_{i}\right)$ & 0.244 & 0.193 \\
$a_{1}$ & $=\operatorname{corr}\left(F_{i}^{*}, Y_{i}^{*} \mid W_{i}^{*}\right)$ & 0.401 & 0.405 \\
$b_{1}$ & $=\operatorname{corr}\left(W_{i}^{*}, Y_{i}^{*} \mid F_{i}^{*}\right)$ & 0.813 & 0.811 \\
$a_{2}$ & $=\operatorname{corr}\left(F_{i}, Y_{i} \mid W_{i}\right)$ & 0.366 & 0.290 \\
$b_{2}$ & $=\operatorname{corr}\left(W_{i}, Y_{i} \mid F_{i}\right)$ & 0.731 & 0.749
\end{tabular}




\section{A7 Nonparametric associations}

In the main manuscript, we assume that the intergenerational transmission in earnings is linear in rank. Here we assess this assumption nonparametrically by plotting the density of the intergenerational copula in 40 bins. We do this separately for each combination of father and child earnings components, and separately for sons and daughters. We use earnings as a five-year average centered around age 40 for children and father earnings averaged over 1990-1999. For sons (Figure A15), the firm-to-firm copula shows a strong overrepresentation at the main diagonal, similarly to what is commonly found for occupational transmission Jonsson et al. 2009). Note that as direct firm inheritance by age 40 is rare, this is driven by resemblance in industry and other contextual characteristics. The worker-to-firm and worker-to-worker copulas both show a more dispersed patterns, but in both cases there is evidence of excess persistence at the top, in the upper right corner. For daughters (Figure A16), the pattern is more complicated. The firm-to-firm diagonal shows a concave pattern. This is because working in the same firm or industry corresponds to a different rank in the female than in the male earnings distribution. Horizontal stripes visible between the 60th and 80th percentile in the daughters' firm distribution reflects women's overrepresentation in the public sector. The picture for worker-to-firm and worker-to-worker transmission looks similar to that of sons, with evidence of excess persistence at the top but also (for worker-toworker transmission) in the bottom. In Figure A17 and A18, we display the same information using mother's earnings. 


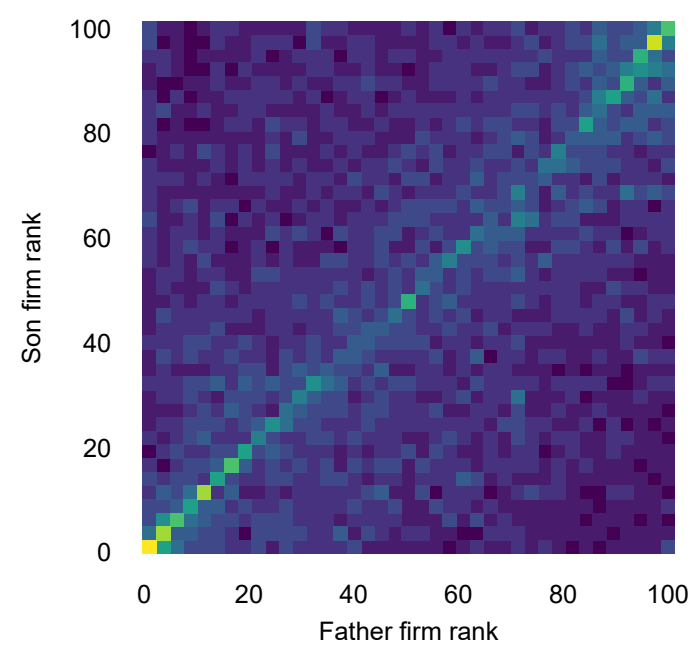

(a) Firm-to-firm

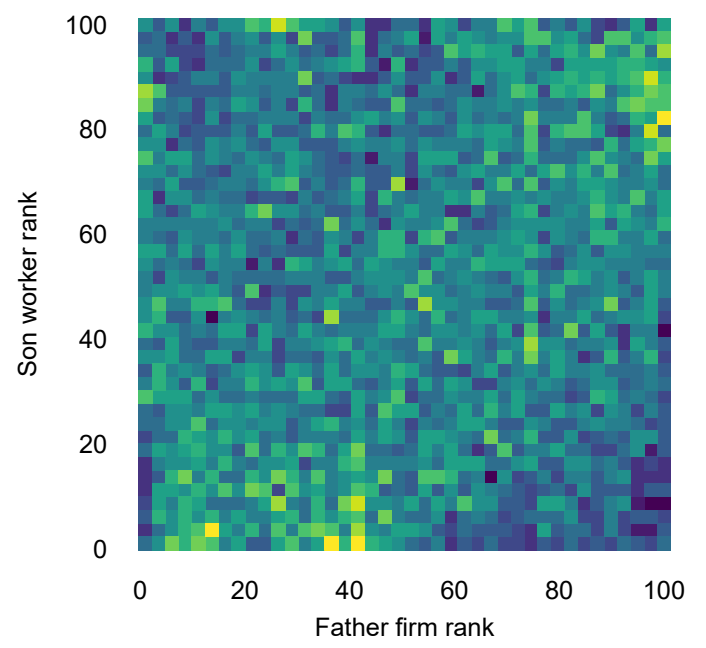

(c) Firm-to-worker

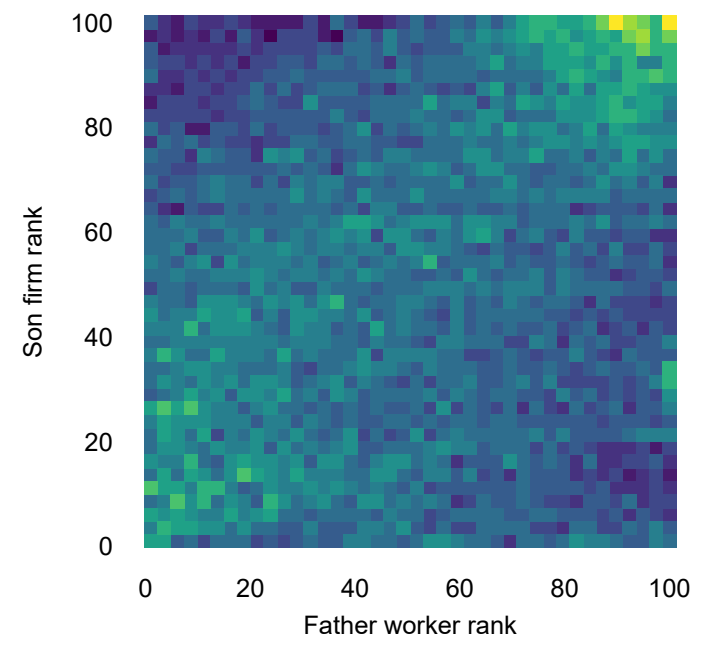

(b) Worker-to-firm

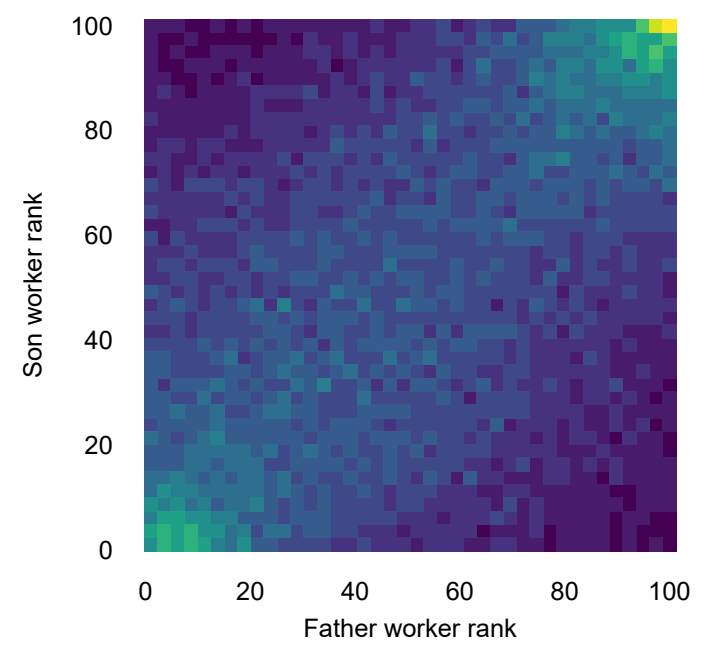

(d) Worker-to-worker

Figure A15: Copula of father and son earnings components. 


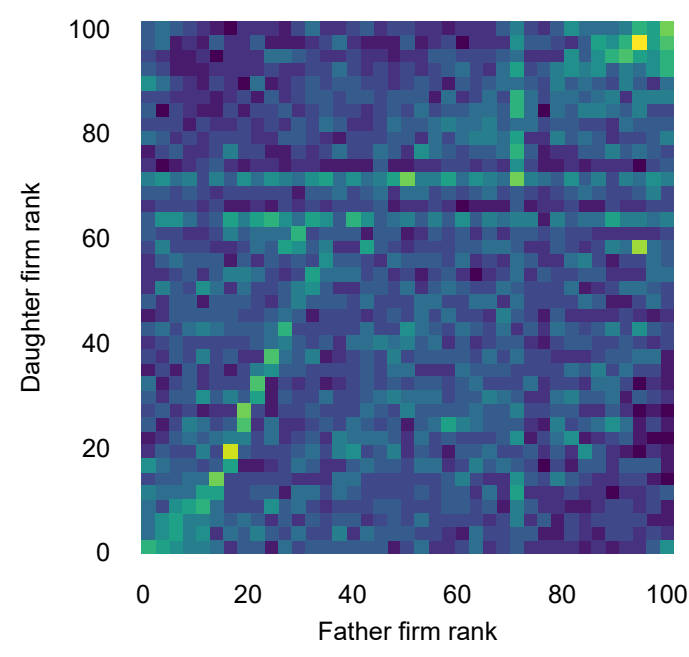

(a) Firm-to-firm

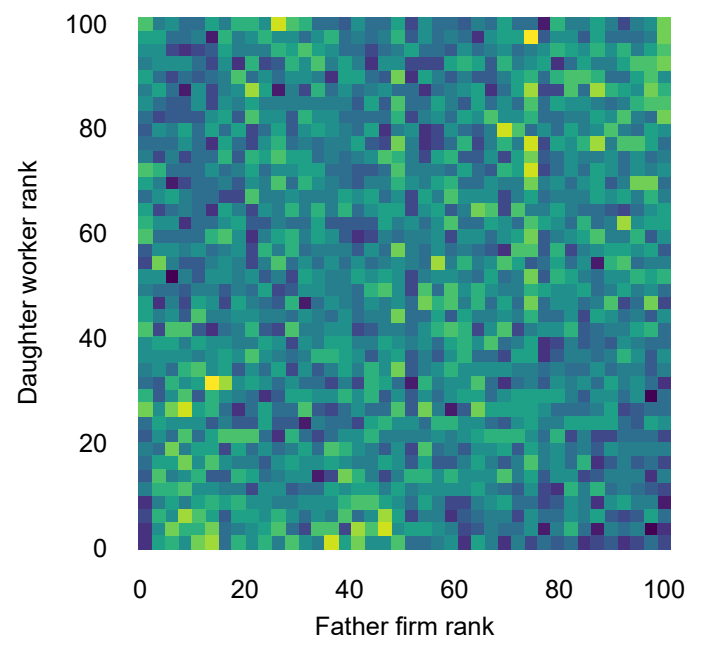

(c) Firm-to-worker

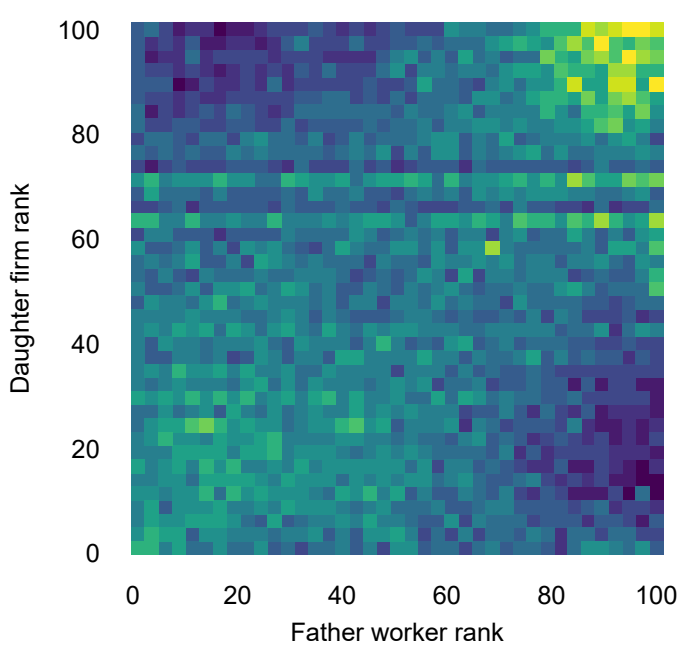

(b) Worker-to-firm

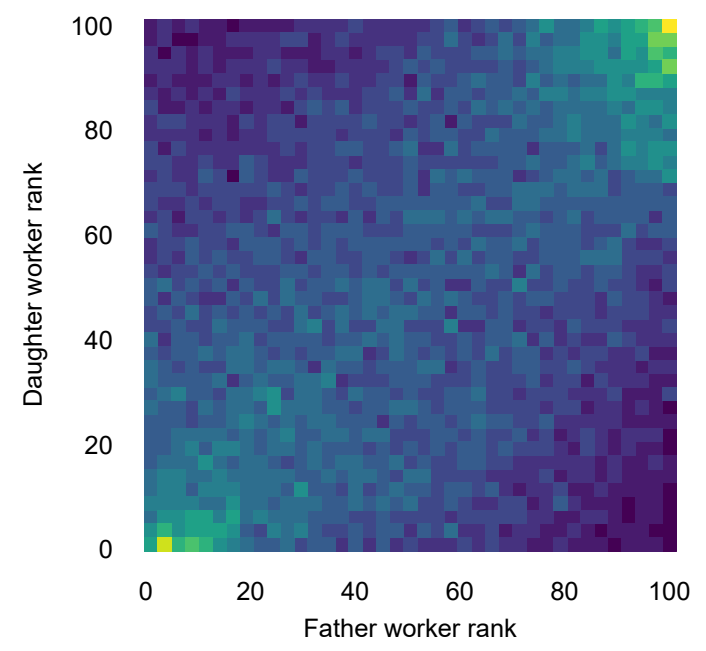

(d) Worker-to-worker

Figure A16: Copula of father and daughter earnings components. 


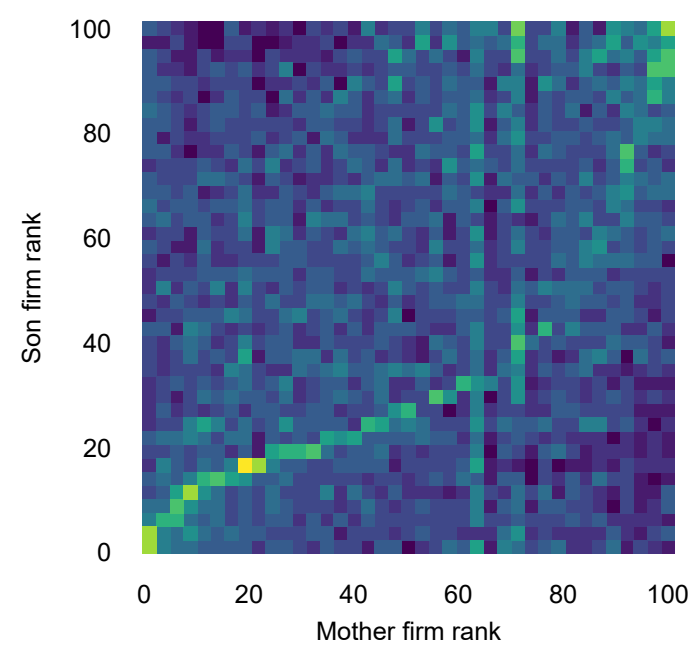

(a) Firm-to-firm

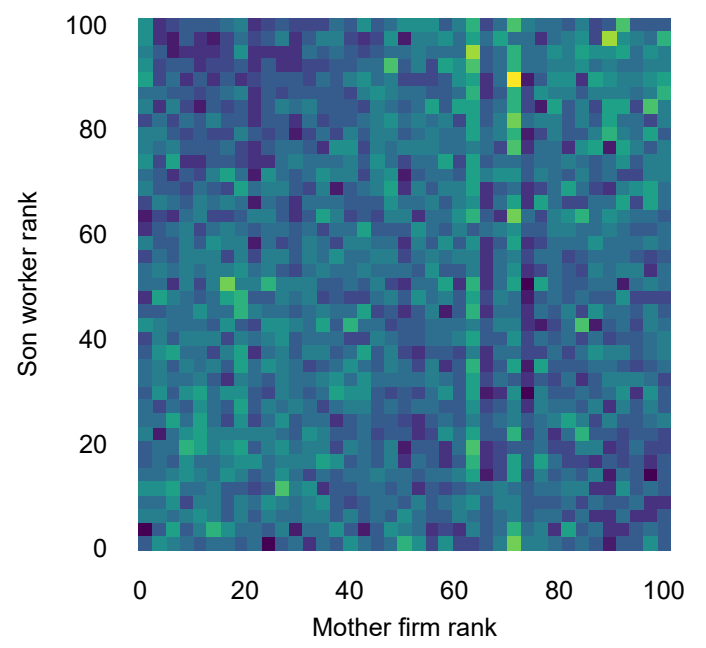

(c) Firm-to-worker

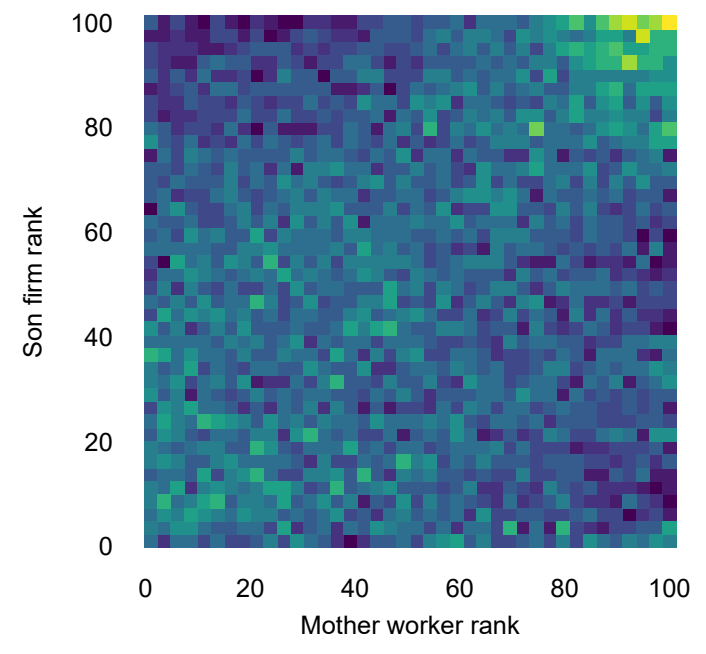

(b) Worker-to-firm

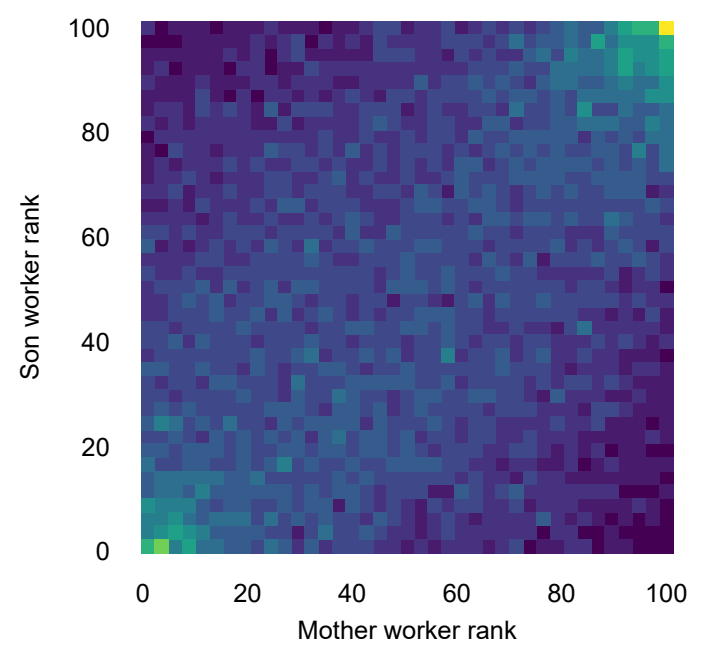

(d) Worker-to-worker

Figure A17: Copula of mother and son earnings components. 


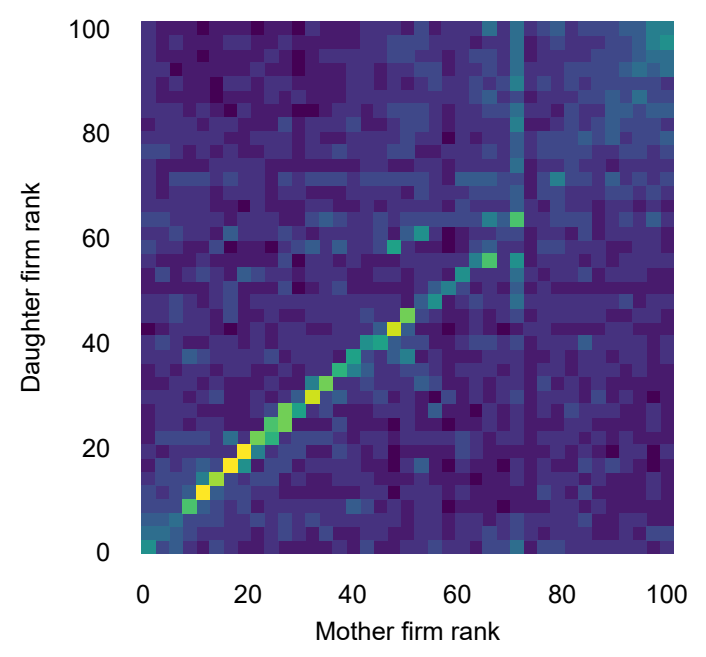

(a) Firm-to-firm

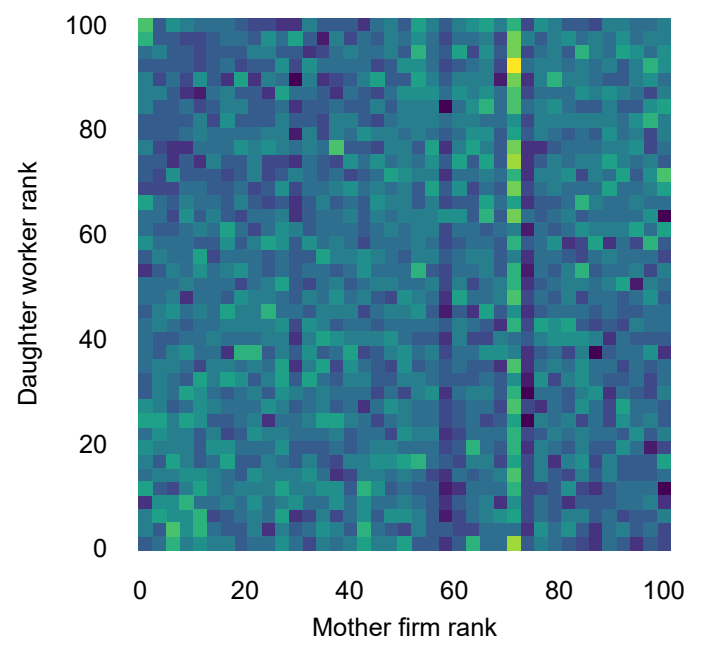

(c) Firm-to-worker

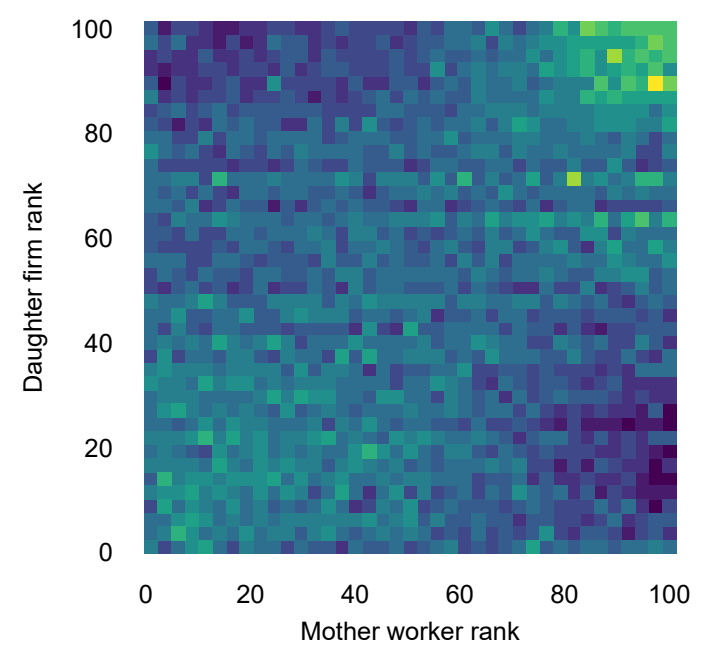

(b) Worker-to-firm

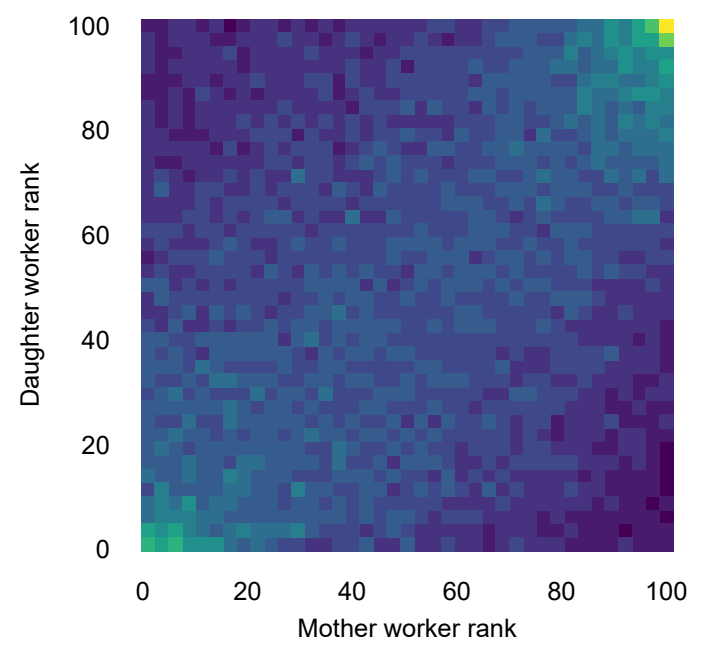

(d) Worker-to-worker

Figure A18: Copula of mother and daughter earnings components. 


\section{A8 Firm identifiers and public sector}

In the main text, we use the terms "employer" and "firm" interchangeably. In fact, the employers in our data encompass a broader set of organizations. The employer IDs or organization numbers (organisationsnummer) in our data are unique identifiers assigned to a broad range of legal entities. Companies and associations receive their organization number from the Swedish Companies Registration Office or Bolagsverket. Other authorities that assign organization numbers depending on the type of entity include The Tax Authority or Skatteverket (non-profit associations), The Mapping, Cadastral and Land Registration Authority or Lantmäteriet (community associations), and The Legal, Financial and Administrative Services Authority or Kammarkollegiet (registered denominations). It is not possible from our data to tell which form of entity is behind a given ID, so we lack a way of restricting the sample to firms narrowly defined. However, we have information on sector which allows us to exclude all public employers. As a robustness test, we rerun our main decomposition analysis excluding public employees (15\% of sons and $45 \%$ of daughters) in Table A6. Our qualitative results are broadly similar. If anything, the proportion of transmission mediated by employers becomes larger with public-sector workers excluded.

Table A6: Decomposition parameters at child age 38-42 excluding public sector.

\begin{tabular}{rlll} 
& & \multicolumn{2}{c}{ Estimate (percent) } \\
\cline { 2 - 3 } Parameter & \multicolumn{1}{c}{ Sons } & Daughters \\
\hline $\begin{array}{r}\text { firm-to-firm } \\
\text { worker-to-firm }=\rho_{\mathrm{ff}} \cdot a_{1} \cdot a_{2}\end{array}$ & $0.017(7.34 \%)$ & $0.011(5.76 \%)$ \\
firm-to-worker $=\rho_{\mathrm{wf}} \cdot b_{1} \cdot a_{2}$ & $0.043(18.1 \%)$ & $0.040(20.5 \%)$ \\
worker-to-worker & $=\rho_{\mathrm{ww}} \cdot b_{1} \cdot b_{2}$ & $0.013(5.58 \%)$ & $0.011(5.80 \%)$ \\
$\mathrm{ff}+\mathrm{wf}+\mathrm{fw}+\mathrm{ww}$ & $=\operatorname{corr}\left(Y_{i}^{*}, Y_{i}\right)$ & $0.164(68.9 \%)$ & $0.134(68.0 \%)$ \\
\hline$\rho_{\mathrm{ff}}$ & $=\operatorname{corr}\left(F_{i}^{*}, F_{i}\right)$ & 0.127 & 0.090 \\
$\rho_{\mathrm{wf}}$ & $=\operatorname{corr}\left(W_{i}^{*}, F_{i}\right)$ & 0.138 & 0.143 \\
$\rho_{\mathrm{fw}}$ & $=\operatorname{corr}\left(F_{i}^{*}, W_{i}\right)$ & 0.050 & 0.043 \\
$\rho_{\mathrm{ww}}$ & $=\operatorname{corr}\left(W_{i}^{*}, W_{i}\right)$ & 0.272 & 0.224 \\
$a_{1}$ & $=\operatorname{corr}\left(F_{i}^{*}, Y_{i}^{*} \mid W_{i}^{*}\right)$ & 0.366 & 0.370 \\
$b_{1}$ & $=\operatorname{corr}\left(W_{i}^{*}, Y_{i}^{*} \mid F_{i}^{*}\right)$ & 0.834 & 0.832 \\
$a_{2}$ & $=\operatorname{corr}\left(F_{i}, Y_{i} \mid W_{i}\right)$ & 0.375 & 0.340 \\
$b_{2}$ & $=\operatorname{corr}\left(W_{i}, Y_{i} \mid F_{i}\right)$ & 0.723 & 0.721 \\
\hline
\end{tabular}




\section{A9 Additional results}

Figure A19 plots child's earnings rank by father's earnings rank, without dividing earnings into firm and worker components (as in main text Figure 3). Figure A20 divides both the child's and father's earnings into worker and firm components. It shows that while the worker-to-worker correlations have the steepest association, worker-to-firm correlations are also quite high. Figure A21 depicts variation in the overall intergenerational earnings correlation across career stages, echoing the pattern from the decomposition in main text Figure 4. Figure A22 shows similar correlations, broken out by each generation's firm and worker components. These correlations are scaled by the shifting role of firm and worker components in determining earnings, to produce the path model-based decomposition in main text Figure 4. Figure A23 shows a relative version of main text Figure 4, in which each path sums to the total intergenerational correlation for each age year. Figure A23 shows more clearly the decline in the relative role of firm-to-firm transmission after labor market entry. It also shows that despite the large rise in worker-to-worker transmission over the career, the worker-to-firm path retains a fairly stable share of overall earnings transmission. Tables A7 and A8 show the correlation matrix for sons and daughters, giving the underlying correlations used in the path model results in main text Table 1. Tables A9 and A10 display the same information using mother's earnings rank and Tables A11 and A12 does so with father's earnings using the log functional form. 


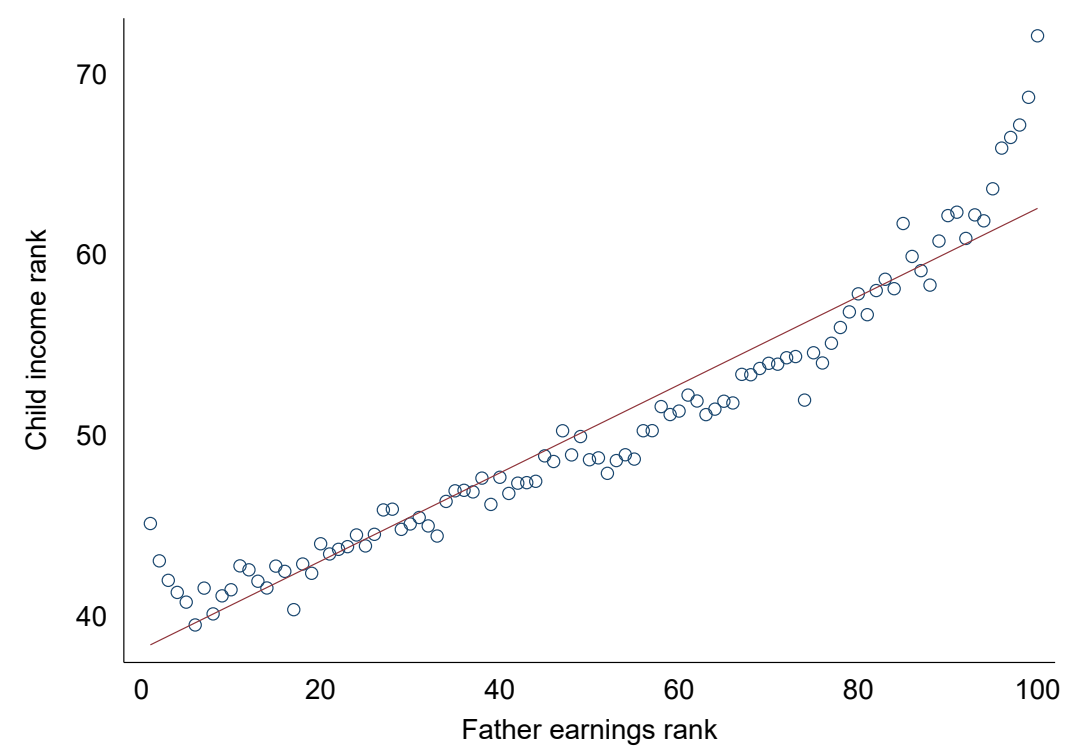

(a) Sons

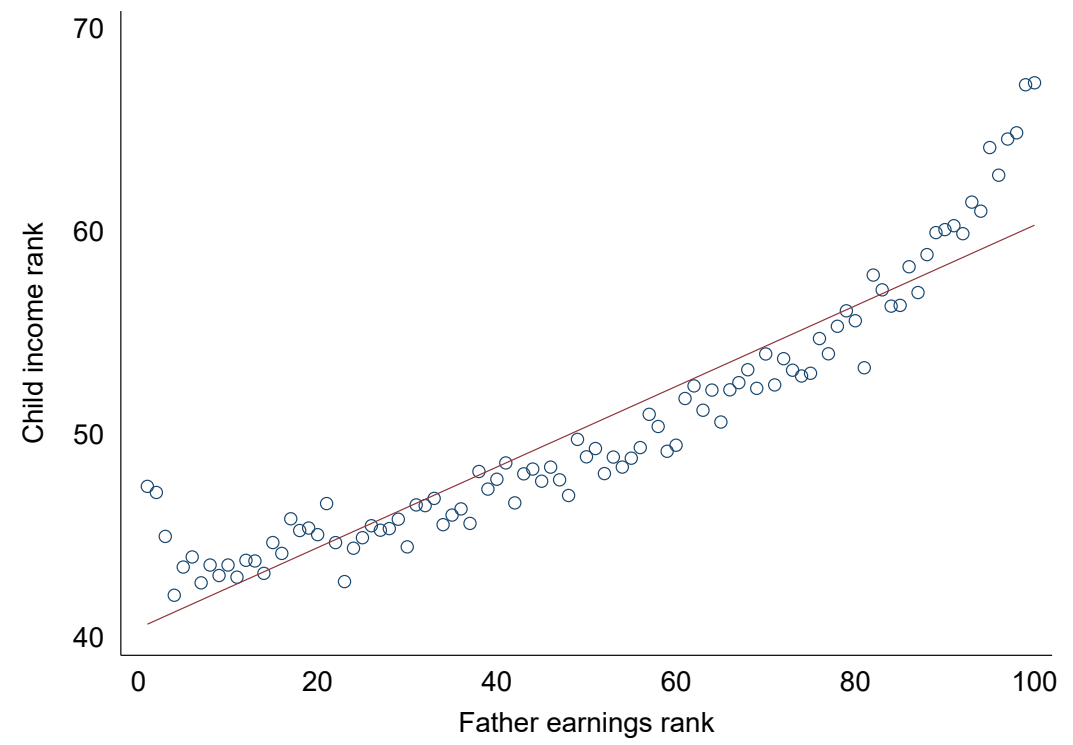

(b) Daughters

Figure A19: Average child earnings rank by father's earnings rank. 


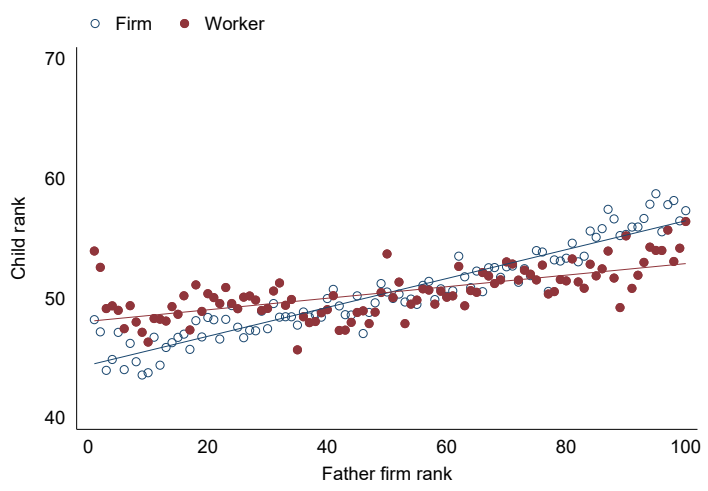

(a) Sons

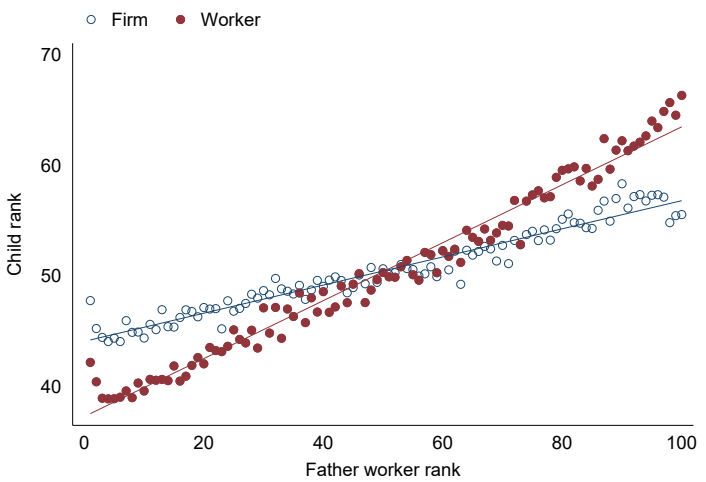

(c) Sons

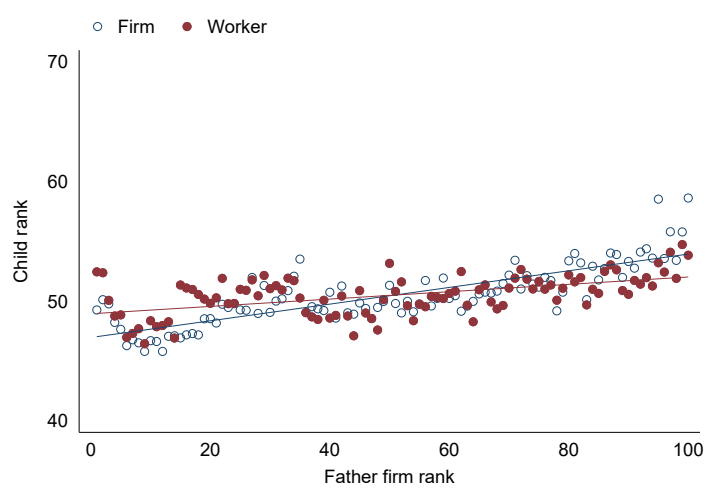

(b) Daughters

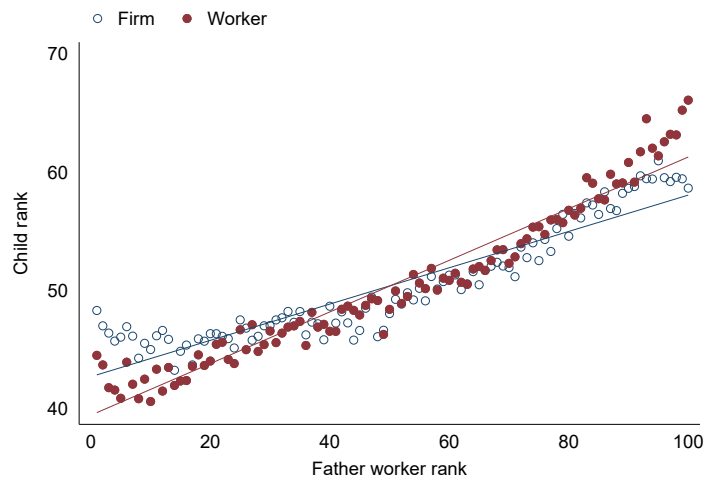

(d) Daughters

Figure A20: Average child firm and worker rank by father's firm and worker rank. 


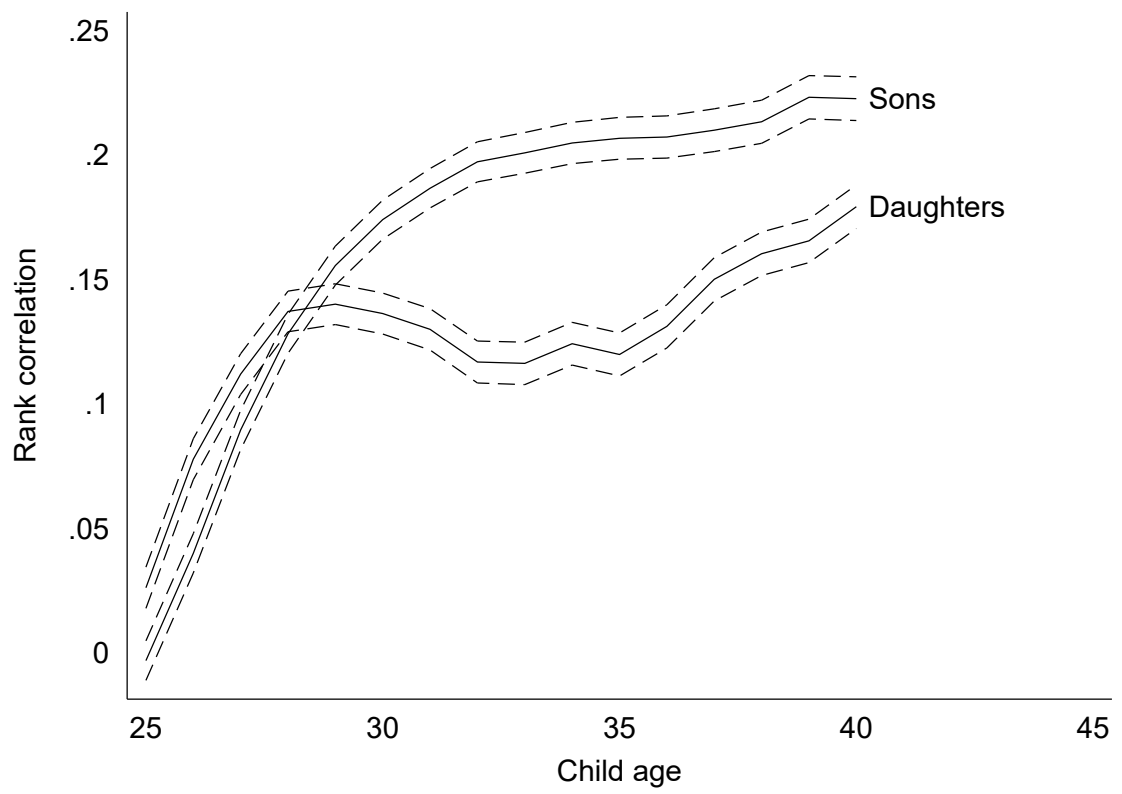

Figure A21: Intergenerational rank correlation in earnings by sex and age of child. Point estimates and $95 \%$ confidence intervals. 


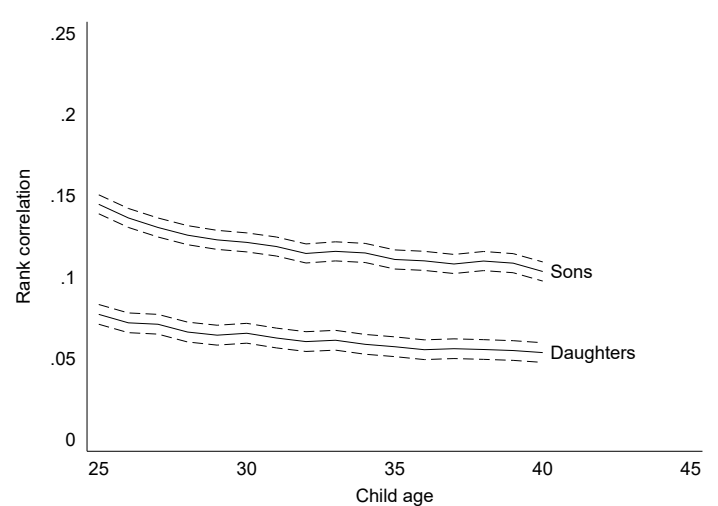

(a) Firm-to-firm: $\rho_{\mathrm{ff}}$

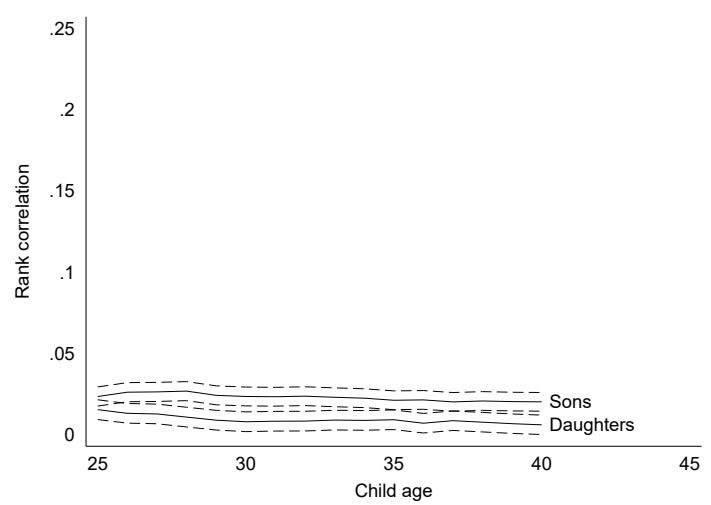

(c) Firm-to-worker: $\rho_{\mathrm{fw}}$

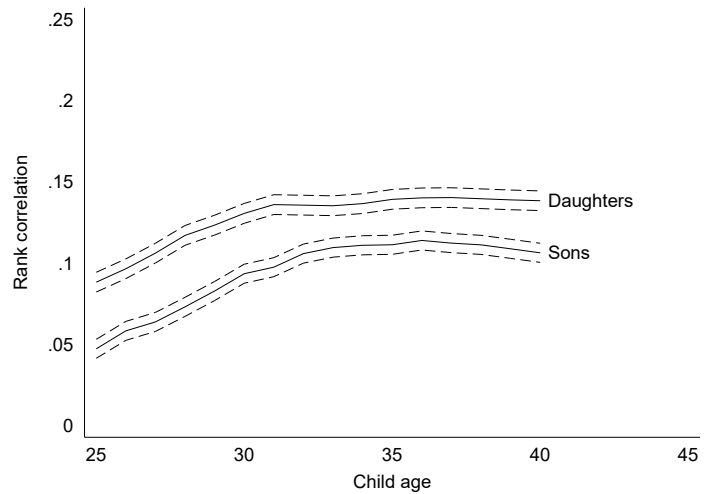

(b) Worker-to-firm: $\rho_{\mathrm{wf}}$

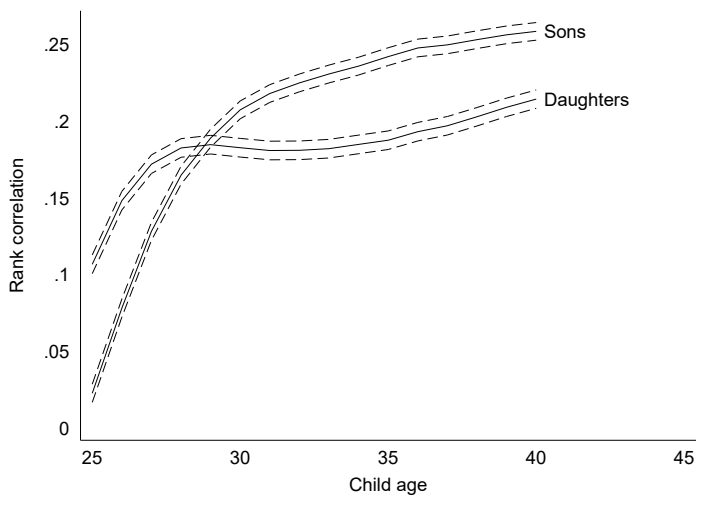

(d) Worker-to-worker: $\rho_{\mathrm{ww}}$

Figure A22: Path coefficients over the early career, by sex and age of child. Point estimates and $95 \%$ confidence intervals. 


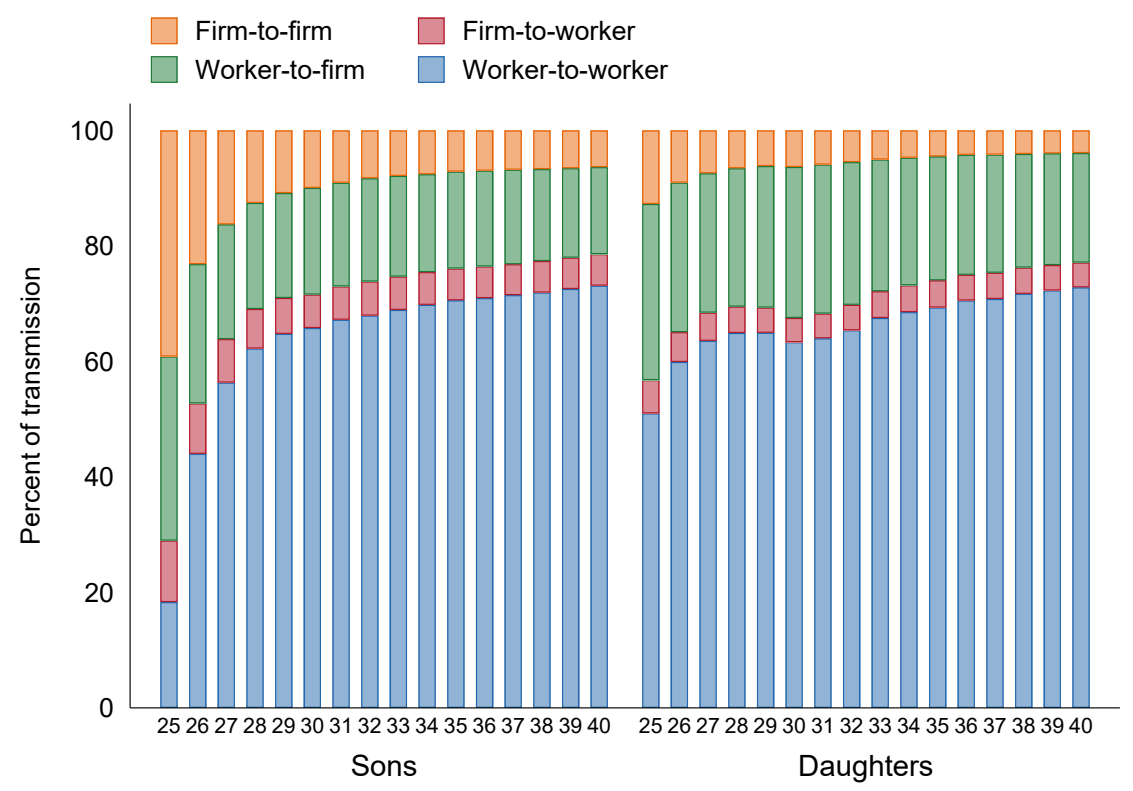

Figure A23: Decomposition of the intergenerational earnings correlation by sex and age of child, main specification, relative numbers. 
Table A7: Correlation matrix: sons.

\begin{tabular}{lcccccc}
\hline \hline Variables & C earnings & C firm & C worker & F earnings & F firm & F worker \\
\hline C earnings & 1.000 & & & & & \\
C firm & 0.572 & 1.000 & & & & \\
C worker & 0.843 & 0.293 & 1.000 & & & \\
F earnings & 0.243 & 0.150 & 0.243 & 1.000 & & \\
F firm & 0.075 & 0.120 & 0.048 & 0.445 & 1.000 & \\
F worker & 0.250 & 0.126 & 0.263 & 0.872 & 0.098 & 1.000 \\
\hline \hline
\end{tabular}

Table A8: Correlation matrix: daughters.

\begin{tabular}{lcccccc}
\hline \hline \multicolumn{1}{c}{ Variables } & C earnings & C firm & C worker & F earnings & F firm & F worker \\
\hline C earnings & 1.000 & & & & & \\
C firm & 0.460 & 1.000 & & & & \\
C worker & 0.817 & 0.228 & 1.000 & & & \\
F earnings & 0.197 & 0.156 & 0.199 & 1.000 & & \\
F firm & 0.044 & 0.070 & 0.031 & 0.449 & 1.000 & \\
F worker & 0.210 & 0.150 & 0.218 & 0.871 & 0.100 & 1.000 \\
\hline \hline
\end{tabular}


Table A9: Correlation matrix: sons. Mother's earnings.

\begin{tabular}{lcccccc}
\hline \hline \multicolumn{1}{c}{ Variables } & C earnings & C firm & C worker & F earnings & F firm & F worker \\
\hline C earnings & 1.000 & & & & & \\
C firm & 0.573 & 1.000 & & & & \\
C worker & 0.842 & 0.294 & 1.000 & & & \\
M earnings & 0.166 & 0.092 & 0.167 & 1.000 & & \\
M firm & 0.062 & 0.077 & 0.045 & 0.297 & 1.000 & \\
M worker & 0.170 & 0.078 & 0.178 & 0.869 & 0.053 & 1.000 \\
\hline \hline
\end{tabular}

Table A10: Correlation matrix: daughters. Mother's earnings.

\begin{tabular}{lcccccc}
\hline \hline \multicolumn{1}{c}{ Variables } & C earnings & C firm & C worker & F earnings & F firm & F worker \\
\hline C earnings & 1.000 & & & & & \\
C firm & 0.462 & 1.000 & & & & \\
C worker & 0.817 & 0.230 & 1.000 & & & \\
M earnings & 0.193 & 0.136 & 0.198 & 1.000 & & \\
M firm & 0.063 & 0.122 & 0.039 & 0.300 & 1.000 & \\
M worker & 0.204 & 0.124 & 0.219 & 0.869 & 0.058 & 1.000 \\
\hline \hline
\end{tabular}


Table A11: Correlation matrix: sons. Log earnings.

\begin{tabular}{lcccccc}
\hline \hline \multicolumn{1}{c}{ Variables } & C earnings & C firm & C worker & F earnings & F firm & F worker \\
\hline C earnings & 1.000 & & & & & \\
C firm & 0.509 & 1.000 & & & & \\
C worker & 0.765 & 0.090 & 1.000 & & & \\
F earnings & 0.209 & 0.116 & 0.196 & 1.000 & & \\
F firm & 0.048 & 0.087 & 0.019 & 0.412 & 1.000 & \\
F worker & 0.215 & 0.093 & 0.210 & 0.838 & -0.015 & 1.000 \\
\hline \hline
\end{tabular}

Table A12: Correlation matrix: daughters. Log earnings.

\begin{tabular}{lcccccc}
\hline \hline \multicolumn{1}{c}{ Variables } & C earnings & C firm & C worker & F earnings & F firm & F worker \\
\hline C earnings & 1.000 & & & & & \\
C firm & 0.433 & 1.000 & & & & \\
C worker & 0.742 & 0.097 & 1.000 & & & \\
F earnings & 0.170 & 0.123 & 0.158 & 1.000 & & \\
F firm & 0.029 & 0.048 & 0.016 & 0.417 & 1.000 & \\
F worker & 0.181 & 0.118 & 0.171 & 0.836 & -0.015 & 1.000 \\
\hline \hline
\end{tabular}

